Aus dem Histologisch-embryologischen Institut München, Direktor Professor Dr. S. Mollier.

\title{
Die Entwicklung der Thymus beim Kaninchen.
}

\author{
Von \\ A. Martmann
}

Assistentin am Histologisch-embryologischen Institut.

Hierzu Tafel IV-VII und 13 Textfiguren.

In h a l t. Seite

I. Einleitung . . . . . . . . . . . . . . . . . . . . 69

II. Stand der Thymusfrage an der Hand der neueren Literatur . . 72

III. Material und Technik . . . . . . . . . . . . . . . . 77

IV. Die Entwicklung der Thymus:

1. Entwicklung der epithelialen Thymus und ihre Bezielhungen zur Parathyreoidea bis zum Auftreten der ersten Lymphocyten in der Thymus . . . . . . . . . . . . . . . . . 78

2. Umwandlung und histogenetische Differenzierung . . . . 91

a) Veränderungen am Epithel . . . . . . . . . . . 91

b) Einwanderung der ersten Lymphocyten . . . . . . 98

c) Beteiligung und Verhalten des Mesenchyms . . . . . 109

3. Die Entstehung von Mark und Rinde . . . . . . . . 131

4. Die Vaskularisierung der Thymus . . . . . . . . . 145

5. Hassalsche Körperchen und ähnliche Differenzierungsprodukte . . . . . . . . . . . . . . . . . . . 153

V. Die Thymus als Lymphocyten lieferndes Organ und ihre Stellung unter den übrigen blutbildenden Organen. . . . . . . . . 161

VI. Zusammenfassung . . . . . . . . . . . . . . . . . 178

\section{Einleitung.}

Im Jahre 1909 veröffentlichte Maximow eine Arbeit über die Histiogenese der Thymus bei Säugetieren, der in kurzen Zwischenräumen ăhnliche Untersuchungen bei Amphibien und Selachiern folgten. Diese führten ihn, wenigstens was die wesentlichsten Punkte anbetrifft, für sämtliche Wirbeltiere zu annähernd dem gleichen Ergebnis und es schien ihm daher die Frage nach dem Wesen und Wert des Thymusgewebes, die seit vielen Jahren 
Gegenstand wissenschaftlichen Streites ist, als erledigt $\mathrm{zu}$ gelten. Für Maximow selbst mag sie es wohl sein; und sie ist es schliesslich auch, wenn man wie Maximow die einzige morphologische Besonderheit der Thymus in der Durchmengung zweier sonst immer streng geschiedener Gewebe sieht. Nun ist es aber eine bekannte Tatsache, dass auch sonst im Körper einzelne Stellen des Epithelgewebes auffallend stark mit Lymphocyten durchsetzt sind, worauf Maximow sogar selbst hinweist (1912), ebenso wie auf die Untersuchungen Jollys (1908) über die Bursa Fabricii der Vögel, welche dieser Autor auf Grund der Ähnlichkeiten, die sie in ihrem Bau und ibrer Genese mit der Thymus darbietet, sogar als "kloakale" Thymus bezeichnet. Auch hier findet sich ebenso wie in der Tonsille ein von Lymphocyten durchsetztes epitheliales Reticulum. All diese Organe, zu welchen er auch die $\mathrm{P}$ e y e r schen Haufen rechnet, und welche dadurch charakterisiert sind, dass Epithel und Lymphocyten nicht nur nachbarlich nebeneinander liegen, sondern sich gegenseitig durchdringend ein einheitliches Ganze, eine Art Symbiose bilden, hat Jolly unter dem Namen "lympho-epitheliale“ zusammengefasst.

Die innige Durcbmengung von Lymphocoyten und Epithel an sich ist also nichts Neues mehr, und daher hat es Mollier (1913) kürzlich unternommen, die lympho-epithelialen Organe miteinander eingehender zu vergleichen, einmal um den von Jolly angedeuteten Vergleich zu vertiefen und nachzusehen, ob sich daraus die Berechtigung ableiten lasse, „von einer einheitlich gebauten Gruppe lympho-epithelialer Organe sprechen zu dürfen; denn es könnten doch vielleicht wesentlich verschiedene Vorgänge sein, die bei einer dauernden Einnistung von Lymphocyten in einem epithelialen Reticulum und bei einer wenn auch scharenweisen Durchwanderung eines Epithels sich abspielen“. Andererseits wollte er vor allem auch gegen Maximow hervorheben, wie wenig erschöpfend seine Bearbeitung der Thymushistiogenese war und wie viele Seiten des Thymusproblems dabei unberücksichtigt blieben. Er ist dabei von einer genauen Untersuchung des strukturellen Aufbaus der Tonsille ausgegangen, die in vieler Hinsicht der Bursa Fabricii näher steht als der Thymus, insofern als sie einfachere Verhaltnisse der Genese darbietet und noch eine gewisse răumliche Trennung des epithelialen und lymphoiden Anteils auch im fertigen Organ zeigt. Auch bleibt sie wie jene gefässfrei. 
Gerade hieraus ergeben sich aber wichtige Unterschiede gegenüber der Thymus. Hiel verschwindet jedes Anzeichen, das an die Entstehung aus soliden Epithelknospen erinnern würde. Ausserdem zeigt sie eine ganz charakteristische Ausbildung von Mark und Rinde, die mit der Mark- und Rindensubstanz, so wie sie in der Bursa Fabricii vorkommen, nicht unmittelbar verglichen werden darf. Die Rindensubstanz der Bursa Fabricii und, wenn man es so nennen will, auch der Tonsille, besteht ausschliessiich aus Lymphocyten lieferndem, gefässhaltigem Mesenchym, während die Rinde der 'Thymus aus einem epithelialen Reticulum und in dessen Maschen liegenden Lymphocyten sich zusammensetzt, welche nach Maximow hier einmal eingewandert sind und sich später selbständig weiter vermehren. Wie erklärt sich aber hieraus das Vorkommen von Gefässen in der ganzen Thymus? Entweder es liegt darin ein durchgreifender Unterschied gegenüber den übrigen lymphoepithelialen Organen oder aber es gibt uns gerade das Auftreten von Gefassen in der Thymus einen Hinweis, wo wir das in der Thymus scheinbar fehlende mesenchymatöse Element zu suchen haben, das dauernd Lymphocyten zu liefern vermag. Bis jetzt hat man sich einfach damit begnügt, die Tatsache festzustellen, dass in die 'Thymus Gefüsse einwachsen, ohne sich darüber Rechenschaft zu geben, wieso es kommt, dass ein ursprünglich epitheliales Organ in dieser Weise mit Gefüssen versorgt wird und ob die Ausbildung von Mark und Rinde damit in Zusammenhang steht. Mollier konnte sich daber noch nicht entschliessen, in der Frage über die Zugehörigkeit der Thymus zu den lympho-epitbelialen Organen definitiv Stellung zu nehmen, da er für ein lymphoepitheliales Organ nicht nur wie Jolly die innige Durchsetzung des epithelialen Reticulums mit freien Lymphocyten fordert, sondern auch die Anwesenheit eines dauernd Lymphzellen bildenden Reticulums ausserhalb desselben, wie es in der Bursa Fabricii und in der Tonsille ohne weiteres nachweisbar ist.

Der Nachweis eines solchen ist aber durch die Untersuchungen Maximows nicht gegeben. Der erfreuliche Fortschritt, den seine Arbeiten auf dem Gebiet der Thymusfrage brachten, liegt darin, dass er die von $\mathrm{Hammar}$ postulierte Immigration von Lymphocyten in die rein epitheliale Thymus nachgewiesen und dadurch der Lehre von der Lymphocytennatur der kleinen Thymuszellen eine neue Stütze gegeben bat. 
Um auf seine Anschauungen näher einzugehen, müssen wir uns den Stand der Thymusfrage zur damaligen Zeit kurz vergegenwärtigen. ${ }^{1}$ )

\section{Stand der Thymusfrage an der Hand der neueren Literatur.}

An der von $\mathrm{Köllike} \mathbf{r}$ festgestellten Tatsache der epithelialen Herkunft der Drüse zweifelt niemand melır, ebenso gilt jetzt als feststehend, dass bei den Säugetieren wenigstens die Hauptmasse der Thymus ihre Entstehung einer Verdickung des ventralen Teiles der dritten Kiementasche verdankt, von wo aus sie als solide Epithelwucherung in die Tiefe versenkt wird, und deren Abschnürung vom Mutterboden früher oder später erfolgt. Über die Mitbeteiligung anderer Epithelpartien (zweite oder vierte Kiementasche, Ektoderm der dritten Tasche etc.) ist man noch zu keinem abschliessenden Ergebnis gelangt. Ich gehe hierauf nicht näher ein, da für die eine mir in genügend jungen Stadien vorliegende Tierspezies (Kaninchen) nur das ventrale Entoderm der dritten Tasche in Frage kommt, und überdies für die Histogenese des Organs eine Mitbeteiligung des Entoderms oder des Epithels mehrerer Kiementaschen ganz gleichgültig ist.

Die wichtigere Frage war die nach der Beteiligung des ursprünglichen Epithels am architelztonischen Bau des fertigen Organs und nach der Art und Menge des hierzu neu verwendeten, der ersten Anlage fremden Gewebes, der Lymphocyten und des Bindegewebes. Hierüber hatten sich drei Theorien herausgebildet. Die der Pseudomorphose, vor allem vertreten durch $\mathrm{His}$, Stieda, Gulland and Maurer, ist der Anschauung, dass das Epithelgewebe allmählich durch sekundär eindringendes Bindegewebe verdrängt wird und nur im Mark in Form der $\mathrm{H}$ a s a l schen Körperchen als primitiver Rest erhalten bleibt. Wahrscheinlich entstand diese Theorie unter dem Einfluss der Lehre von der Spezifität der Keimblätter, die eine Umwandlung von epithelialem in lymphoides Gewebe auf Grund entwicklungsgeschichtlicher Tatsachen nicht zugeben will.

Diese Theorie findet sich auch noch bei v. Ebner, allerdings in etwas veränderter Form, indem er nämlich nur dem Mark der Thymus epitheliale Herkunft zuerkennt und die Rindensubstanz analog den Vorgängen bei der Entstehung der Tonsillen sich nur als aus lymphoidem Gewebe gebildet denlit.

Eine andere Gruppe von Autoren, als deren Hauptvertreter Herrmann und Tourneux, Rabl, O. Schultze, Prenant, Beard gelten, nehmen an, dass die epithelialen Thymuszellen schon frühzeitig zum grössten

1) Ich sehe von einer eingehenderen Besprechung der einzelnen bis zum Jahre 1909 erschienenen Arbeiten ab und verweise diesbezüglich auf die ausführliche bistorische Übersicht der Literatur in der Arbeit $\mathrm{Ma}$ a i m o w s selbst (Arch. f. mikr. Anat., Bd. 74, 1909), sowie auf das in jeder Hinsicht erschöpfende Referat von Hammar: "Fünfzig Jahre Thymusforschung" (Erg. d. Anat. u. Entw.-Gesch., Bd. 19, 1909), das kurz nach der Arbeit Maximow s erschien. 
Teil eine Umwandlung in lymphoide Elemente erfahren, dass also eine ${ }_{n}$ Transformation" eines Gewebes in ein anderes stattfinde. B e ard (1903) geht sogar so weit, die Thymus bei Selachiern (Raia batis) als die erste und wichtigste Quelle der Lymphocyten hinzustellen. Selbstverständlich wird mit dieser Anschauung der Lehre von der Spezifität der Keimblätter ein arger Stoss versetzt. Um diesen Schwierigkeiten zu entgehen, betrachtet ein Teil der Anhänger der Transformations-Theorie die Thymus zeitlebens als rein epitheliales Gebilde; es werden hier keine echten Lymphocyten erzeugt, sondern nur lymphocytenähnliche Thymuszellen, die an Ort und Stelle durch Umwandlung der Epithelzellen entstehen und sich unter günstigen Bedingungen wieder in letztere zurückverwandeln können. Damit fällt die Thymus als blutbildendes Organ. Hauptvertreter dieser Richtung sind Stöhr, Cheval und Marcus; letzterer macht für die Veränderung der Epithelzellen eine Störung der Kernplasmarelation im Sinne R. Hertwigs geltend.

Retterer und heliève fassen die kleinen Thymuszellen als echte Lymphocyten auf; sie sehen aber darin nichts besonderes, da sie alle Lymphocyten des Körpers aus Epithelzellen entstehen lassen.

Mi e t e n s (1909), der vor allem das Thymusreticulum verschiedener Säugetierembryonen untersucht hat, führt dasselbe auf die alte epitheliale Anlage zurück; bezüglich der kileinen Rundzellen spricht er: sich nicht näher aus, deutet jedoch an, dass er auch für sie den gyleichen Ursprung für wahrscheinlich hält.

B a s ch (1906) griff die Frage experimentell an; er beobachtete nach Entfernung der Thymusdrüse bei Hunden Störungen im Knochenwachstum und bis zu einem gewissen Grade auch der Intelligenz, ollne eine kompensatorische Hypertrophie des ïbrigen lymphoiden Systems im Körper. Dies

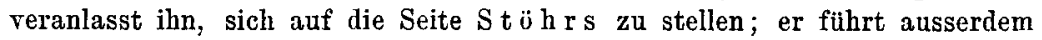
auch an, dass B ang bei der physiologisch-chemischen Untersuchung von Thymus- und Lymphdrüsen gewisse Unterschiede feststellen konnte, die für seine Theorie zu sprechen scheinen. Neuerdings (1913) gibt er jedoch gewisse Beziehungen zwischen Thymus und lymphatischem Apparat zu.

In neuerer Zeit trat dann neben dem Streit um die Lymphocytennatur der kleinen Thymuszellen auch eine stärkere Betonung des zelligen Reticulums als eines selbständigen Bestandteiles der Thymus in den Vordergrund und es entstand eine neue Lehre, welche die beiden entgegengesetzten Theorien der Pseudomorphose und der Transformation miteinander zu vereinigen sucht; nach ihr beteiligen sich zwei Keimblätter, das innere und das mittlere, am Aufbau des Organs, wenn auch ihr Auftreten nicht gleichzeitig erfolgt; das Thymusparenchym hat also einen gemischten Ursprung; über die Vermischung und weitere Differenzierung beider Gewebe gehen die Ansichten wieder weit anseinander.

v. E bner (1902) und in gewisser Beziehung auch $\mathrm{Sch}$ af $\mathrm{fer}$ $(1908,1909)$ sind der Ansicht, dass das Bindegewebe und die Gefässe des Markes in die epitheliale Anlage hineinwachsende, mesodermale Elemente seien und dass ausserdem um die alte Epithelknospe herum sich ein bindegewebiger Mantel lege, aus welchem allein die Rinde des Organs hervorgeht. 
Der bedeutendste neuere Thymusforscher H a m mar (1905, 1907, 1909), der die neue Anschauung als Infiltrations- oder Immigrations-Theorie bezeichnet hat, berichtet, dass $\mathrm{z}$ wischen den netzförmig auseinander weichenden Epitheizellen echte Lymphocyten auftreten, die sich dann selbständig weiter vermehren and durch Ansammlung in den peripheren Schichten die Rinde des Organs bilden. Nur über ihre genaue Herkunft kann er noch keinen Aufschluss geben, da er Einwanderungsbilder nicht beobachten konnte.

Auch im 0 . Hertwigschen Lehrbuch wird als Ursache für die lymphoide Umwandlung des Organs die Einwanderung von Lymphocyten angefïhrt.

Da sich rein morphologisch keine Unterschiede nachweisen lassen, wird nun zunïchst experimentell die Natur der kleinen Thymuselemente als wesensgleich mit derjenigen echter Lymphocyten festgestellt. Dazu dient vor allem die grosse Hinfälligkeit der Lymphocyten gegenüber den Röntgenstrahlen, die von He in e ke $(1903,1904)$ für lymphoide Organe zuerst festgestellt wurde, und R u dberg (1907) gelang es in der Tat, durch Behandlung mit X-Strahlen die Thymuslymplocyten aus dem Parenchym fast völlig auszurotten. Überliess er das bestrablte Organ einer Regeneration, die schon nach relativ kurzer Zeit kräftig einsetzt, so beobachtete er zunächst eine Üherschwemmung des perivaskulären Bindegewebes und der Lymphgefässe mit Lymphocyten, sodann treten dieselben Zellen zuerst auch im Marke wieder auf und verbreiten sich von da aus nach den Rindenpartien weiter durch selbständige Teilung. Interessant ist dabei, dass trotzdem die Regeneration von Lymphocyten bereits in Gang gekommen ist, dennoch die Degeneration im Thymusmark vorerst weiter geht, ein Umstand. der nach des Autors eigener Meinung "von einem gewissen Grade funktioneller Selbständigkeit dieser beiden Hauptkomponenten des Parenchyms" zeugt und "nicht gerade zugunsten der Auffassung spricht, die in den Reticulumzellen die Mntterzellen der Thymuslymphocyten erblickt"

J o n s on (1909) nützt für seine Untersuchungen die längst bekannte, aber unaufgeklärte Tatsache aus, dass, abgesehen von der physiologisclien Involution des Organs in Alter, dasselbe auch bei bestimmten krankluaften, namentlich kachektischen Zuständen einer gewissen Atrophie verfällt. Er unterwirft Kaninchen einem chronischen und akuten Hungerzustand und erreicht dadurch zunächst ebenfalls eine ganz augenfällige Verminderung der Lymphocyten in der Rinde und Anhäufung derselben in den perivaskulären Lymphbahnen. Erst später folgen dann Degenerationserscheinungen in den Lymphocyten sowie auch an den Zellen des Reticulums. Die Regeneration erfolgt auch hier wieder durch Einwanderung von Lymphocyten und Zunahme der Mitosen.

Schaffer (1910) hält die echte Lymphocytennatur der kleinen Thymuszellen ebenfalls für bewiesen, da er ihre Umwandlung in Plasmazellen beobachten konnte, wenn er sich auch sonst über ihre Herkunft nicht näher ausspricht.

Kurz darauf (1909) erschien Maximows erste Thymusarbeit, in welcher er sich vollständig auf den Standpunkt H a mmars stellt. $\mathrm{Er}$ erbringt den bisher noch fehlenden Nachweis der direkten Einwanderung der 
Lymphocyten zwischen die Epithelzellen der ursprünglichen Anlage; djese werden durch die in ihnen weiter wuchernden Lymphocyten weiter auseinandergeschoben, ihre Verbindung an vielen Stellen gelockert und so , a $\mathrm{uf}$ rein $\mathrm{mech}$ a is che Weis $\mathrm{e}^{\prime 1}$ ) ein epitheliales Reticulum aus sternförmig verästelten, mitcinander durch Ausläufer verbundenen Epithelzellen hergestellt. Ein primäres epitheliales Reticulum fand er nicht. Die einwandernden Zellen sind sehr polymorph. Es handelt sich zum Teil um richtige grosse Lymphocyten, zum Teil aber auch um kleinkernige Wanderzellen, die aber in der Thymus selbst alsbald den Charakter von typischen grossen Lymphocyten annehmen. Die Vermehrung der Lymphocyten in der Thymus erfolgt ausser durch die ziemlich lang andauernde Einwanderung immer neuer Zellen vor allem durch eigene intensive Vermehrung, wobei ihre Mitosen sich von denen der Epithelzellen leicht unterscheiden lassen Bei ihrer Wucherung werden die Lymphocyten immer kleiner, bis sie den Habitus der kleinen, dankelkernigen und schmalleibigen Thymusrundzellen angenommen haben. Der Verfasser ist jedoch der Ansicht, dass sie sich jederzeit wieder in grosse, blasse Lymphocyten zurückverwandeln können. Das Marl entsteht auf andere Weise und auch erst viel später als die Rinde, dadurch, „dass an einzelnen begrenzten Stellen die Epithelzellen bypertrophieren, sich zu syncytialen gross- und blasskernigen Massen verbinden, während sich die Lymphocyten aus diesen Bezirken entfernen oder an Ort und Stelle degenerieren". Die einzelnen Markinseln können später zu Strängen zusammenfliessen; in ihnen entstehen dann durch eigenartige Veränderung der Zellen die Hassalschen Körperchen. Auf die Vaskularisation der Thymus geht M a xim ow nur kurz ein. Die Gefässe dringen namentlich in den tieferen Teilen der Septen in das von Lymphocyten durchsetzte Epithel ein, zum Teil werden sie sicherlich auch passiv mit einbezogen, dadurch, dass sie von Organteilen umwachsen werden.

Auf die Stellung der Thymus als blutbildendes Organ werde ich später noch zu sprechen kommen.

Die Publikationen von $\mathrm{H}$ a $\mathrm{mm}$ a $\mathrm{r}$ und $\mathrm{Max}$ i mow riefen zunächst bei den Anhängern der Transformations-Theorie heftigen Widerspruch hervor. Stöhr (1910) vertritt gerade auf Grand der zahlreichen Mitosen die autochthone Entstehung seiper kleinen Thymuszellen gegen $\mathrm{H}$ a $\mathrm{m} \mathrm{mar}$; da er ihnen ebenfalls amöboide Bewegung zuerkennt, fällt diese als Beweis für ihre Lymphocytennatur. Bezüglich der Empfindlichkeit gegen Röntgenstrahlen beruft er sich auf $\mathrm{He}$ inele, der in der Thymus einen etwas langsameren Zerfall fand als in echten Lymphdrüsen. Gegen $\mathrm{Maximow}$ macht er geltend, dass die Einwanderung der Lymphocyten gerade da, wo man sie erwarten würde, nämlich an der Oberfläche des Organs, nicht zu beobachten ist; ausserdem sieht er in den , besonders dunklen verkleinerten Epithelzellen", die Maximow gefunden hat, einen Beweis für seine Theorie, indem er diese Zellen als Übergangsformen deutet.

Zu einer ganz neuen Auffassung kommt D u stin (1911, 1913), der allerdings nicht die 'Thymus von Säugetieren untersuchte, sondern von

1) Im Original nicht gesperrt gedruckt. 
Reptilien, Urodelen und ganz neuerdings auch von Anuren. Für ihn sind die kleinen Thymusrundzellen die einzigen, für das Organ charakteristischen Bestandteile, die aus der ursprünglichen epithelialen Anlage hervorgegangen sind. Alles übrige, was er in der Thymus findet, Reticulum, H a s s a l sche Körper, Riesenzellen, myoide Zellen etc., ist erst sekundär hineingelangt und daher als der Anlage fremd zu betrachten. Bezüglich der Frage nach dem histologischen Wert des Thymus-Reticulums scheint Was s jutots chkin (1913) der Transformations-Theorie anzuhängen; doch geht dies aus der Arbeit nicht ganz klar hervor.

$\mathrm{Ham} \mathrm{mar}$ und $\mathrm{M}$ a $\mathrm{xim}$ ow sind bei ihren Untersuchungen nicht stehen geblieben; beide haben erst kürzlich (1911 und 1912) für die Thymus der Selachier festgestellt, dass auch hier die Genese in prinzipiell derselben Weise erfolgt, wie bei Sängetieren durch Einwandern von Lymphocyten in die epitbeliale Anlage, wodurch letztere zu einem Reticulum aufgelöst wird; auch hier geht die Struktur des Marks nicht aus der ursprünglichen kompaliten Anlage hervor, sondern ist bedingt durch sekundäre Hypertrophie und Verschmelzung einzelner Reticulumzellen.

Nach Maximow (1912) finden sich genau dieselben Verhältnisse auch bei den Amphibien wieder, und gerade beim Axolotl, den auch Dustin (1911) mit so entgegengesetztem Resultate untersuchte, ${ }^{1}$ ) sollen sich alle Vorgünge der Histogenese in klassisch einfacher und eindeutiger Weise beobachten lassen.

Salkind (1912) nimmt neben dez fortdauernden Aus- und Einfuhr kleiner Lymphocyten noch eine autochtbone Entstehung delselben in der Thymus an. Diese geschieht aber nicht auf Kosten des Epithels, sondern eines neben diesem vorhandenen und mit ihm innig verflochtenen mesenchymatösen Reticulums, das er durch eine besondere Fürbemethode dargestellt haben will. Leider fehlt eine genauere Ausführung seiner Ansichten, die nur den Charakter einer vorlänfigen Mitteilung tragen; sie hätten sonst, durch klare Abbildungen gestützt, das Problem seiner Lösung um ein gutes Stück näher gebracht.

Selbstrerständlich sind auch die Experimente von $R u d b e r g$ und Jonson nicht die einzigen ihrer Art geblieben. So haben Regaud und Crémieu (1912) gefunden, dass in der Thymus der Katze nach der Behandlung mit Röntgenstrablen die kleinen Zellen um so rascher zugrunde gehen, je näher der Peripherie des Läppchens sie liegen; da nun bekannt ist, dass in anderen Zellenreihen die Zellen einer selben Generation im jugendlichen Alter leichter zugrunde gehen als im reifen (vergl. Spermatocyten), und die Auswanderung vorwiegend durch die Gefässe des Markes erfolgt, ziehen sie den Schluss, dass auch in der normalen Thymus eine kontinuierliche zentripetale Bewegung der kleinen Zellen vorhanden ist (vergl. S p u l e rs Auffassung der Tonsille). Nach sehr ausgiebiger Bestrahlung fanden sie zwischen dem Fett- and Bindegewebe des Mediastinums nur mehr ganz vereinzelt sternförmige grosse Zellen ohne Lymphocyten, ohne Anzeichen irgendwelcher Regeneration, selbst nach mehr als 2 Monaten.

1) D u s t in benutzte zu seinen Untersuchungen allerdings keine Larven, sondern ausgewachsene Tiere. 
Jolly (1912) und Levin (1912) konstatierten in der Thymus junger hungernder Meerschweinchen und Vögel eine Evolution, d. h. Zunahme und Vergrösserung der Hassalschen Körper. Diese waren zum Teil von Leukocyten durchsetzt und zeigten, sobald sie eine gewisse Grösse erreicht hatten, eine Neigung zur Cystenbildung durch Verflüssigung der zentralen Partien, nachdem sie vorher häufig Keratin ausgebildet hatten. Der Zusammenhang mit dem Reticulum war immer sehr deutlich.

Gerade diese letzteren Befunde legen aber wieder einen Vergleich mit der Tonsille sehr nahe. Mollier hat sich in seiner letzten Publikation der von $\mathrm{Hammar}$ und $\mathrm{Maximow}$ vertretenen Ansicht angeschlossen, dass die Hassalschen Körperchen als Komplexe degenerierender Epithelzellen aufzufassen seien. Indem er diese Anschauung erweitert, sieht er in den in allen grösseren Körperchen vorkommenden Leukocyten nicht Leukocyten im engeren Sinne, sondern Lymphocyten in allen möglichen Stadien der Degeneration und würde es gegebenenfalls auf Grund neuer klärender Untersuchungen über die Histogenese der Thymus für möglich halten, das $\mathrm{H}$ a s s a l sche Körperchen dem Inhalt einer Tonsillenbalghöhle gleichzusetzen. Jene würden also die Stelle der ursprünglichen Oberfläche des Epithels markieren, eine Ansicht, die durch die nachgewiesene Verhornung nur gestützt wird.

Immer wieder wird man dazı gedrïngt, Tonsille, Bursa Fabricii und Thymus in eine gewisse Parallele zu bringen. Dass sich daraus aber auch wieder neue Fragen ergeben, vor allem in Hinsicht auf die Lmphocyten und das ihnen als Mutterboden dienende Gewebe, das Mesenchym, wurde bereits in der Einleitung erwähnt. Hier kann aber nur eine sorgfältige Untersuchung der Thymusgenese zum Ziele führen, die bei den ersten Anfïngen beginnend Epithelplakode und umgebendes Gewebe in gleicher Weise beobachtet und berücksichtigt und ihr gegenseitiges Verhalten nicht nur bis zu annähernd der definitiven Gestalt, sondern bis zur völligen Ausbildung des Organs alsomindestens bis nach der Geburt verfolyt.

\section{Material und Technik.}

Als Untersuchungsmaterial wählte ich in erster Linie die Embryonen von Kaninchen, da dieselben leicht zu beschaffen sind und ihr Alter genau festgestellt werden kann. Es stand mir vom 10. Tag des Fötallebens an bis zur Geburt eine lückenlose Serie zur Verfügung. Die Embryonen wurden entweder ganz oder nach Eröffnung der Thoraxwand fixiert in ZenkerFormol, Müller-Formol nach Orth mit Zusatz von 2-3 proz. Eisessig, Sublimat, Carn oy schen Gemisch $(6: 3: 1)$, und zu besonderen Zwecken auch in Fle m mingscher Lösung, dann langsam in steigendem Alkohol gehärtet, und sorgfältig über Chloroform oder Zedernholzöl in Paraffin eingebettet. Wo es möglich war, wurde die Thymus vor der Einbettung herauspräpariert, was vom 19. bis 20. Tage ab leicht gelingt. Von jedem Stadium bis zum 20. Tage wurde mindestens ein Embryo in Serienschnitte zerlegt und zur Übersicht meist mit Azur II-Eosin gefärbt, nach der von Maximow angegebenen Methode, ausserdem kamen an einzelnen besonders dünnen Schnitten noch die verschiedensten Färbungen zur Anwendung, auf die ich hier nicht näher 
eingehen will, da ich sie spätcr doch mehrfach berühren muss. Es ist gerade bei diesem Organ notwendig, sich nicht auf enne oder wenige Färbungen zu beschränken, da man mit verschiedenen Methoden oft ganz überraschend verschiedene Bilder erhält; so treten z. B. bei der Färbung mit Azur II-Eosin and noch besser mit Pappenheim s Panchromatischem Gemisch (1911) die Wanderzellen sehr schön und deutlich hervor; sie heben sich dagegen kaum ab bei der Methode nach Pasini, obwohl gerade diese das Epithel sehr gut gegen das Bindegewebe differenziert.

\section{Die Entwicklung der Thymus.}

1. Entwicklung der epithelialen Thymus und ihre Beziebungen zur Parathyreoidea, bis zum Auftreten der ersten Lymphocyten in der 'I' hymus.

Über diesen Abschnitt kann ich mich im allgemeinen kurz fassen, besonders da hierüber eine neuere sorgfältige Arbeit von Hanson (1912) vorliegt, deren Resultate ich im wesentlichen bestititigen kann.

Bei einem 10 Tage alten, 3,2 nmm langen Embryo ist überhaupt noch keine Thymusanlage vorhanden, doch zeigt das Epithel der 2., 3. und 4. Tasche, namentlich im ventralen Teil, eine grössere Zahl von Karyokinesen als das übrige Pharynxepithel. Das Mesenchym ist im Kopfteil sehr dichtzellig. Die Ausläufer der einzelnen Zellen sind noch ziemlich kräftig und breit und färben sich gut. Wanchmal findet man zwischen ihnen Blutzellen, die nicht in einem Gefäss zu liegen scheinell. Wie sie hierher gelangt sind, lässt sich natürlich schwer sagen, doch sind sie sicher nicht an Ort und Stelle entstanden. Freie Lymphocyten sieht man im Mesenchym nirgends; es gelingt auch noch nicht $\mathrm{zu}$ beobachten, dass sich einzelne Zellen aus dem mesenchymatösen Verband lösen.

Ein Embryo desselben Wurfes, der aber schon $4 \mathrm{~mm}$ lang war, zeigt keinen grossen Fortschritt. Die beiden ersten Kiemenspalten sind durchgebrochen; deutliche Plakoden lassen sich noch nicht nachweisen, doch ist das Epithel der 2. bis 4. Kiementasche dorsal und besonders ventral mehrreihig geworden und fallt durch die grosse Zahl von Mitosen auf. Im Mesenchym finden wir die einzelnen Zellen vielleicht etwas weiter auseinander geschoben. Sie sind aber im Vergleich zu späteren Stadien immer noch sebr plump; die Kerne sind gross und hell, meist länglich oval, manchmal gekrümmt, das Chromatin ist in sehr feinen Körnchen 
ziemlich gleichmässig verteilt. Meist findet man ein bis zwei dunkle Schollen, von welchen es sich schwer sagen lässt, ob es sich um echte Nukleolen handelt.

Das Protoplasma erscheint stellenweise fein granulär. Sehr häufig sind die Mitosen namentlich im Kopfmesenchym. Zur Teilung rundet sich die Zelle meist ab (Fig. 1), so dass sie frei zu liegen scheint oder doch höchstens durch einen oder zwei feinste Fortsätze noch mit ihrer Umgebung verbunden bleibt; dies gilt nicht nur für die Phase der Metakinese, sondern man findet nicht selten auch freie Zellen im Knäuelstadium. Ausseldem fallen die sich teilenden Zellen durch ihre Grösse auf. Freie Zellen mit ruhendem Kern sind noch nirgends zu finden. Die Gefïsse sind sehr zahlreich vorhanden, doch wie immer im Mesenchym ist es schwer, überall eine deutlich geschlossene endotheliale Wand für sie festzustellen.

Bei dem nächsten 12 Tage alten, $6 \mathrm{~mm}$ langen Embryo sind die Zellen des Mesenchyms schon sehr viel weiter auseinander gerückt (Fig. 2), so dass ihre Auslaufer hănfig sehr dünn und fein ausgezogen erscheinen; die Form der Zellen ist öfter spindelig mit zwei bis drei starkeren, sich dann in feinere Äste auflösenden Fortsatzen; die Form der Kerne ist derjenigen der Zelle angepasst (Fig. 1 und 2); bezüglich ibrer Struktur hat sich nichts geändert. Dagegen ist interessant, dass im Protoplasma eine schaumig wabige Struktur sich deutlicher ausprägt wie früher und dass man niclit selten richtige Vakuolen von verschiedener Grösse antreffen kann (Fig. 2). Dies ist ein Zeichen dafür, dass neben dem passiven Gedehntwerden durch die Ausbildung einer reichlicheren Menge von Intercellulartlüssigkeit schon im Innern des Syncytiums jener aktive Prozess begonnen hat, der durch Verschiebung protoplasmatischer Zellbestandteile zur Loslösung einzelner Zellen aus dem syncytialen Verband führt (Fig. 2). In der Tat kann man im Mesenchym dieses Embryo, wenn auch noch sehr spärlich, freie echte Wanderzellen finden. Sie fallen auf durch ihre dunklere Färbung, die zwar vorwiegend das Protoplasma betrifft, doch ist auch der Kern chromatinreicher und kleiner als der der sternförmigen Mutterzellen. Die Kernstruktur sowie die Zahl und Grösse der Nukleolen ist die gleiche geblieben; meist liegt der Kern etwas exzentrisch in dem rundlichen Protoplasmaleib, und zeigt sich sogar hie und 
da schon nierenförmig eingedellt, manchmal enthält das Protoplasma feine blaue (Azur II-Eosinfärbung) Granulationen, doch glaube ich nicht, dass es sich dabei schon um die Ausbildung spezifischer Körnchen bandelt, da diese besonder's in den sich teilenden Zellen deutlich hervortreten und auch im Protoplasma von Mesenchym- und Epithelzellen zu sehen sind, in letzterem allerdings meist in etwas gröberer Form. Naximow (1909) hat ebenfalls solche Körnchen beschrieben; er hält sie für in den Zellen angehiufte Sekretionsprodukte, da sie fast niemals mit Degenerationserscheinungen verknüpft sind.

Man findet allerdings keine direkten Zerfallsprodukte von Zellen; dennoch möchte ich die Körnchenproduktion nicht als einen aktiven Produktionsvorgang in der Zelle auffassen, sondern höchstens als eine im geeigneten Moment fixierte Phase ihrer Stoffiwechseltätigkeit ohne bestimmte Beziehung zu spezifischen Stoffen. Vielleicht bezeichnen sie eher eine abnorme Tätiglieit der Zellen, gerade weil man sie nur an circumscripten, aber ganz unbestimmten Stellen findet. Bei einem 5,4 $\mathrm{mm}$ langen, 10 Tage alten Embryo, bei welchem die Thymusplakode angedeutet war, fanden sich in und unter dem Kiementaschenepithel ähnliche Körnchen (blaurot bei Hämatoxylin-Eosin-Orange GFärbung) in sehr grosser Zahl und wechselnder Grösse. Einzelne Kerne des Epithels und des Mesenchyms waren auffallend dunkel gefärbt, erwiesen sich aber sonst in ibrer Struktur unverändert. Ähnliche, allerdings weniger ausgedehnte Stellen fand ich noch öfter, wenn auch nicht regelmässig vor.

In einer soeben erschienenen Arbeit beschreibt $\mathrm{H}$. $\mathrm{Rabl}$ (1913) ähnliche Einschlüsse in und unter dem Kiementaschenepithel. Da er solche auch zwischen den Zellen findet, schliesst er, „dass sie Anhäufungen von Exkretionsstoffen darstellen, die, wenn sie nicht eliminiert werden, einen schädigenden Einfluss auf die Zellen auszuüben vermögen“. In der Bursa Fabricii der Vögel sind von v. Schumacher (1904) ebenfalls derartige Körnchen beschrieben und den "tingiblen Körperchen" von Flemming gleichgestellt worden.

Sucht man nun nach den Kiemenspalten und ibren Derivaten, so ist man überrascht, nur einen sehr geringen Fortschritt zu finden. Der Mandibular- und der Hyoidbogen haben sich weiter vorgeschoben, so dass der 3 . und 4. Bogen in die Tiefe 
verlegt erscheinen und ein deutlicher Sinus praecervicalis ausgebildet ist. Der entodermale Anteil des Schlundtaschenepithels ist überall mehrschichtig, zeigt aber noch nirgends Verschiedenheiten in der Struktur; welche schon jetzt eine Abgrenzung des Bezirkes der später daraus entstehenden Organe ermöglichen würden. Ventromedian am Schlunde, etwa in der Höhe des Hyoidbogens, findet sich eine seichte Aushöhlung, die spütere mediale Thyreoidea-Anlage, und vom ventrolateralen Teile der 3 . Tasche geht ein Divertikel nach kaudal und etwas medial, ziemlich genan dem Verlauf der Branchialarterie folgend, bis es am Truncus arteriosus endigt. Dies ist die erste Anlage der Thymus. Sie umfasst rechts sechs, links nur fünt Sclinitte (Dicke $10 \mu$ ), ist also sehr liurz und zeigt ein feines Lumen. Die epitheliale Wandung ist durch nichts von der des übrigen Schlundes velschieden; denn die scholligen Einschlüsse, die man hier in den Epithelzellen manchmal sieht, sind für das übrige Entoderm bereits oben beschricben und selbst von einer rascheren Zellproliferation kann kaum die Rede sein, da Teilungstiguren durchaus nicht hüufiger sind, als im ülrigen Pharynxepithel. Bezüglich der Mitosen möchte ich bemerken, dass dieselben in dem jungen Epithel hier durchans nicht auf die basale Schicht beschränt sind, sondern ebenso liäufig an der Obertlitche und in den Mittelschichten vorkommen.

Irgendwelche Beziehungen zum umgebenden Gewebe fehlen natürlich vollständig.

Wenn man nun auch in unmittelbarer Nähe der Tuymusanlage selbst noch nicht das Auftreten von Wanderzellen konstatieren kann, so darf man dem Nesenchym die Fähigkeit, auch an dieser Stelle solche $z u$ liefern, doch nicht mehr absprechen. sobald man den Vorgang schon an anderen Stellen beobachtet hat. Wir kennen ja das auslösende Moment nicht, das zur Lymphocytenlieferung im Mesenchym führt, wir können nur den Zeitpunkt ihres ersten Auftretens feststellen, ${ }^{1}$ ) das ist $\mathrm{zu}$ einer Zeit, wo die

1) Es ist hier nur das im embryonalen Körper befindliche Mesenchymgewebe gemeint; in der Dottersackwand findet man selbstrerständlich neben Erythroplasten schon massenhaft grosse und kleine Lymphocyten und von bier ans sind sie auch bereits in die Gefässe eingeschwemmt worden, allerdings in noch sehr geringer Zahl. Sie sind morphologisch den Lymphocyten aus dem Mesenchym absolut gleich (vgl. Fig. $2 a$ und $b$ ). 
Leber als blutbildendes Organ noch nicht in Betracht kommt und Milz und Lymphfollikel noch gar nicht existier'en. Damit fält auch die Anschauung Beards, welcher die Thymus bei Selachiern als erste und alleinige Quelle der Lymphocyten (aller weissen Blutzellen überhaupt) hinstellt und dies auch lür die anderen Klassen der Vertebraten geltend machen will. Übrigens haben schon Hammar und Maximow gezeigt, dass auch bei Selachiern irn Mesenchym früher Lymphocyten zu finden sind, als sie in der Thymusanlage auftreten, mag man sie nun als eingewandert oder in loco entstanden auffassen.

Bell (1906) lat bei Schweineembryonen die Lymphocrten zuerst in der Thymus selbst und erst später anch ausserhalb derselben gefunden; er sieht darin eine Stütze für die Transformationstheorie, doch gibt er selbst zu, auf die anderen lymphoiden Organe gar keine Rücksicht genommen zu haben; es fehlt also der Beweis für seine Lehre.

Ist die Thymus erst angelegt, so schreitet ihle weitere Entwicklung rasch fort. Bei einem nur ca. 12 Stunden alteren, $8 \mathrm{~mm}$ langen (allerdings sehr stark gekrümmten) Embryo ist das vorher beschriebene Divertikel bereits vom Mutterboden losgelöst und zu einem ziemlich langen Strang ausgewachsen, der von dem Ganglion des Vagus entlang der dritten Branchialarterie bis zum Truncus arteriosus herabreicht und in seinem unteren Teil etwas dicker erscheint als im oberen. Die Halsbucht hat sich zu dem Ductus praecervicalis verengt, dessen blindes aufgetriebenes Ende als Vesicula praecervicalis in die Tiefe versenkt ist. In diesem Stadium liegt sie dem oberen Thymusende noch sehr nahe; sie entfernt sich aber im weiteren immer mehr von ihm und kommt, einer raschen Atrophie verfallend, beim Kaninchen weder für die Bildung der Thymus noch der Parathyreoidea in Betracht (vgl. Hanson, 1912). Maximow irrt also, wenn er sie im Thymusgewebe aufgehen lïsst. Doch scheint dies bei anderen Säugern vorzukommen, wie sich aus den Untersuchungen von Rubens (1912) am Meerschweinchen ergibt.

Der seitliche Epithelstrang selbst zeigt bereits einen gewissen Grad von Differenzierung. In dem grösseren caudalen Teil ist das Lumen meist noch vorhanden, wenigstens virtuell durch die Stellung der Zellen angedeutet; meist liegt es schon etwas exzentrisch und zwar melir nach medial verschoben, so dass sich 
nach der Seite hin ein stärkeres Wachstum geltend macht. Die Zellen selbst zeigen, was ihre Form, Grösse und Struktur anbelangt, noch vollständige Übereinstimmung mit denen des Pharynxepithels. Zellgrenzen sind nur schlecht zu sehen, vielleicht ïberhaupt nicht immer vorhanden.

Etwas anders verhält sich der am meisten cranial gelegene Teil, doch möchte ich bemerken, dass bei gewöhnlicher HümatoxylinEosin-Färbung ein Unterschied gegen die 'Thymus kaum zu sehen ist, höchstens in der Grösse der Zellen, aber sicherlich nicht so deutlich als $\mathrm{H}$ an $\mathrm{s} 0 \mathrm{n}$ ihn abbildet. Die Zellen der Parathyreoideaanlage, denn um diese handelt es sich hier, sind etwas kleiner; nach Pasini fürben sich die Kerne irtensiver rot als die der Thymusanlage, mit Panchrom erscheint das Protoplasma mehr rötlichviolett. Wit Methylgrün-Pyronin bleiben die Zellen im ganzen etwas heller. Die Anlagen beider Organe greifen ineinander ïber, wie dies Hans on beschrieben hat. Die definitive 'Trennung erfolgt erst viel spaiter, sobald die Atrophie des Cervikalteils der Thymus beginnt und selbst dann bleibt ein dünner epithelialer Strang als Verbindungsbrücke zwischen beiden Organen lange erhalten. Darin liegt vielleicht ein Hinweis auf eine engere phylogenetische Verwandtschatt beider Organe, denn so merkwiirdig dies vielleicht auf den ersten Blick scheinen mag. so zeigt doch die Parathyreoidea im Aufbau und der Verwendung ihrer Gewebe mehr Ähnlichkeit mit der Thymus als mit der Schilddrïse.

Für die Chelonier hat erst kürzlich P. A imée (1911 und 1912) auf engere Beziehungen zwischen beiden Organen hingewiesen; es soll hier nämlich nach der alljäbrlichen, durch die Jahreszeit bedingten Involution der Thymus die Regeneration des Organs auf Kosten der Parathyreoidea erfolgen. Bedenkt man die enge genetische Zusammengehörigkeit, so hat dieser Befund nichts Befremdendes melır und es wäre interessant, zu erfahren, ob sich ahnliche Verbaltnisse auch bei anderen Poikilothermen aufdecken lassen, deren Thymus alljährlich einer physiologischen Evolution und Involution anheimfällt.

Von anderer Seite werden dagegen genetische und physiologische Beziehungen zwischen Parathyreoidea und Thyreoidea in den Vordergrund gestellt (Halpenny und Thompson, 1909), die auch morphologisch zum Ausdruck kommen sollen. 
Die histologische Differenzierung der Parathyreoidea erfolgt viel rascher als die der Thymus, wenigstens beim Kaninchen. Obwohl beide Organe dann anscheinend nichts mehr miteinander zu tun haben, möchte ich über die Parathyreoidea ein paar Worte anfügen, da sie sehr interessante Wachstumsverhältnisse darbietet. Schon in ganz jungen Stadien, wo noch kaum ein Unterschied im Bau des Epithels festzustellen ist, failt die viel bessere Gefässversorgung des Epithelkörperchens auf gegenüber der der Thymusanlage (Fig. 3 a und 3 b). Während letztere in relativ weiten Abstinnden von weiten dünnwandigen, unregelmiissig angeordneten Gefässen umgeben ist, die caudalwärts ihren Abtuss gegen die Vena jugularis zu haben, ist ersteres von einem sehr dichten kapillären Plexus umspannt, der sowohl mit der Carotis als auch mit der Jugularis mehrfach in Verbindung steht. Dies wird in den nächstfolgenden Stadien noch auffülliger; denn während die 'Thymus noch lange gefüsslos bleibt, wachsen die Epithelien der Parathyreoidea zwischen den Kapillaren weiter; so dass bei Embryonen von 13-14 Tagen (10-12 mm Lünge) das ganze Organ aus einem Netz dünner solider Epithelbalken besteht, zwischen welchen die Kapillaren verlaufen (Fig. 3 a). Die Gefüsse liegen mit ihrer endothelialen Wand den Epithelzellen direkt an; häufig ist die Gefasswand auf dem Schnitt überhaupt nicht zu sehen. Die Epithelzellen sind gleichmassig polygonal, gegeneinander abgeplattet, kaum kleiner als die der Thymus. Sie färben sich im allgemeinen etwas heller, zeigen aber den gleichen wabig reticularen Bau ihres Protoplasmas. Ihre Anordnung ist unregelmässig, d. h. man kann sehr bald nicht mehr die ursprüngliche um ein zentrales Lumen angeordnete Stellung erkennen, was bei der Thymus noch sehr lange gelingt, selbst wenn das wirkliche Lumen längst schon geschwunden ist. Eine eigentliche Membrana propria fehlt, ebenso wie im fertigen Organ. Doch sind die schmalen Epithelbalken nach aussen durch eine scharfe, aber äusserst feine, sich dunkel färbende Linie abgegrenzt (Fig. 3 a), die ich nicht als ein Produkt der Unterlagszellen ansprechen, sondern als den Epithelzellen selbst zugehörig erachten möchte, etwa in der Art eines feinen Oberflächenhäutchens. Gegeneinander selbst sind die Epithelzellen schlecht abgesetzt, obwohl man nicht eigentlich von einem Syncytium reden kann, da man doch hin und wieder Zellgrenzen sieht und die einzelnen Zellterritorien 
sich auch in der Färbung des Protoplasmas kundgeben. In Teilung befindliche Zellen sind immer scharf abgegrenzt.

Sehr bald macht sich beim Epithelkörperchen schon eine gewisse Auflockerung des epithelialen Verbandes der Zellen geltend, was vielleicht mit dem raschen Wachstum und dem frülizeitigen Eindringen der Gefüsse zusammenhängt. Gerade hier lässt sich die besondere Gestaltung der Epithelformation gut beobachten, die aus wenigen (nur zwei bis drei) Schichten bestehende epitheliale Wand waichst rascher als ihre Umgebung und ist daher zunachst gezwungen, sich einzufalten. Auf diese Weise gelangt das kapillarenhaltige Mesenchym zwischen die Epithellager. Nun ist aber der weiteren Ausdehnung der letzteren nach den Seiten hin eine Grenze gesetzt durch ihre Lage zwischen der Carotis und Jugularis: die Epithelfalten werden daher bei weiterem Wachstum zuerst gegeneinander gedrückt und schliesslich beginnen sie sich einzurollen, sich nach innen weiter zu entfalten und zum T'eil miteinander zu verkleben. Die hierdurch entstehenden, ganz charakteristischen Bilder sind auf T'extfig. 1 in schematischer Form
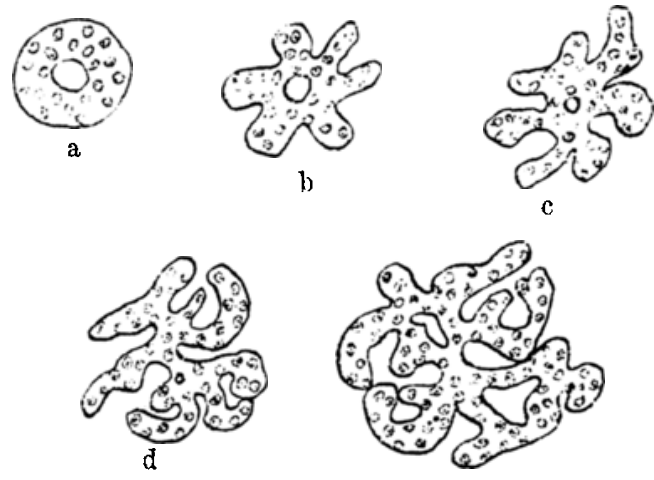

Fig. 1

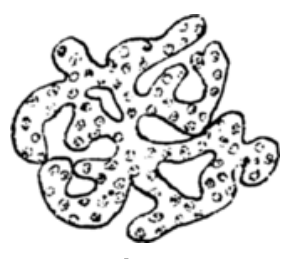

e

veranschaulicht. Man sieht, wie das Mesenchym förmlich in das Innere des Organs hineingewallzt wird. ${ }^{1}$ ) Etwas weiter caudal hat diese eigentümliche Formation aufgehört; wir finden nur noch eine dünne geschlossene Zellschicht, welche, entsprechend dem Parathyreoideastrang von Hanson, den caudalen Ausläufer der

1) Vgl. Prenant (1894): ${ }_{n}$ Les travées épithéliales s'appliquent les unes contre les antres ou se replient sur elles-mêmes." 
Parathyreoidea und den cervikalen Thymuskopf und Hals einschliesst, konzentrisch um ein grösseres Gefäss gelagert. Gerade dieses Gefäss, dessen dünne Wand bei einigermassen praller Füllung nicht mehr zu erkennen ist, scheint sehr auffällig mitten im Epithel gelegen.

Da ich es bei drei Embryonen desselben Wurfes beiderseits wohl entwickelt und bei einem vierten wenigstens angedeutet fand, habe ich versucht, Parathyreoidea und Thymus mitsamt den anliegenden Gefässen zu rekonstruieren.

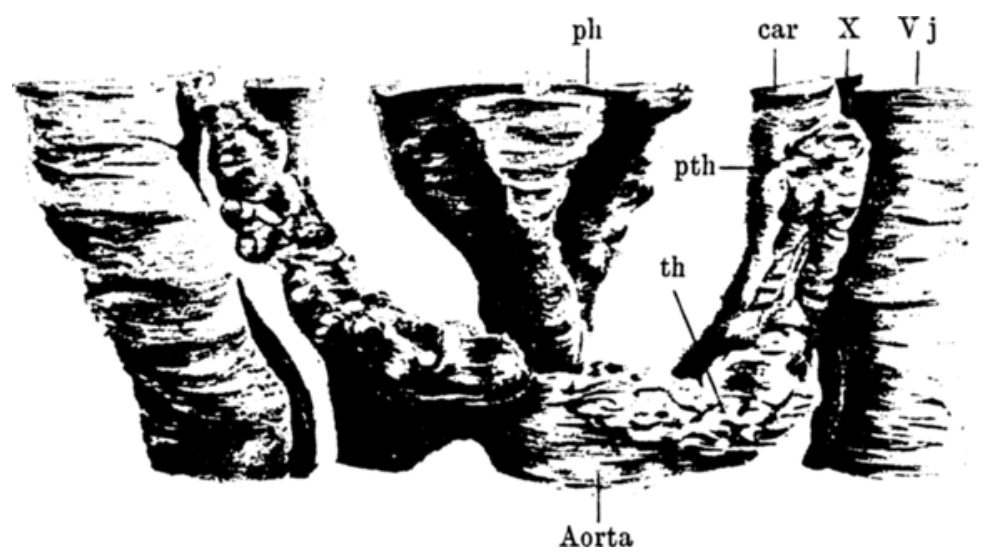

Fig. 2. Rekonstruktion nach einem 13 Tage alten $9,8 \mathrm{~mm}$ langen Kaninchenembryo. Vergrösserung des Modells 100 mal. Abbildung verkleinert. ph $=$ Pharynx; $\quad$ car $=$ Carotis $; \mathrm{X}=$ Vagus $; \mathrm{Vj}=$ Vena jugularis $;$ pth $=$ Parathyreoideaanlage; th $=$ Thymusanlage.

Das Entwicklungsstadium (Textfig. 2) ist etwas jünger als das der Fig. 4 von Hanson zugrunde gelegte. Die Knospenbildung ist stärker ausgeprägt als $\mathrm{H}$ a $\mathrm{n}$ s o $\mathrm{n}$ sie abbildet, namentlich im oberen der Parathyreoidea entsprechenden 'Teil ist es unmöglich, alle Feinheiten der Obertläche herauszumodellieren. Die Verdickung des caudalen Endes, der späteren Brustthymus, tritt von vorne gesehen nicht so deutlich hervor, da sie in dorsoventraler Richtung am ausgeprägtesten ist. Dagegen ist die ventromediale Abknickung des unteren 'Thymusendes (Hammars Aortenkrümmung) sehr ausgesprochen. Die dem Aortenbogen zugekehrte Seite zeigt wenig Vorwölbungen (vergl. die Fig. $3 \mathrm{~b}$, die einen Schnitt dieser Serie darstellt). Die Grenze zwischen Parathyreoidea und Thymus ist noch nicht immer mit Sicherheit $z u$ bestimmen; sie entspricht 
ungefähr der in Textfig. 3 eingezeichneten schwarzen Linie. Die roten Felder bezeichnen den Verlauf der dem Organ eng anliegenden Gefässe. Es sind weite Endothelröhren. Gelingt es,

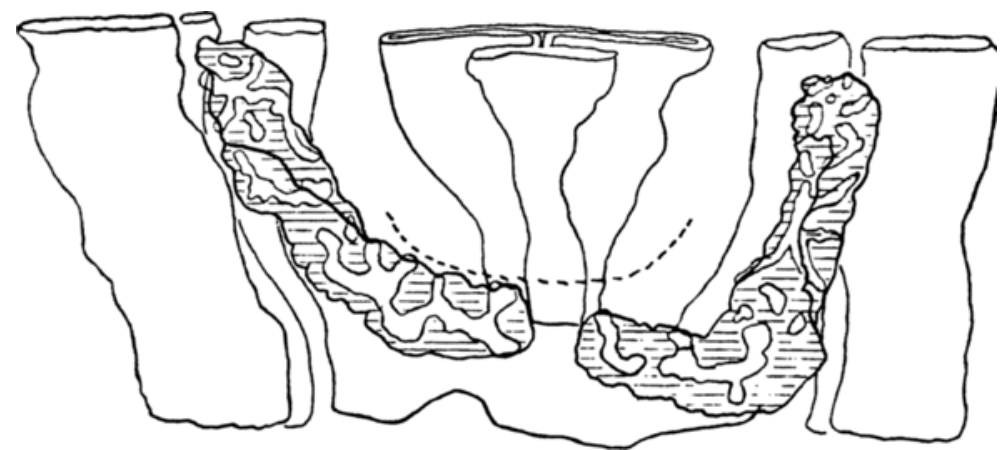

Fig. 3. Die punktierte Linie gibt die Lage der Tlyreoidea an.

ihren Zusammenhang mit einem grösseren Gefäss festzustellen und dies weiter $\mathrm{zu}$ verfolgen, so findet mall am häufigsten Beziehungen zur Vena jugularis; ausgesprochene Arterien fehlen hier überhaupt noch. Erst bei wenige Tage älteren Embryonen (Textfig. 5) war es mir möglich, einen arteriellen Zuftuss zu finden, der sich in einem kleinen paarigen, fast median gelegenen Gefäss bis zum Aortenbogen verfolgen liess. Da die Blutversorgung der 'Thymus beim heranwachsenden Kaninchen nichts mehr mit der $\mathrm{Ca}$ rotis und Jugularis zu tun hat, entsprechend der Lageveründerung des Organs, so ist klar, dass während der Entwicklung hier noch weitgehende Verschiebungen statthaben müssen.

Durchschneidet man den in Textfig. 2 abgebildeten linken Parathyreoideathymusstrang, so erhält man das in Textfig. 4 wiedergegebene Bild. Der Hohlraum im Innern stellt nicht etwa das ursprüngliche Lumen dar, sondern das oben erwähnte zentrale Gefäss. Cranial löst sich dasselbe

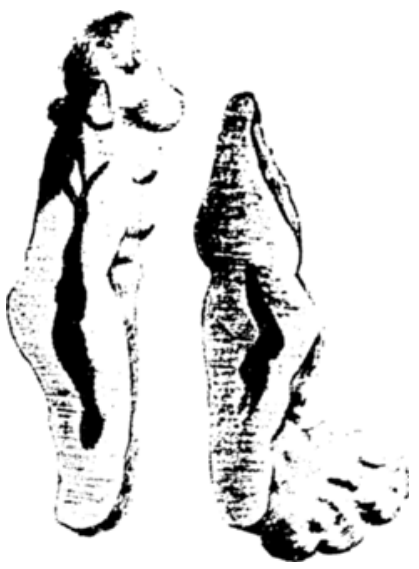

Fig. 4. in das zwischen den Epithelbälkchen der Paratbyreoidea gelegene liapillarnetz auf; caudal endigt es meist blind, indem es noch 
in den Thymusteil hinabreicht; nur zweimal fand ich einen sehr engen Abfluss nach aussen, der aber nicht ganz dem caudalen Ende entsprach, sondern etwas höher oben die Epithelschicht durchbrach.

Über die Bedeutung dieses auffallend weiten, merkwürdig gelegenen Gefüsses vermag ich nichts auszusagen; offenbar handelt es sich nur um eine ganz vorübergehende, der Parathyreoidea zugehörige Bildung, denn schon bei 14 'Tage alten Embryonen ist es nicht mehr konstant zu finden, jedenfalls sehr viel enger geworden und noch später fehlt es überhaupt. Gleichzeitig erscheint aber auch der beide Organe verbindende indifferente Epithelstrang sehr reduziert, so dass man vielleicht an einen Zusammenhang des Gefässes mit der Resorption dieser Epithelpartien denken dürfte. Morphologische Beweise dafür sind jedoch nicht $\mathrm{zu}$ erbringen.

Lehren wir nunmehr zu der 'Thymus zurück. Das nüchste mir zur Verfügung stehende Stadium stammt aus einem $9,5 \mathrm{~mm}$ langen, 13 Tage alten Embryo, nur wenig alter als der, welcher der Rekonstruktionsfigur ('lextfig. 2) entspricht. Es zeigt die Form der Thymus wenig verïndert; der craniolaterale Teil ist zu einem etwas längeren kompakten Strang ausgezogen, der zwischen Jugularis, Vagus und Carotis verläuft und sich als Cervikalteil erweist, während das caudale der Carotis (bezw. Aorta) anliegende Ende des Stranges schon ziemlich verdickt erscheint und bereits flache Erhebungen aufweist, welche die spätere Wachstumszone anzeigen. Das Lumen im Innern ist stellenweise noch erhalten, doch findet man es meist schon stark exzentrisch liegend. Die Gefässe gehen selten bis dicht an das Organ heran. Trotz der zahlreichen Mitosen im Innern des Organs hat eine histologische Umwandlung noch nicht begonnen; die Zellen sind mehr zylindrisch als kubisch, radiär um das Lumen angeordnet; selbst wo dieses nicht mehr vorhanden ist, kann man aus der Stellung der Kerne seine ursprüngliche Lage noch erkennen. Die Mitosen liegen unregelmässig verteilt und zwar findet man sie ebenso häufig im Gervikalstrang als im dickeren Brustteil, ein Beweis dafür, dass das Wachstum der Thymus noch in allen Teilen gleichwertig ist und nur in dem einen Fall mehr in die Länge, im anderen mehr in die Breite geht. Dies hängt mit der Streckung des Halses und der dadurch bedingten Lageveränderung des Organs zusammen. 
Die weitere Verănderung, soweit die caussere Form in Betracht kommt, ergibt sich am besten aus der Fig. 22, die einem 14 Tage alten Embryo entspricht. Die Knospenbildung im Brustteil tritt hier auffälliger hervor. Diese Epithelwucherungen, wenn man sie als solche bezeichnen darf, sind aber noch seln flach und mehl durch kleine Wachstumsverschiebungen im Innern des Organs bedingt, als durch lebhafte Proliferation nach aussen. Dementsprechend können wir auch nicht erwarten, auf dem Schnittbild tief einschneidende Bindegewebssepten zu finden. Das Epithel als solches ist ganz unverändert, alle Zellen sehen einander gleich, was Fürbung und Struktur anbelangt. Nur wenn eine Zelle sich in Teilung befindet, erscheint ilır Protoplasma heller (Fig. 3 b). Im übrigen unterscheiden sich die Mitosen in nichts von denen der Parathyreoidea sowie von denen des Mesenchyms. In allen Fällen stellen die Chromosomen linge, schlanke Stäbchen dar, die sich zu einem schönen Steru zusammenordnen, ohne jede Verklumpungserscheinung. Eine alusgesprochene Membriuna propria als Grenze nach aussen fehlt auch hier; doch ist die feine Grenzlinie gegen das Bindewebe im ganzen schürfer als bei der Parathyreoilea.

Betrachtet man die Hachen Epithelvorwölbungen genau, so findet man bereits, dass hier das Wachstum nicht mehr gleichmässig zentrifugal nach allen Seiten erfolgt, sondern es macht sich häufig ein Vorschub nach einer die Obertlache des Organs tangential treffenden Richtnng geltend. Dadurch werden zwei Forgänge eingeleitet: einmal wird der weiteren Verzweigung der primitiven Epithelknospen Vorschub geleistet, die nun rasch grosse Dimensionen annimmt, und fernerhin wird ein Prozess angedeutet, den wir bereits bei der Parathyreoidea beobachtet haben, nämlich ein langsam fortschreitendes Wachstum, nicht nur in zentrifugaler Richtung, sondern auch parallel der Oberfläche des Organs, gleichsam im Kreise herum, was für das Verstindnis der weiteren Formbildung von grosser Wichtigkeit ist. In den nachsten Stadien machen sich auch bereits die ersten Anzeichen der histologischen Umwandlung des Organs geltend, die im folgenden Kapitel besprochen werden sollen.

Textfig. 5 zeigt die äussere Form der Thymus eines 16 tägigen 14,7 mm langen Kaninchenembryos; die Knospenbildung im Brustteil ist sehr ausgeprägt und dementsprechend schneiden breite 
Bindegewebssepten jetzt tief in das Organ ein. Wo zwei Epithelknospen zusammenstossen, können sie wieder miteinander verwachsen, so dass Strassen von gefässführendem Bindegewebe jetzt

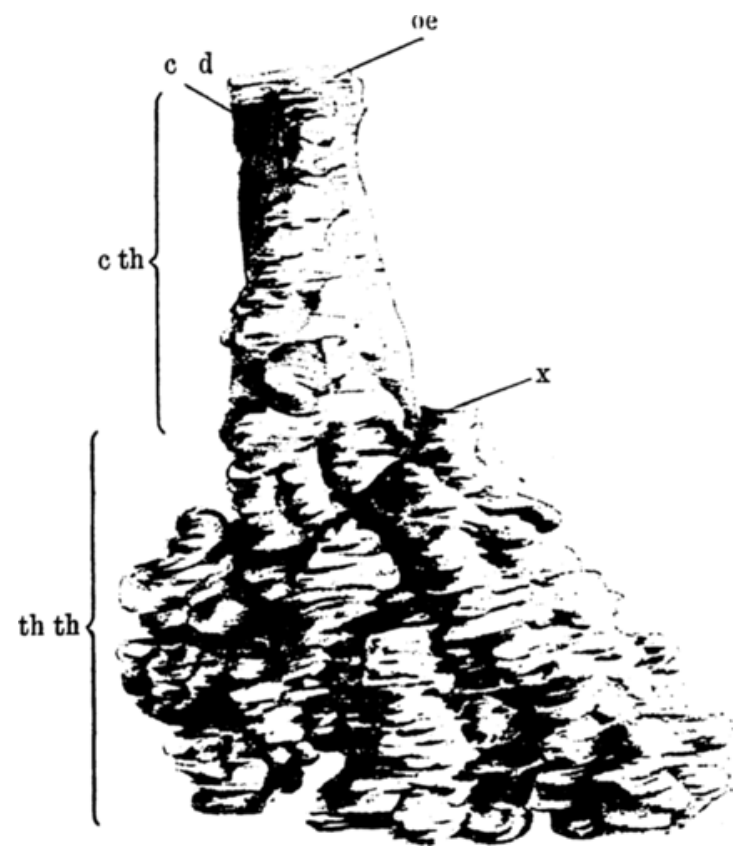

Fig. 5. Rekonstruktion nach einem 16 Tage alten $14,7 \mathrm{~mm}$ langen Kaninchenembryo. Vergrösserung des Modells 100 mal. Abbildung verkleinert. oe $=$ Ósophagus; $\mathrm{cd}=$ Carotis dextra; $\mathrm{c}$ th $=$ cervikaler, th th $=$ thorakaler Abschnitt der Thymus. Bei $\mathrm{x}$ ist der Cervikalteil der linken Thymus abgeschnitten.

mitten durch das Organ zu gehen scheinen; eine eigentliche Abtrennung von Epithelpartien durch Bindegewebe findet jedoch nicht statt.

$\mathrm{Zu}$ der eigentlichen Organogenese bleibt nicht mehr viel hinzuzufügen. Der Cervikalteil macht zwar noch einen Ansatz zur Knospenbildung, wie aus der Textfig. 5 hervorgeht, doch bleibt er Zeit seines Bestehens rein epithelial. Bei einem Embryo von 18 Tagen ist er nurmehr als dünner Strang erhalten, nach 20 Tagen ist er, wenigstens makroskopisch, verschwunden.

Die beiden Brustabschnitte dagegen wachsen mächtig gegeneinander zu. Sie kommen mit der Umbildung der grossen Gefäss- 
stïmme vor den Aortenbogen $\mathrm{zu}$ liegen und behalten diese Lage dauernd bei. Caudal erreichen sie den Herzbeutel schon sehr frühzeitig, werden aber erst durch die weitere Ausgestaltung der Lungen und die damit verbundene Ausdehnung der Pleurahöhlen in den ventralen Teil des Mediastinums zusammendrängt. Bei Embryonen von 20 Tagen ist die definitive Form erreicht und wenigstens am fixierten Objekt das Organ leicht herauszupräparieren.

2. Umwanding und histogenetische Differenzierung.

a) Veränderungen am Epithel.

Für Maximow ist das Auftreten der ersten Lymphocyten in der Thymusanlage der wichtigste Vorgang für die Ausgestaltung des Parenchyms und mit dem Nachweis ihrer Einwanderung aus dem umgebenden Mesenchym gelten ihm die für die Histiogenese der Thymus in Betracht kommenden Fragen eigentlich als erledigt. Daher betrachtet er auch das Thymusreticulum nicht als primär entstanden, "sondern sekundär, als einfache mechanische Folge der Lymphocyteninvasion “.

Sicherlich spielt dieser Prozess fül die Genese des Organs eine bedeutende Rolle; aber ebensowenig dürfen andere Vorginge unterschätzt werden, welche der Lymphocyteninfiltration vorangehend ihr den Boden bereiten, nämlich die Veränderungen am Epithel und andererseits die erst durch dieselbe gegebene Möglichkeit der Mitbeteiligung des Mesenchyms und der Gefässe, wie sie uns aus der fertigen Thymus bekannt sind und wie sie in dieser Weise keinem der anderen lympho-epithelialen Or'gane mehr zukommen. Die Durchwanderung des Epithels allein ist für die Thymus sicherlich nicht das einzig massgebende.

Die histologische Differenzielung ist immer am caudalen Ende der Thymus am weitesten fortgeschritten; Maximow und andere haben dies bereits beschrieben. Daher kann man, wenn man einmal über die einzelnen Stadien der fortschreitenden Entwicklung überbaupt orientiert ist, dieselben fast alle an einem einzigen Organ untersuchen. Der dünne epitheliale Strang, welcher die definitive Thymus noch lange mit der Parathyreoidea velbindet, macht die lymphoide Umwandlung nicht mit. Er kommt daher bei der weiteren Besprechung nicht mehr in Betracht.

Die ersten Veränderungen am Epithel lassen sich schon bei 14 Tage alten ca. $10 \mathrm{~mm}$ langen Embryonen nachweisen; aller- 
dings nicht regelmässig. Sie treten immer da zuerst auf, wo man bald danach die ersten Wanderzellen findet, d. h. in dell zentralen Partien des Organs; die Entwicklung geht zunächst also von innen nach aussen. Wenn man einen Schnitt durch die Thymusgegend aus einem ca. 14 Tage alten Embryo bei schwacher Vergrösserung betrachtet, so fällt die hellere Färbung im Innern des Organs auf (Fig. 22), die fast den Eindruck erweckt, als habe schon eine Trennung in Mark und Rinde stattgefunden. I)ie Untersuchung mittels der Immersion lehrt abel sofort, dass es sich nur um Besonderheiten in der Struktur des Epithels handelt, die wir im folgenden beschreiben wollen. Die Form der Zellen ist in den Randpartien länglich zylindrisch; sie stehen sehr dicht gedıängt, hüufig miteinander verkeilt, so dass die Zellgrenzen oft schlecht zu sehen sind. Nach der Mitte zu werden sie mehr polygonal und an Stellen, wo das Epithel selir dick ist, platten sie sich förmlich $a b$, so dass man an einzelnen Stellen eil geschichtetes Plattenepithel vor sich zu haben glaubt (Fig. 19). Auch die \%ellgrösse nimmt ungekeht wie in der fertigen Thymus nach innen zu ab, doch gebe ich zu, dass diese Abnahme vielleicht nur eine scheinbare ist, da der sich der Zellform anpassende Kern am Rande leicht in seinem lïngsten Durchmesser getroffen und daher grösser erscheint als die weiter auseinander liegenden mehr rundlichen Kerne der Mitte; Zellgrenzen sind hier nicht eigentlich wahrzunehmen, doch sind die einzelnen Zellterritorien hier leichter abzuschïtzen, da zwischen ihnen feine Spalt- und Hohlraumbildungen auftreten, auf welche wir noch zurückkommen werden. Die Kerne sind hell und saftig, mit einer feinen Membran versehen, die manchmal stärker hervortritt und dann dem Kern ein dunkleres Aussehen verleibt. Hier ist auch meist das Chromatin in gröberen Zügen angeordnet, wăhrend es für gewöhnlich in feinsten Körnchen gleichmässig verteilt erscheint. Die Erfahrung lehrt, dass die dunkleren Kerne vor kurzer Zeit eine Teilung durchgemacht haben, von welcher sie noch nicht völlig erholt sind. Dafür spricht, dass man sie selten einzeln findet und dass sie an Grösse hinter den übrigen Zellkernen zurückstehen. Jeder Kern besitzt ein bis zwei verschieden grosse Nukleolen.

Die Mitosen sind über den ganzen Schnitt verteilt. Sie finden sich nicht nur in der Nähe des alten Lumens, wie Maximow es beschreibt, wenn sie auch hier etwas haufiger zu treffen sind. 
Die in Teilung befindlichen Zellen erscheinen viel grösser, ihr Protoplasma fallt als heller, gegen die Umgebung gut abgegrenzter Hof heraus (Fig. 17 und 19); die Chromosomen sind lang und schlank, meist stark gekrümmt; auch Polkörper und Spindel sind bei den gewöhnlichen Färbungen meist deutlich zu sehen. Ich möchte gleich hier bemerken, dass die karyokinetischen Figuren des Mesenchyms dasselbe Bild zeigen; verklumpte Mitosen mit kurzen plumpen Chromosomen findet man in jugendlichen Stadien nirgends (Fig. 1, 26, 6, 17), auch nicht in den grossen Lymphocyten des strömenden Blutes.

Am interessantesten ist das Verhalten des Protoplasmas; hier werden wir auch die eigentlichen Verinderungen zu erwarten haben. An den zylindrischen Zellen der basalen Schicht ist es dasselbe geblieben, wie in der früheren Epithelknospe; fein schaumig wabig, mit einer gewissen Neigung, sauere Farbstoffe aufzunehmen, ohme ausgesprochene Vakuolen umgibt es in nicht allzu dicker Schicht die einzelnen Kerne. Gegen das nnliegende Gewebe ist es scharf abgesetzt durch einen feinen, aber ganz deutlichen Saum, der sich nach den Methoden von Mallory und Pasini blan fürbt, aber nicht als eigentliche Membrana propria aufgefasst werden kamn. In den 'Tiefen der einschneidenden Bindegewebspapillen wird er meist undeutlich und geht später ganz verloren (lig. 17, 18, 23). In etwas älteren Stadien (wo die lymphoide Umwandlung schon in vollem Gange ist) ist es mir gelungen, mit den oben genannten Methoden in den basalen Epithelzellen feinste Füserchen darzustellen, die am Rand der Zellen verlaufend, senkrecht gegen die Basis gerichtet sind (Fig. 4).

Anders verhült sich das Protoplasma im Innern des Organs. Das hellere Aussehen wird nicht etwa verursacht durch eine weniger ausgesprochene Chromophilie, sondern durch eine merkwürdige Auflösung des Epithels (Fig. 23), die auf den ersten Blick den Gedanken an Degeneration wachruft. Erst wenn man die Erscheinung zeitlich vor- und rückwärts verfolgt, wird einem das Bild klar und verständlich. Die schon in der Wabenstruktur des Plasmas gegebenen kleinen Hohlräume erweitern sich zum Teil zu Vakuolen, die ihrerseits wieder zu grösseren Hohlräumen zusammenfliessen, so dass manchmal förmliche Spalten zwischen den Zellen entstehen. Der Prozess erfolgt jedoch nicht so regelmässig, wie ihn Mollier für die Entstehnng der Saftlücken im 
Tonsillenepithel beschrieben hat, sondern die Vakuolen sind nicht gleichmässig gross und ausserdem ist ihre Lage zum Fern eine sehr wechselnde. Wir haben es hier eben nicht mehr mit einem geordneten epithelialen Zellverband zu tun. Gleichzeitig verliert das Protoplasma seine gleichmässige Dichte; es färbt sich an einzelnen Stellen dunkler als an anderen und arbeitet hin und wieder feine fibrillare Strukturen heraus, die aber ebenfalls, was Zeit und Ort ihres Auftretens betrifft, durchaus keine Regelmässigkeit darbieten. Nun ist eigentlich das epitheliale Reticulum fertig und zur Aufnahme der Lymphocyten vorbereitet (Fig. 23), (vgl. auch Fig. 13, 14 ${ }^{1}$ ), 19), nur sind die Maschen des Netzes im Vergleich zu später noch sehr klein, so dass man bei der Betrachtung im Schnitt eher den Eindruck hat, eine siebartig durchlöcherte Platte vor sich zu haben, als ein nach drei Dimensionen verspanntes System protoplasmatischer Züge. Maximow hat dieses Bild sicher auch schon gesehen, da er von der Vakuolisierung des Epithels spricht: er fasst sie aber, wie gesagt, nur als Folge der Lymphocyteninvasion auf. Und dennoch ist sie, wie man sich leicht überzeugen kann, vorhanden, noch ehe eine einzige fremde Zelle in der 'Thymus auftritt. Daher werde ich viel eher zu der Annahme gedrüngt, dass diese Auflockerung des Eipitlels ein primürer Vorgang ist, der, erste Schritt zu der nachfolgenden Metaplasie, an welcher die Epithelzellen nicht nur passiv, sondern alitiv teilnebmen. Es ist leicht verständich, dass den Lymphocyten erst der Boden in ihrer neuen Wohnstätte bereitet werden muss; denn dass es sich hier nicht nur um die Einwanderung derselben in ein fremdes Gewebe handeln kann, ist klar. Die biologischen Beziehungen zwischen Epithel und Lymphocyten sind in der Thymus noch fester, inniger als in der Tonsille. Hier vermebren sich diese nur selten weiter; sie bleiben eine Zeitlang lebend im Epithel und fallen darnach einer eigenartigen Degeneration anheim, bei welcher die Metamorphose des Kernes das Sinnfälligste ist. Dass ähnliche Erscheinungen auch in der Thymus gelegentlich vorkommen können, ist kein Grund dafür, die Thymus und die Tonsille als absolut gleichwertig hinsichtlich ihres Baues und ihrer Funktion zu erklären, auch die von Jolly beschriebene Entwicklung der

1) Um zu viele Figuren zu vermeiden, wurde hier gleich ein Stadium gezeichnet, in dem die Einwanderung der lymphoiden Zellen bereits begonnen hat; denkt man sich dieselben hinweg, so hat man das oben beschriebene Bild. 
Bursa Fabricii, obwohl sie manchen wertvollen Wink für das Verständnis der Thymusgenese gegeben hat, vermag hier nicht alle Rätsel zu lösen. Denn auch in der Bursa behält das Epithel dem lymphoiden Gewebe gegenüber eine viel grössere Selbständigkeit als in der Thymus, wie sich aus dem weiteren ergeben wird. Schon die Ausarbeitung einer liriftigen Basalmembran deutet dies an.

Es liegt natürlich sehr nahe, in dem veränderten aufgelockerten Epithel nach Degenerationsformen zu suchen, die man aber überraschenderweise nicht findet. Es haben sich sogar die liörnigen und scholligen Einschlüsse, die im Pharynxepithel ganz junger Stadien so hüutig waren, fast völlig verloren. Wenn man diese wie Maximow als Zeichen einer sekretorischen Tätigkeit des Epithels auffasst, so kann das Aufhören dieser Sekretion gleichtalls als ein Schritt vorwärts zur weiteren Umwandlung des Epithels gedeutet werden. Nur eines ist merkwürdig: Es fallen nämlich einzelne Epithelzellen durch ihre dunklere Fürbung auf, sowohl was l'rotoplasma, als Kern anbetrifft (Fig. 5); auch die Form der /ellen ist dann meist verändert; sie erscheinen zusammengedrückt, geruetscht. Dem entspricht auch ihre Lage in den peripberen Teilen des Organs. Ob diese Zellen, dem Überdruck von seiten der Nachibarschaft erliegend, dem Untergang anheimfallen, lïsst sich nicht ohne weiteres sagen; sicher zugrunde gehende Zellen findet man jedenfalls nicht. Vielleicht ist die starke Färbbarkeit nur der Ausdruck einer vorübergehenden Verdichtung der Zellsubstanz, die nach dem Ausgleich der Druckverhältnisse wieder zu ihrem ursprünglichen Volumen zurückkehrt. Auch $\mathrm{M}$ aximow beschreibt sie als "dunkle Epithelzellen", die sich vialleicht "zeitweilig in einem besonderen funktionellen Zustand befinden und ein entsprechendes besonderes Aussehen erlangt haben". Sie sollen beim Meerschweinchen sehr viel häufiger vorkommen als beim Kaninchen und dann tatsächlich die Klarheit der Bilder trüben. Wahrscheinlich haben auch andere Autoren sie geselien (Prenant 1894, Bell 1906, Stöhr 1910) und sie als die Übergangsformen zu Lymphocyten, hezw. lymphocytoiden Zellen gedeutet. Sie unterscheiden sich jedoch deutlich von ihnen durch die fehlende Basophilie ihres Protoplasmas und die etwas verschiedene Struktur ihres Kernes. 
Wenden wir uns nun, nachdem der Bau der Zelle im einzelnen besprochen ist, noch einmal dem Gesamtgefüge $z u$, so möchte ich noch auf einen Punkt zu sprechen kommen, der mir bisher nicht genügend berücksichtigt worden zu sein scheint, das ist das Lumen. Gewöhnlich wird nur angegeben, dass ein solches noch oder nicht mehr vorhanden ist, vielleicht wird auch noch die Form und Lage genauer prazisiert; nur Maximow erwähnt an einer Stelle, dass es ihm geschienen habe, als ob zwischen den Epithelzellen vom Lumen aus ein feiner Spalt nach aussen führe. Mir fiel zunächst an etwas älteren Embryonen als sie der Rekonstruktion von T'extfig. 5 zugrunde liegen, auf, dass ein Lumen, welches sich ein paar Schnitte weit ganz gut verfolgen lässt, dann plötzlich aufhört, um nach einigen weiteren Schnitten an einer ganz entfernten Stelle wieder aufzutauchen. Ausserdem war die Weite sehr wechselnd und einmal finden sich Zellen im Lumen, die sich bei wciterer Untersuchung als Bindegewebszellen erwiesen. Dies veranlasste mich, die ursprüngliche Lichtung des Kiementaschendivertikels von Anfang an zu verfolgen und dabei stellte sich heraus, dass das alte Lumen eigentlich nur im Cervikalteile längere Zeit erhalten bleibt, wähend das verdickte caudale Ende des Parathyreoidea-Thymusstranges, welches die bleibende Brustthymus liefert, von Anfang

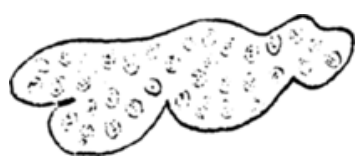

a

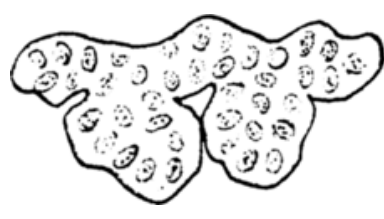

Fig. 6.

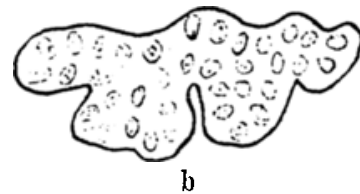

b

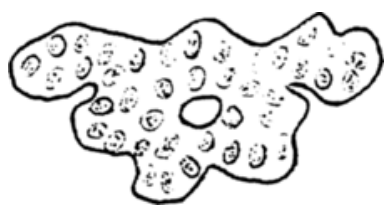

d

an eine kompakte Wucherung darstellt. Wie gelangt nun nachträglich ein Lumen in dieselbe? Um später nicht wiederholen zu müssen, werde ich hier gleich etwas vorausgreifen; denn die im folgenden beschriebenen Bildungen gehören schon etwas ălteren 
Stadien an, wenn die Brustthymus durch verstärktes Wachstum sich vom übrigen Teil abzusetzen beginnt. Der scheinbar komplizierte Vorgang ist eigentlich ganz einfach und wird am besten durch ein schematisches Bild veranschaulicht: Fig. 6. Zwei solide Epithelknospen wachsen aus dem ursprünglichen Strang helvor (a) und zwar, wie die beiden Pfeile angeben (b), in einseitiger Richtung. Bei der weiteren Entwicklung wird das Epithel gezwungen, sich einzurollen, die Zellen kommen fest aneinander zu liegen (c) und verwachsen schliesslich miteinander (d). Prenant (1894) hat den in ähnlicher Weise bei der Parathyreoidea (Glandule Carotidienne) erfolgenden Vorgang sehr treffend beschrieben: „Les cellules épithéliales se replient sur elles-mêmes". Das Lumen, das auf diese Weise zustande kommt, ist immer sehr klein und führt, wenn man es weiter verfolgt, schliesslich nach aussen durch einen oder mehrere feine Spalten. Allseitig umschlossene Hohlräume, also Cysten, werden nicht gebildet. Nur so liisst sich leicht elkliiren, warum man manchmal auf einem Querschnitt zwei Lumina an verschiedenen Stellen findet, warum ihre Lage eine so wechselnde ist und warum sie kein durchgehendes System bilden. Dass eine um ein solch feines Lumen angeordnete Epithelzellengruppe den Eindruck eines Drüsenläppchens hervorrufen kann, ist leicht verständlich; es ist auch der Gedanke, dass die Thymus nach Art einel acinösen Drüse sich entfalte, schon melırfach geäussert worden (vgl. das Referat Hammars). Man kaun sich aber mit Hilfe der Rekonstruktionsmethode sofort übel'zeugen, dass die Ähnlichkeit nur eine scheinbare ist und die Thymus niemals einen Liippchenbau in diesem Sinne zeigt.

Natürlich kann die obenbeschriebene Art der Lumenbildung nur verhältnismässig kurze Zeit andauern. Mit dem rascheren und weiter ausgedelınten Wachstum der epithelialen Zellverbănde verwischt sich dieser Vorgang ganz, besonders, da längst, auch schon die histologische Differenzierung eingesetzt hat. Wenn nun trotzdem noch ähnliche Hohlraumbildungen zustande kommen, so sind die Kanäle viel weiter und sie stellen nicht mehr eine einfache Lichtung im Innern des Epithels dar, sondern sie enthalten dann bereits fremdes Gewebe, Mesenchym und Gefässe (Fig. 6, wo zugleich der nach aussen führende Spalt zu sehen ist und Fig. 13, die eine uhnliche Stelle bei stärkster Vergrösserung darstellt). 


\section{b) Einwanderung von Lymphocyten.}

Die lymphoide Umwandlung des Organs scheint nicht immer zu dem gleichen Zeitpunkt zu erfolgen; bei mehreren, dem gleichen Wurfe zugehörigen 16 tägigen Embryonen zeigten sich bei den einen schon Wanderzellen in der Thymus, während sie bei den anderen noch vollständig frei davon war. Es entspricht dieses Stadium ungefähr dem ersten von Maximow genauer beschriebenen.

Das Epithel zeigt im Innern besonders schön bei Färbung nach Mallory und Pasini (Fig. 23) die oben erwänte lockere vakuoläre Struktur, ist aber nach aussen überall, selbst in den tieferen Septen noch, durch einen deutlichen, feinen blauen Saum

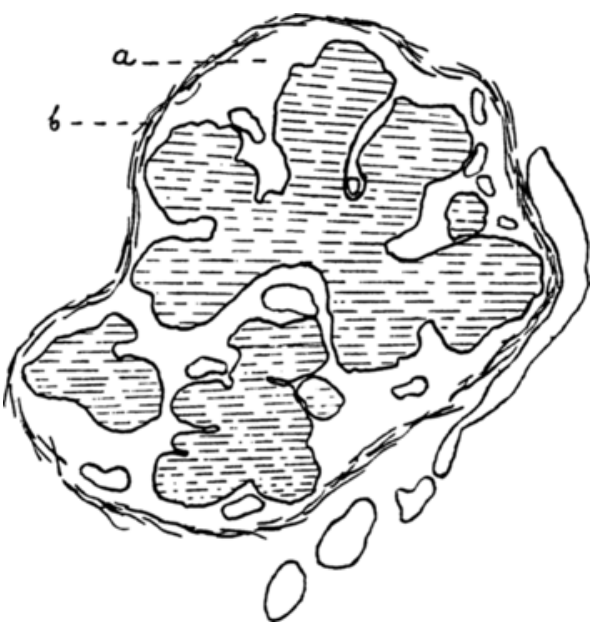

Fig. 7. Schnitt durch die Thymus eines 16 tägigen Kaninchenembryos. Gezeichnet mit dem A b beschen Zeichenprisma unter Benutzung von Apochr. $16 \mathrm{~mm}$ und Compens.-Ocul. 4. Gefässe rot. gegen die Umgebung abgegrenzt. Bei der Färbung mit Azur IIEosin tritt dies viel weniger hervor, dagegen sind hier die Zellen des Mesenchyms sehr schön differenziert, was bei den reinen Bindegewebsund Epithelfürbungen nicht der Fall ist. Noch şchönere Resultate zur Unterscheidung der einzelnen Zellformen des Mesenchyms gibt die von Pappenheim (1911) angegebene Färbung mit Panchrom, welche die Methode von Giemsa mit der eosinsauren Methylenblaufärbung von JennerMa y verbindet oder die von Kardos (1911) ausprobierte Triacidfärbung, die das Fuchsin $\mathrm{S}$ durch Panchrom ersetzt.

Betrachtet man die auf dem Schnitt rosettenförmige Thymus und das umgebende Gewebe ganz oberflächlich, so lassen sich deutlich zwei Schichten unterscheiden (Textfig. 7), eine innere 
sehr lockere, etwa der Cambiumschicht des Periosts vergleichbar (a) und eine aussere (b), das Organ konzentrisch umschliessende, welche die Einbuchtungen zwischen die Epithelknospen nicht mitmacht und aus länglichen, spindelförmigen, aber noch saftigen Bindegewebszellen besteht, die schon ziemlich reichlich feinere und gröbere Fasern ausgearbeitet haben. Mi etens (1909) beschreibt um die Thymus des Rindes ein Bindegewebslager in drei Schichten, ohne jedoch auf deren Bedeutung năher einzugehen. Diese eigenartige Kapselbildung um das Organ, die der fertigen Thymus in dieser Form nicht mehr zukommt, muss uns auffallen; durch sie wird um die epitheliale Anlage herum ein Bezirk von Mesenchym abgegrenzt, der offenbar zur Thymus selbst gehört. Die Anschauung v. Ebners scheint gerechtfertigt; denn der Gedanke, dass aus dem lockeren embryonalen Mesenchym durch lymphoide Umwandlung die Rinde der Thymus entstehe, liegt hier auf der Hand. Innerhalb dieser Kapsel findet man auch bereits Gefüsse und damit wäre eine Schwierigkeit, nämlich die Vaskularisierung der Rindensubstanz, gelöst; das Eindringen derselben in das kompakte epitheliale Mark ist freilich dadurch noch nicht erklärt.

Die Wandung der meist weiten Gefusse besteht nur aus einer einfachen Lage platter Endothelzellen, die nach aussen häufig noch den Zusammenhang mit dem Mesenchym zeigen. Im Inhalt findet man neben vielen kernhaltigen, roten Blutkörperchen nur sehr wenige Lymphocyten. Die Gefässe gehen manchmal bis dicht an das Epithel heran, aber selten tief in die Septen hinein; erst etwas später, bei Embryonen von 17 und 18 Tagen, beginnen sie auch hier vorzudringen, doch scheint mir dieses Vordringen vorerst mehr passiver Natur zu sein, bedingt durch die weitere Ausdehnung des Epithels. Die innerhalb der Kapsel liegende Mesenchymschicht besteht aus grossen Zellen, die durch sehr fein verästelte Fortsätze zusammenhängen. Das Protoplasma farbt sich meist hell und ist ohne besondere Einschlüsse oder auffallende Strukturen. Dagegen lassen sich bei geeigneter Färbung an der Zelloberfläche feinste Fäserchen darstellen (Fig. 19), die den weichen, lockeren Bau des Gewebes noch verdeutlichen. Gröbere Fasern findet man nicht, auch nicht in unmittelbarer Umgebung der Gefässe. An der Oberfläche des Epithels, bezw. an seiner Unterseite, sind die Zellen meist etwas 
abgeplattet, sie schmiegen sich der Wand an, bleiben aber deutlich von ihr getrennt. Die Kerne sind gross, länglich oval und saftreich und besitzen ein feines Chromatinnetz mit ein bis zwei Nukleolen. Hellere Höfe im Zellinnern sind nicht zu sehen, dagegen manchmal Vakuolen gegen die Oberfläche $\mathrm{zu}$, doch lässt sich natürlich schwer sagen, inwieweit hier die Fortsatzbildung beteiligt ist.

Zur Teilung, die in den früberen Stadien nicht aussergewöbnlich häufig vorkommt, zieht die Zelle ibre Fortsïtze meist ein; sie entwickelt dann an ihrer Obertläche etwas wie eine Membran, d. h. sie ist gegen ibre Umgebung scharf abgesetzt; es kann aber diese Trennung nicht lange dauern, da man die jungen, an ihrer geringeren Grösse kenntlichen Zellen wieder mit den übrigen verbunden findet. In den Einsenkungen zwischen den Epithelknospen sind die Mesenchymzellen meist etwas dichter zusammengedrängt, doch lässt sieh natürlich nicht unterscheiden, ob dies schon die Folge einer lebhafteren Vermehrung, oder nur der Unmöglichkeit, sich weiter auszudehnen, ist (Fig. 6 und 17).

Wichtiger als der Bau der fixen Mesenchymzellen im allgemeinen ist jetzt die Frage nach der Art und Menge der beweglichen Wanderzellen in der Ümgebung der Thymus. Dass sie schon viel früher vorkommen können, wurde bereits erwähnt. In der 'Jat findet man nun auch in der Nähe der Thymus ziemlich viel freie Zellen, welche den für die sogenannten grossen Lymphocyten charakteristischen Habitus aufweisen. Es sind ziemlich rerschieden grosse, rundliche Zellen, deren Protoplasma bei Panchromfärbung einen tief dunkelblauvioletten Ton annimmt, während die übrigen Bindegewebszellen melır rötlichviolett und viel heller aussehen. Der Kern ist gross, rund, scharf konturiert, mit einem deutlichen, aber feinen, sich dunkelblau färbenden Chromatinnetz und meist einem bis zwei ziemlich grossen Nukleolen (Fig. 24). Häufig liegit er etwas exzentrisch in der Zelle; in seltenen Fällen ist er nierenförmig eingedellt. Obwohl er in dem stark basophilen Protoplasma als heller Fleck imponiert, färbt er sich doch im ganzen etwas dunkler als die umliegenden Bindegewebskerne. Die Form der Zelle ist fast immer rund oder mit ganz kurzen Pseudopodien versehen; nur bier und da sieht man noch einen Fortsatz im Zusammenhang mit dem umliegenden Gewebe, der 
die Abstammung der Zellen aus dem Mesenchym dokumentiert (Fig. 19). Nicht selten kann man hier um die Kerne eine Anhäufung von dichterem, stärker basophilem Protoplasma beobachten, als erstes Zeichen, dass die Zelle sich aus dem syncytialen Verband zu lösen gedenkt. Die Struktur des Protoplasmas ist sehr feinwabig; grössere Vakuolen an der Peripherie der Zellen sind in der Regel vorhanden. Vereinzelte Zellen, sowohl freie als fixe, enthalten in ihrem Protoplasma dunkelblaue bis rotviolette Körnchen eingelagert. Welcher Natur diese Granulationen sind, vermag ich nicht anzugeben. Sie bilden ein durchaus unregelmässiges Vorkommnis. Wahrscheinlich sind sie identisch mit den von Maximow an anderer Stelle beschriebenen cyanophilen und erythrophilen Körnern, die bei allen Embryonen, aber in ungleicher /ahl, vorkommen sollen und deren physiologische Bedeutung noch unbekamnt ist. Sie treten nicht nach allen Fixierungen gleich deutlich hervor (besonders stark nach Sublimat und Carnoy, weniger nach Zenker und Orth) und sind auch nach der Firbung mit Panchrom oder nach Kardos viel auffilliger als mit Azur II-Eosin.

Echte kleine Lymphocyten mit dunklem Kern und dem ganz schmalen Protoplasmasaum findet man in diesen früben Stadien im Crewebe noch nirgends (ausser im Mesenchym der Dottersackwand), wohl aber schon im strömenden Blut der Gefïsse. Auch habe ich bei so jungen Embryonen nur selten Mitosen in den grossen Lymphocyten finden können. Sie scheinen zunïchst alle in loco aus ihrem Muttergewebe zu entstehen. Kommen aber Teilungen vor, so sieht mall schöne, klare Bilder (Fig. 6 and 17), ebenso wie in den Mesenchymzellen, die den häufig beschriebenen "verklumpten Mitosen" der kleinen Lymphocyten durchaus unähnlich sind.

Zellen mit spezifischen Granulationen fehlen im Mesenchym noch vollständig; sie lassen auch wenigstens in der Umgebung der Thymus noch sehr lange auf sich warten.

Was die Zeit ihres ersten Auftretens betrifft, so findet man die freien Wanderzellen in vermehrter Anzahl bereits bei Embryonen von 10-11 mm Länge (14 Tagen), aber nur in der Umgebung des Thymuskörpers. Das Mesenchym um den Kopfund Cervikalteil ist noch völlig frei von ihnen. Erst bei Embryonen von ca. $20 \mathrm{~mm}$ Länge (17 Tagen) treten sie auch hier in grösserer Zahl auf; sie machen allerdings kaum mehr einen Versuch, ein- 
zudringen. Die lymphoide Umwandlung im thorakalen Abschnitt ist dann bereits in vollem Gange.

Das Eindringen der Lymphocyten erfolgt nicht sofort nach ihrem ersten Auftreten. Die frühesten Einwanderungsbilder habe ich bei einem Embryo von 15,2 mm Länge (16 Tagen) gefunden, von welchem auch die Fig. 19 entnommen ist, während drei andere Embryonen desselben Wurfes, die untersucht wurden, noch eine rein epitheliale Thymus besassen. Von einem derselben stammt das Rekonstrulitionsbild (Textfig. 5).

Über den Prozess der Einwanderung selbst kann ich mich kurz fassen, da hierüber bereits die genaue und ausführliche Schilderung von Maximow vorliegt, der ich mich vollstindig anschliesse auf Grund meiner eigenen Beobachtungen. Die Formen der eindringenden Lymphocyten sind allerdings häufig verändert; doch ist die Deformation nicht so gross, als man es bei der Durchwanderung eines so fest gefügten Gewebes erwarten würde, jedenfalls findet man lange nicht jene bizarren Formen, die einem bei der Durchmusterung des Mundhöhlen- oder 'Trachealepithels begegnen. Dies mag zunächst merkwüldig berühren; ausserdem ist aber sofort auffallig, dass die Lymphocyten gewisse Pradilektionsstellen für die Einwanderung besitzen; nämlich die zwischen den Epithelknospen gelegenen weiten, mit Mesenchym erfüllten Spalten. Der Grund hierfür ist nicht schwer zu finden. Wir haben es hier mit einem Locus minoris resistentiae $\mathrm{zu}$ tun; das aufgelockerte, fast schon zum Reticulum gedelnte Epithel gestattet den Eingang ohne weiteres, während die dicht geschlossenen Zellreihen der Oberfliache den andringenden Lymphocyten Widerstand entgegensetzen. Es wäre sonst nicht einzusehen, warum diese nicht auf dem kürzesten Wege zu ihrem Ziel zu gelangen suchten, denn eine vermelrte Entstehung vou Lymphocyten in den Einschnitten zwischen den Höckern, wie Maximow es will, kann ich in diesen Stadien noch nicht bestatigen, nur eine dichtere Anbaufung von Mesenchymzellen, die allerdings ebenfalls tür die weitere Entwicklung der Thymus von grosser Bedeutung ist, wje sich aus dem folgenden ergeben wird.

Vielmehr sehe ich gerade in dem Umstand, dass die Lymphocyten vorwiegend, ja fast ausschliesslich, von der Spitze jener "Bindegewebspapillen" aus einwandern, eine Bestätigung dafür, dass eine primäre Veränderung des Epithels vorhanden sein muss, 
welche in der starken Vakuolisierung, in der Auflösung zum syncytialen Reticulum manifest wird. Freilich fehlt uns noch jeder Anhaltspunkt über die physiologischen Vorgange, welche die ursprüngliche epitheliale Anlage zu dieser Veränderung, die mit der geläufigen Auffassung der Morphologen von einem Epithel in direktem Widerspruch steht, veranlassen und hernach die Einwanderung so grosser Mengen von Lymphocyten bewirken. Die Vorstellung Maximows, dass das Thymusepithel bei seinem Wachstum auf das Mesenchym einen besonderen Reiz ausübt und die fixen Zellen des Wesenchyms veranlasst, sich in wandernde amöboide Elemente zu verwandeln tund dass es nandererseits zweifellos auch eine positiv chemotaktische Wirkung auf diese Wanderzellen ausübt", ist doch wohl eher eine Lmschreibung als eine Erklärung des für uns bis jetzt dunkel gebliebenen Vorganges.

Die Einwanderung der Lymphocyten von der Tiefe her ist auch der Grund dafür, dass man anfangs die fremden Zellen nur im Zentrum des Organs findet, während die Peripherie noch ganz frei von ihnen ist, denn die Mehrzahl der an der ausseren Obertlïche der Thymus als dunklere auffallende Zellen gehören den oben beschriebenen dunklen Epithelzellen an.

Wir haben nun zunächst das Schicksal der Wanderzellen im Innern des Epithels weiter zu verfolgen: Die Frage, ob sie sich mit dem blossen Eindringen begnügen oder zwischen den Epithelzellen ihre Wanderschaft noch weiter fortsetzell, ist nicht schwer zu beantworten; denn man findet die grösseren der Wanderzellen meist mit Pseudopodien versehen (Fig. 14, 16 und 19). Sie sind also ohne Zweifel noch nicht zur Ruhe gekommen. Dabei lässt sich beobachten, dass die vorgeschobenen Fortsätze fast stets gegen eine grosse zwischen den Epithelzellen vorhandene Vakuole gerichtet sind; offenbar empfindet die Zelle den einzwăngenden Aufenthalt im Epithel als unangenelm und trachtet in eine für sie möglichst bequeme und günstige Lage zu kommen. in der sie sich dann einstweilen zur Ruhe setzt. An den kleineren Formen sind Bewegungserscheinungen viel seltener zu konstatieren. In der T'onsille liegen die Verbältnisse etwas anders. Hier handelt es sich nach Spuler (1910) tatsächlich um einen kontinuierlichen Lymphocytenstrom, der von innen nach aussen geht. Sobald es im Innern des Epithels aus irgend welchen Gründen zur Stauung 
kommt, wird eben durch den sich steigernden Druck das Epithel mit samt seinem Inbalt abgehoben und fällt der Zerstörung anheim. Ähnliche Vorgänge können sich, wie sich später zeigen wird, auch in der Thymus abspielen, doch immer nur unter bestimmten Voraussetzungen und niemals in so ausgedehntem Maße. Selbstverständlich spielt auch in den ganz jungen Stadien der Thymusentwicklung der Lymphstrom, welcher durch das aufgelockerte Epithel zirkuliert, eine gewisse Rolle bei der Fortbewegung der Wanderzellen; namentlich bei der jetzt rasch fortschreitenden histogenetischen Differenzierung kommen ausgedehnte passive Verschiebungen derselben im Organ sicherlich vor.

Wichtiger noch ist die liage nach der Vermehrung der Wanderzellen im Epithel. Durchmustert man anfmerksam alle Kernteilungsfiguren, die man im Schnitte durch die Thymusanlage eines 17-18 lage alten (ca. $20 \mathrm{~mm}$ langen) Embryos fudet, so ist man zunïchst erstaunt, lauter gleichförmige Bilder zu sehen, d. h. die Mitosen sind wohl in den verschiedensten Stadien vorhanden, aber man kann unter ihnen nicht zwei 'Typen unterscheiden, die zwei verschiedenen Zellarten mit Bestimmtheit zugerechnet werden könnten, so wie sie von $\mathrm{Hammar}$, M a x i m ow und anderen für die Thymus beschrieben wurden und wie ich dies für etwas spätere Stadien selbst bestütigen kann. Das nächstliegende ist, an Epithelzellenmitosen zu denken und die vorlüufge Vermehrung der Lymphocyten im Epithel nur durch neueinwandernde Elemente zustandekommen zu lassen. Zumal die aus dem Mesenchym frei werdenden Zellen sich um die Epithelknospen herum viel mehr als früher zu häufen beginnen.

Andererseits aber sehen die Mitosen der Mesenchynzellen, wie schon früher betont, denjenigen im Epithel sehr ähnlich, so dass man die Möglichkeit, dass einzelne der in der Thymusanlage vorkommenden Zellteilungen den Lymphocyten zugehören, nicht ohne weiteres von del Hand weisen kann. Vielleicht liegt eben darin, dass das Aussehen der Kernteilungsfigur sich andert, ein sichtbarer Ausdruck tür eine innere Differenzierung der Zelle, die in den jüngsten eben eingewanderten Elementen noch nicht zustande gekommen ist. Sieht man sich nun unter den noch ausserhalb der 'Thymusanlage im Mesenchym liegenden Wanderzellen nach Zellteilungen um, so ist man überrascht, sehr viel weniger zu finden, als man erwartet bätte nach der Zahl der 
Zellen; immerhin aber kommen welche vor, die sich von den Mitosen im Mesenchym nur durch die dunklere Färbung des umgebenden Protoplasmas unterscheiden. Dieser Befund mag als Stuitze dafür dienen, dass in den ganz jungen Stadien die Wanderzellen sich vorwiegend durch Nachschub aus dem lockeren Mesenchym ergänzen, wo jederzeit eine Entstehungsmöglichkeit gegeben ist, während sie sich später durch Teilung selbständig weiter vermehren, wenn an das Mesenchym durch die Ausbildung von Stïtzgerüsten andere Anforderungen gestellt werden. Dann ist auch der Zeitpunkt gekommen, für die Lymphocyten eigene, an bestimmte Orte geknüpfte Stätten der Entstehung zu schaffen.

Wit dem Eindringen allein der Wanderzellen in die epitheliale Anlage ist es nicht getan, sondern sie erfahren gleichzeitig eine bestimmte innere Umwandlung. Auch Maximow betont für das Kaninchen die sofort nach dem Eindringen in das Epithel erfolgende Umbildung zu sogen. grossen Lymphocyten, welche gerade für dieses 'Tier das Studium der Immigration so erleichtert. Durch ihr stark basophiles l'rotoplasma heben sie sich sehr gut gegen ihre Umgebung ab, so dass sie bei schwacher Vergrösserung sofort als dunkle Punkte im Epithel auffallen. Die eingewanderten Zellen sind in der Tat sehr gleichförmig in ihrem Bau, sowohl was Grösse, Form und Struktur anbetrifft; ausserdem lassen sie alle Körnelungen vermissen.

Die noch ausserhalb des Epithels liegenden Zellen erscheinen dagegen sebr polymorph, sie zeigen bald einen sehr grossen, bald nur einen sehr schmalen hellen Protoplasmahof und gerade die durch ihre starke Basophilie auffallenden Zellen, dieselben, die auch in der Thymus vorkommen, sind in der Minderzahl vorhanden und finden sich dann auch meist schon in der Nähe des Epithels. Hier lassen sie anch am besten die Fortsatzbildungen beobachten; ein Zustreben gegen das Epithel ist unverkennbar. Das war es wohl auch, was Maximow veranlasste, nach einem vom Epithel ausgehenden Reiz zu suchen, der eine attraktive Wirkung auf das Mesenclymm entfaltet. In den jungen, den vorliegenden Beobachtungen entsprechenden Stadien, die zwischen dem 16.-18. Tage zu suchen sind, mag dies der Fall sein; aber sehr bald genügt die Einwanderung allein nicht mehr und anch die nun reichlicher einsetzende selbständige Vermehrung der Lymphocyten in der Thymus vermag nicht mehr den Bedarf an 
Zellen zu decken. Dann kann von einem chemotaktischen Reiz nicht mehr die Rede sein; auch die später einsetzende Differenzierung in Mark und Rinde wird dadurch keineswegs erklitrt. Die Dauer der eigentlichen Einwanderung selbst ist also ziemlich beschränkt; sie beginnt bei Embryonen voll ca. $14 \mathrm{~mm}$ Länge (15.-16. Tag) und erreicht ihren Höhepunkt gegen Ende des 17. Tages, also bei Embryonen von ca. $21 \mathrm{~mm}$ Länge. Daln klingt sie sehr rasch $a b$ und hört fast ganz auf. Selbstverständlich findet man auch später noch immer vereinzelt von der Obertläche einwandernde Zellen. Sie sind aber selten und nur mit Mühe zu sehen und würden allein keinen Beweis für die Immigrationstheorie geben, denn auch in der fertigen Thymus lassen sich in der Tiefe der Septen, wo, die Grenze des Parenchyms gegen das Bindegewebe verwischt erscheint, stets Bilder beobachten, die als Einwanderungsbilder gedeutet werden können (Fig. 26), olne dass man hieraus allein einen Schluss auf die Genese des gesamten Organs ziehen dürfte.

Betrachtet man die Thymus eines 17 tagigen Embryos als Ganzes, um die Fortschritte gegen früher nochmals festzustellen, so ergibt sich folgendes: die linke Thymus ist etwas langer als die rechte $(1,8: 1,55 \mathrm{~mm})$; der Cervikalteil reicht bis zur Witte des seitlichen Thyreoidealappens und ist beiderseits zu einem langen, nicht sehr dicken Strang ausgezogen, der etwa die Hälfte der gesamten Thymusanlage ausmacht. Cranialwirts schliesst sich auf ein kurzes Stück der ebenfalls in seiner Lünge und Breite stark reduzierte Parathyreoideastrang anl, der nach wenigen Schnitten in das der Schilddrüse bereits angelagerte Epithelkörperchen übergeht. Der oberste (etwa $0,25 \mathrm{~mm}$ lange) Abschnitt der cervikalen Thymus besteht aus einem nur wenige Zellagen umfassenden kompakten epithelialen Balken, der ziemlich gerade zwischen Carotis und Vagus nach abwärts verläuft und in seinem Innern keine Spur eines Lumens mehr aufweist. Seine Kontur ist gegen das umgebende Mesenchym scharf abgesetzt und letzteres zeigt keinerlei Verănderung. Allmällich treten am Strange Knospenbildungen auf, erst flache und in grösseren Zwischenrăumen; bald werden sie höher und erscheinen gegeneinander abgeplattet; die aus früheren Stadien bekannten Einrollungsbilder lrommen wieder zum Vorschein und plötzlich ist'auch eine ziemlich weite Lichtung zu sehen, in welcher deutlich fremde- 
Zellen liegen. Wie diese in das Lumen hineingelangt sind, zeigt die Fig. 6, die einem weiter caudal gelegenen Schnitt entnommen ist. Man sieht hier deutlich den nach aussen führenden Spalt. Derartige Öffinungen habe ich bei der Verfolgung des Lumens noch mehrere gefunden; sie liegen durchaus nicht immer auf der gleichen Seite des Organs, ebenso wie die Dicke der Wand sehr stark wechselt. Eingewanderte Lymphocyten tindet man an diesen Stellen noch nicht, auch nur wenig freie Wanderzellen im Mesenchym; dagegen zeigt sich das Epithel stellenweise valiuolisiert und aufgelockert (Fig. 13) und liisst hin und wieder die dunklen „kontrahierten" Epithelzellen (Maximow) erkennen (vgl. Fig. 5).

Ganz ander's gebaut erweist sich der thorakale Abschnitt der Thymus, der aber olıne scharfe Grenze in den cervikalen Teil übergeht. Die bindegewebigen Einsenkungen zwischen den einzelnen Epithelknospen sind noch tiefer, weiter und breiter geworden als fiüher; in ihnen ziehen Gefïsse bis dicht an das Epithel heran, so dass man anf dem Schnitt durch das bereits sehr komplizierte Organ den Eindluck hat, als sei schon die ganze Thymus von Gefässen durchset\%t und man sehr genau untersuchen muss, häufig unter Zuhilfenalıne von Immersionssystemen, um nachzuweisen, dass die ursprüngliche epitheliale Anlage immer noch gefusslos ist. Das die Zwischenräume ausfüllende Bindegewebe hat durch die grosse Anzahl freier Zellen aller möglichen Formen, die es jetzt bevölkern und die mit Vorliebe sich in der Nähe der Gefüsse ansammeln, ein eigenartiges Aussehen bekommen, ebenso wie das Epithel selbst, in welchem jet/t nicht mehr die lockere vakuolüre Struktur das Auffälligste ist, sondern die Durchsetzung mit grossen basophilen Lymphocyten. Letztere sammeln sich zwar immer noch vorwiegend im Zentrum des Organs an, man findet sie jetzt aber auch einzeln oder in kleinen Gruppen beisammen liegend an der Peripherie der Lappchen, sofern man schon von solchen reden darf. Immer bleiben einzelne Epithelbezirke von der Einwanderung völlig verschont. die auch ganz. regellos im Organ verstreut liegen, bald in der Mitte eines Epithelzapfens, bald arn Rande. Sie zeigen keinerlei Beziehung zu der Differenzierung von Mark und Rinde, vorerst wenigstens, und bilden keine Ausgangspunkte für eine Hypertrophie von Epithelzellen, denn ihre Elemente unterscheiden sich, was die Grösse anbetrifft, durchaus nicht von den übrigen, böchstens. 
fallen sie durch ihr festeres Gefüge auf. Vielleicht ist dies auch der Grund, weshalb die Lymphocyten nicht in sie einzudringen vermögen.

Eine Beobachtung mag noch auffallen; es reihen sich die Lymphocyten manchmal selbst epithelähnlich längs des Epithels auf, so dass der zentrale Strang perlschnurartig von Wandel'zellen besetzt erscheint (Fig. 7). Immer erweist sich der Bau des Epithels an solchen Stellen als sehr locker. Möglicherweise wird hier schon vorbereitet, was im weiteren genauer beschrieben werden soll, nämlich die Mitwirkung des gesamten umgebenden Mesenchyms an der Histiogenese der Thymus, nachdem die Einwanderung von Lymphocyten allein sich als nicht mehr genügend erweist.

Noch immer ist der in der nächsten Umgebung der Thymus befindliche Mesenchymabschnitt durch eine faserreiche, das Organ nach Art einer Kapsel umgebende Bindegewebsschicht von dem übrigen sehr viel zellärmeren (iewebe abgetrennt (vgl. Fig. 7); nur um den Cervikalstrang, der einer raschen Rückbildung anheimfullt, fehlt dieser Mantel vollständig. Im übrigen umgibt er beide Thymusanlagen getrennt. Selbst in den Thorakalpartien, wo die einzelnen Epithelzapfen und Stränge ineinander zu greifen beginnen und die Herstellung einer einheitlichen Thymus angebahnt wird, wie es sich bereits im früheren Stadium zeigt (vgl. 'Textfig. 5), bleibt, im mikroskopischen Bilde wenigstens, durch die trennende Faserschicht die parige Anlage des Organs noch lange deutlich. Die nach inmen von den Fasern liegende Mesenchymschicht ist so zellreich geworden, dass die Abgrenzung gegen das ursprüngliche Bindegewebe nicht nur schwer, sondern manchmal geradezu unmöglich wird, namentlich in der Tiefe de1 Papillen, wo das Reticulum des Bindegewebes hart an das zum Netzsyncytium aufgelöste Epithel anstösst (Fig. 17). Hier ist dann auch meist die feine trennende Grenzlinie, die sonst lange erhalten bleibt, schon früher zugrunde gegangen. Nur durch den Verlauf der Gefüsse lassen sich der epitheliale und der bindegewebige Abschnitt der Thymus noch auseinander halten, denn das innerhalb des Fasermantels liegende zellreiche Mesenchymgewebe darf man jetzt wohl zur Thymusanlage rechnen. Das Epithel ist bis jetzt noch immer gefüssfrei. Es lässt sich in diesem Abschnitt ihrer Entwicklung die Thymus am ehesten mit der Tonsille vergleichen; beide Organe stehen jetzt annahernd auf derselben Stufe. Wir 
finden bei beiden tief ins Mesenchym einschneidende epitheliale Zapfen und Schlauche (sie sind in der embryonalen Tonsille auch häufig solid), umgeben von einem dicht mit Wandelzellen erfüllten jugendlichen gefüsshaltigen Mesenchym; das Epithel selbst an vielen Stellen schon aufgelöst zum Reticulum und durchsetzt von Lymphocyten, aber niemals gefüsshaltig. Dadurch bleibt in der Tonsille selbst bei weiterer Ausbildung des Mesenchyms immer eine gewisse Selbständigkeit zwischen beiden (ieweben gewahrt, die in der 'Thymus bald verloren geht. Hier lässt sich höchstens aus der Anordnung der Gefässe noch ein Schluss ziehen auf die ursprüngliche Verteilung beider Gewebe.

\section{c) Beteiligung und Verhalten des Mesenchyms.}

Schon im vorhergehenden Stadium ist durch die reichliche Lieferung von Wanderzellen ein Vorgang eingeleitet worden, der nunmelr ganz in den Vordergrund tritt und das Bild der Histiogenese der Thymus bis zur definitiven Ausgestaltung des Organs im wesentlichen beherrscht, das ist die Mitbeteiligung des Nesenchyms am Aufbau des Organs, nicht in Form der groben bindegewebigen Septen, welche zwischen den Epithelknospen liegen, die Cefïsse an sie heranbringen und ihnen zur stütze dienen; auch nicht als einzelne lymphoide Elemente, die gesondert in das Epithel eindringen und dasselbe durchwandern, wie bisher, sondern in Form von zusammenhängendem undifferenziertem Nesenchym, in dem noch alle Möglichkeiten weiterer Ausgestaltung darinmen stecken, welches also in gleicher Weise für die Lieferung von Blutzellen (Lymphocyten) und Gefässzellen (Endothel), sowie durch Ausarbeitung eines Fasergerüustes als Stütz- und Verspannungssystem herangezogen werden kann. Es werden jetzt die Verhilnisse immer komplizierter, die relativ einfachen Bilder, die das von einzelnen Lymphocyten durchsetzte, gefüssfreie Epithel bisher bot, werden seltener, es beginnt jetzt recht eigentlich die Ausgestaltung des merkwïrdigen lymphoiden Organs, als welches man die Thymus kennt, und das Jolly $(1911,1913)$ veranlasst hat, wegen der eigenartigen Durchmengung von epithelialem und lymphoidem Gewebe es mit der Tonsille und der Bursa Fabricii zu einer gesonderten Gruppe, der „lympho-epithelialen Organe “ zusammenzufassen. Unter diesen nimmt aber die Thymus wiederum eine Sonderstellung ein; denn bei der Tonsille und der Bursa Fabricii 
bleibt die Durchmischung beider Gewebsarten immer eine mehr obertlachliche; das Epithel ist zwar so reichlich von Lymphocyten durchsetzt, dass es aus der ursprünglich kompakten Form zu einer Netzform aufgelöst wird, aber das die Lymphocyten liefernde Gewebe bleibt ausserhalb des Epithels und nimmt die Form an, in welcher man es auch sonst im Körper vorfindet, es bildet charakteristische Lymphfollikel aus.

Anders in der Thymus. Im ausgewachsenen Organ wenigstens findet man niemals Bildungen, welche in irgend einer Weise an einen echten Lymphfollikel erinnern würden, trotzdem ist in der Literatur, namentlich der alteren, häufig genug von Thymusfollikeln die Rede. Es fehlt aber dem lymphoiden Gewebe der Thymusrinde die konzentrische Schichtung um einen Mittelpunkt, in welchem Flemming das Wachstumszentrum erblickte und den er deshalb sobald gewisse rein äusserliche Bedingungen erfüllt waren, als Keimzentrum bezeichnete. Vielmehr sind dort zwischen grossen, zu einem weitmaschigen Netz verspannten sternförmigen Zellen, auf deren Natur ich spater noch einzugehen habe, die Lymphocyten gleichmasssig dicht und regellos eingelagert. Dass der epitheliale Anteil der Tonsille und der Bursa Fabricii dauernd gefassfrei bleibt, während bei der Thymus sowohl Mark als Rinde von Gefässen durchsetzt sind, wurde schon früher erwähnt. Auch hierin liegt ein Unterschied zwischen den Organen, der wahrscheinlich nicht nur für die morphologische Ausbildung, sondern vor allem auch für ihre physiologische Bedeutung viel durchgreifender und weittragender ist, als man auf den ersten Anblick meinen würde.

Ich gebe nun zunächst die Beschreibung der weiter folgenden Stadien und beginne mit einem 18 tägigen $23,8 \mathrm{~mm}$ langen Fötus (vgl. Fig. 27). Die Parathyreoidea hat bereits das definitive Aussehen erreicht; ihre Zellen sind ziemlich klein, gleichförmig und dicht gedrängt; die Gefässe sind enger geworden als früher und liegen den Epithelzellen überall unmittelbar an. Vom Mesenchym findet man im Innern fast nichts mehr; auch die umgebende Faserkapsel ist nicht sehr deutlich ausgebildet. Es liegt als ein rundlicher Körper den seitlichen Thyreoidealappen an, ventral von der Carotis und läuft kaudal in einen spitzen Zipfel aus, der kontinuierlich in einen dünnen Zellstrang, den alten ParathyreoideaThymusstrang, übergeht, welcher nach abwärts noch mit der Thymus, die allerdings scharf gegen ihn abgesetzt ist, zusammen- 
hängt. Diese beiden dünnen Säulen entfernen sich immer mehr von der Carotis; sie liegen dem Mittellappen der Thyreoidea fast direkt auf und konvergieren in medialer und ventraler Richtung. Auf dem Querschnitt bestehen sie oft nur aus zwei bis drei Zellen, die meist das ursprüngliche Aussehen besitzen. Manchmal fallen die Kerne durch ihre dunklere Färbung auf; bei der Untersuchung mit der Immersion zeigen sie dann eine etwas faltige Membran, sind in der Form verbogen und baben ihr Chromatin in gröberen Schollen zusammengedrangt. Wirkliche Degenerationsbilder findet man aber nicht. Dagegen kommen noch spärliche, aber wohl ausgebildete Kernteilungen vor.

Das umgebende Mesenchym enthält nur sebr wenige freie Wanderzellen und hat keine Faserkapsel ausgebildet; im Strang selbst fehlen die Lymphocyten vollständig. Auch die Gefässe der Umgebung liegen weiter auseinander.

Am dünnsten sind die Strunge unmittelbar oberhalb der Thymus. Letztere hat jetzt ungefuhr die Form eines Kegels mit nach oben gerichteter Spitze. Mit der unteren Hälfte liegen beide Organe dicht aneinander und hier platten sie sich gegenseitig $a b$; die trennende Bindegewebsmembran bleibt aber dauernd erhalten. Die obere Hälfte der Thymus ist gegen die untere in der Entwicklung weit zurück; dennoch sind die Bilder auch hier jetzt andere geworden als früher, so dass man sie einer genaueren Untersuchung unterwerfen muss. Die Lymphocyteneinwanderung ist hier lange nicht so ausgesprochen, wie in den weiter caudal gelegenen Partien; nur vereinzelt findet man fremde Zellen im Epithel. Dies hat aber wiederum den Vorteil, dass dadurch der Überblick über die Beziehungen zwischen Epithel und Mesenchym viel weniger gestört wird und einem manche Verhältnisse klar werden, deren Ergründung weiter unten nabezu unmöglich erscheint.

Wenn man sich die Thymus in diesem Stadium rein äusserlich makroskopisch vorstellt, so hat sich eigentlich wenig verändert. Die Grösse ist nahezu dieselbe geblieben und die Epithelknospen sind im oberen Teil immer ehel noch flach und breit obne tiefe weite Lücken dazwischen. Dagegen zeigen die Schnittbilder, dass sich das Mesenchym im Innern in ganz überraschender Weise ausgebreitet hat (Fig. 6); es bildet im Innern eine helle lockere Zone, gegen welche der feste geschlossene Rand des Epithels scharf absticht, so dass man bei flüchtiger Betrachtung den Eindruck 
gewinnt, als ob bereits Mark und Rinde ausgebildet seien. Dies kann natürlich nicht der Fall sein, da ja dann die Rolle beider Gewebsbestandteile vertauscht wäre. Die năchste Frage ist nuI, wie das Bindegewebe in das Innere des Organs hineinkommt. Der Schnitt zeigt, dass trotz der scheinbaren Flachheit der Knospen die Septen sehr tief einschneiden, und nur weil sie so schmal sind und ganz zwischen das Epithel eingezwängt, das Obertlächenbild von ihnen wenig beeintlusst wird; daher sie auch der Beobachtung so leicht entgehen kömen. Erst in der Tiefe, wo das Epithel lockerer ist, kann sich auch das Mesenchym besser ausbreiten und seine gewohnte Form anmehmen. So besteht also keine Schwierigkeit, das Mesenchym im Innern von dem der (Oberflüche abzuleiten, da der Zusammenhang direkt sichtbar ist, und damit făllt die Notwendigkeit, eine komplizierte Lmwandlungstheorie aufzustellen. Freilich beginnt in der 'Tiefe bereits die Auflösung des Epithels zum Reticulum; es zeigt aber doch noch ein viel festeres Gefüge als das Mesenchym, so dass es noch leicht von ihm zu unterscheiden ist (Fig. 13). Man muss also nur genügend junge Stadien untersuchen, denn später ist die Unterscheidung tatsächlich nicht mehr möglich.

Verfolgt man nun diese feinen Bindegewebssepten Schritt für Schritt, so stellt sich heraus, dass sie nicht einfach ins Epithel einschneidende Papillen (Zapfenform) bilden, als Unterlage für die eindringenden Gefässe, sondern sie umgeben die einzelnen Knospen ringsum wie dünne Hüute oder Schalen, die unter sich wieder zusạmmenhängen. Wenn es also gelünge, das Epithel der 'Thymus durch Maceration $\mathrm{zu}$ entfernen und das Mesenchym in seiner natürlichen Form stehen bleibend zu erhalten, so würde man schon ein ziemlich kompliziertes Gerüst bekommen in Form eines weiten Netzes, dessen einzelne Maschen aber nicht durch Stränge markiert welden, sondern durch fächenförmig ausgebreitete Lamellen ${ }^{1}$ ). Dabei bleibt aber zu bedenken, dass es nicht zu einer Abschnürung von einzelnen Epithelteilen kommt, sie bleiben alle miteinander verbunden. Hüufig sind diese Verbindungsbrücken allerdings sehr schmal und $z \mathbf{u}$ dünnen Flächen oder Strängen ausgezogen. An solchen Stellen verschwindet die scharfe Grenze

1) Dass diese Lamellen nicht kompakt sind, sondern ihrerseits auch wieder durchlöchert, ist selbstverständlich, da sie ja aus lockerem embryonalem, wenn auch zellreichem Mesenchym bestehen. 
des Epithels gegen das Bindegewebe zuerst, dadurch wird auch der Angriff des Mesenchyms wesentlich erleichtert (Fig. 27). Diese Verbindungsbrücken liegen jetzt auch nicht mehr so, dass sie alle radiär von einem zentralen Strang aus auszugehen scheinen, sonder'n sie sind ganz unregelmüssig, manchmal auch Seitenknospen (ich vermeide mit Absicht den Ausdruck Lilppchen) miteinander verbindend und sicherlich nicht alle primür vorhanden, sondern auch durch sekundäre Aneinanderlagerung und Verwachsung von Epithelknospen entstanden, so wie dies schon früher für die Entstehung des Lumens geschildert wurde. Auch jetzt findet man noch oder wiederum Hohlräume in der 'Thymus; während aber früher das Lumen klein und absolut leer war, ist es jetzt nicht selten gross und von Mesenchym erfüllt (Fig. 6). Eimmal fand ich sogar gerade bei einem 18 tägigen Fötus ein Getïss im Lumen, das nach oben in einer breiten Öffnung nach aussen ging, während es sich caudal in zwei dünnere Stränge auflöste, wovon der eine sich durch einen schmalen Spalt bis zur Oberflache durchzwängte und der andere nach wenigen Schnitten mit dem Lumen blind endigte.

Die Verschmelzung zweier Epithelknospen kann natürlich an solchen Stellen zustandekommen, wo sich wirklich Epithel mit Epithel berïhrt, sobald eine Mesenchymlamelle dazwischen liegt, geht dies nicht melr. Dadurch wird das Schnittbild im weiteren noch mehr kompliziert. Dem Wachstum des Organs nach aussen ist durch die Ausbildung einer Faserhülle bereits eine Grenze gesetzt; will sich jetzt das Epithel noch weiter ausdehnen, so kann dies nur durch vielfache Einfaltung geschelien.

Es ist nur sehr wichtig. zu erfahren, ob das Mesenchym nur infolge des Wachstums der epithelialen Anlage passiv mit in das Organ eingezogen wird, oder ob es am Wucherungsprozess aktiv mit teilnimmt. Anfänglich ist, wie dies auch $\mathrm{Maximow}$ annimmt, sicherlich nur das erstere der Fall; jetzt bietet aber das Mesenchym doch andere Bilder dar als früher. Es ist zellreicher geworden, was nur durch Vermehrung der eigenen Zellen erfolgt sein kann. Wenn man nun nach Karyokinesen sucht, so findet man solche am häufigsten in denjenigen Mesenchymabschnitten, die schon innerhalb der Thymusanlage liegen. Hier sind auch die freien Wanderzellen am zahlreichsten. Die Annahme einer aktiven Proliferation des Gewebes erscheint also 
wohl gerechtfertigt. Eines allerdings ist befremdlich, nämlich der Ümstand, dass man hier in dem cranialen Teil der Thymus so wenig Einwanderungsbilder und so wenig Lymphocyten im Epithel selbst findet (Fig. 13), während der Prozess in den mehr caudal gelegenen Partien bereits seinen Höhepunkt erreicht hat und die Lymphocyten daselbst so dicht gedrängt sind, dass die Klarheit der Bilder dadurch beeinträchtigt wird (Fig. 27). Ich kann mir nur folgende Erklälung dafür denken: Durch die einwandernden Lymphocyten wird die schon vorher eingeleitete Vakuolisierung des vielschichtigen Epithels weiter getrieben und dem lymphoiden Gewebe das Eindringen erleichtert. In diesen vordersten Partien nun, wo die Zellschichten nicht mehr so zahlreich sind, and das Mesenchym in die Zwischenräume rascher mit eingezogen wird, fällt die Notwendigkeit der Bearbeitung des Epithels durch Lymphocyten fort; es genügt die primüre Vakwolisierung und die endgültige Auflösung zum Reticulum kaun durch das Andringen des Mesenchyms selbst bewirkt werden. In del 'Tat verwischt sich auch der Unterschied in den Bildern aus verschiedenen Stellen der Thymus sehr bald. Bei einem nur 2 Tage älteren Fötus (20-21 'lage) sehen alle Schnitte gleich aus.

Es ist leicht verstandlich, dass man versucht ist, in der Phylogenie eine Erklärung zu suchen für das besondere Zusammenarbeiten von Epithel und Bindegewebe; doch sind die Anhaltspunkte, die sich hieraus gewinnen lassen, so gering an Zahl und Wert. dass "es sich kaum lohnt, sie anzuführen. Beliannt ist, dass bisher bei Amphioxus und den Myxinoiden eine Thymus oder ein Homologon derselben noch nicht gefunden wurde; ebenso sind die Frgebnisse für Petromyzonten trotz der Untersuchungen von Schaffer, Beard und Gaskell noch sehr zweifelhaft. Über die Entwicklung der Selachierthymus liegen mehrere neuere Arbeiten vor, von welchen die eine von Fritsche (1910) ausdrücklich eine frühzeitige Beteiligung mesodermaler Elemente in Abrede stellt; das Organ ist stets scharf durch eine bindegewebige Kapsel abgeschlossen, nur Gefässe wachsen von hier aus in das Gewebe ein. Sie bestätigt also in gewisser Hinsicht die Anschauung Beards (1903). Im folgenden Jahr erschien die Arbeit Hammars (1911), welche die kleinen Thymuszellen als mesodermale Elemente hinstellt, die in Form echter Lymphocyten in der epithelialen Anlage auftreten und sich hier weiter vermehren 
und wieder ein Jahr später erbrachte Maximow (1912) wie für die Süugetiere auch hier den noch fehlenden Beweis der Einwanderung. Hierbei blieb er aber stehen, ebenso wie ihm auch zur Erklärung der Genese der Amphibienthymus die frühzeitige Immigration mesenchymatöser Elemente und zwar als einzelne freigewordene Zellen nicht als zusammenhüngendes Gewebe genügt. Dieser Ansicht tritt Dustin $(1911,1913)$ sehr energisch entgegen in zwei neuen Arbeiten über die Thymus von Axolotl und zwei anuren Amphibien (Bufo vulgaris und Rana fusca), in welchen er seine bereits früher bei der Untersucliung der Reptilienthymus gewonnenen Anschauungen bestaitigt. Zwar hatte er sich nicht eigentlich mit der Entwicklungsgeschichte des Organs beschäftigt. Er lässt aber durchblicken, dass er auf Grund der periodischen Evolution und Involution des Organs gleiche Verhältnisse auch für die Genese annimmt; nach ihm sind Bindegewebszellen, vorwiegend solche, welche die Gefitsse begleiten, in hervorragender Weise an dem Aufban des Organs beteiligt, so dass er auf dieselben auch das Reticulum der fertigen Thymus zurïckführt. Allerdings geht aus seinen Arbeiten nicht hervor, wie er sich den primären Zusammenstoss zwischen Epithel und Bindegewebe denkt.

Diese wenigen Angaben, die alle den letzten Jahren entstammen, genügen, um zu zeigen, dass sich aus der Phylogenie rorerst wenigstens keine weitere Aufklarung geben lüsst und dass exakte vergleichend-anatomische Studien hier dringend nötig wären.

Fine Sonderstellung nehmen die Teleostier ein. Hier bleibt die Thymus mit ganz wenigen Ausnahmen dauernd mit dem Oberfächenepithel verbunden; dieser Umstand gibt uns allerdings keine Erklärung für die histogenetische Umwandlung, die trotzdem in gleicher Weise wie bei anderen Wirbeltieren erfolgen kann, aber er weist auf die Möglichkeit naher Beziehungen zur Tonsille hin, insbesondere, da nach der Beschreibung von Hammar (1909) die Anlage der Thymus bei Teleostiern sehr lange gsfässfrei bleibt. Das die Gefässe an das Parenchym heranführende Bindegewebe dringt ähnlich hohen Schleimhautpapillen gegen das Epithel vor; erst nach dem Einwachsen der Kapillaren in das Organ selbst erhalten diese auch eine bindegewebige Adventitia.

Nach dieser kurzen Abschweifung kehren wir zur Schilderung der Kaninchenthymus (18 tägiger Embryo) zurück. Das caudal 
verbreiterte Ende der Thymus zeigt schon eine sehr viel stärkere Lappung als der craniale oben beschriebene Teil (Textfig. S). Die einzelnen Epithelknospen liegen weiter auseinander gedrängt und erscheinen am freien Ende wie kolbig aufgetrieben. Hier ist eben noch die Möglichkeit einer weiteren Ausdehnung vorhanden und hier findet man auch die häufigsten Mitosen. Auch das

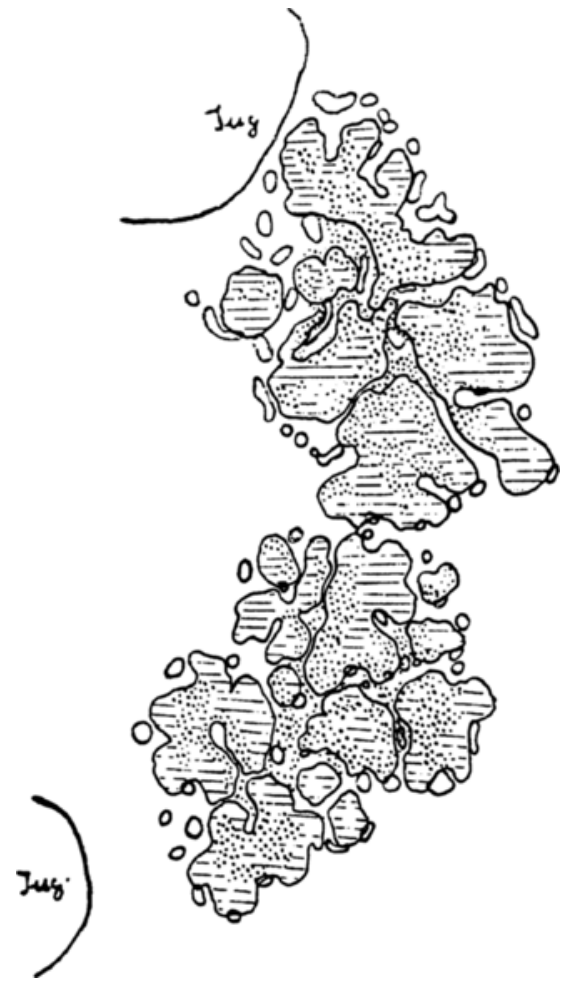

Fig. 8. Schnitt durch die Thymus eines 18 tägigen Kaninchenembryos. Gezeichnet mit dem $\mathrm{Ab}$ be schen Zeichenprisma unter Benutzung von Apochr. $16 \mathrm{~mm}$ und Comp Ocul. 4. Die schraffierten Stellen sind rein epithelial oder von ganz spürliclien Lymphocyten durchsetzt; die punktierten zeigen die Verteilung des dicht zelligen lymphoiden Gewebes in und ausserhalb der Thymusanlage, soweit es noch möglich war, eine Grenze festzustellen Gefässe rot.
Epithel erscheint hier noch fest geschlossen: Valiuolen sind selten und Lymphocyten nur spärlich eingewander't. Die feine Grenzschicht ist überall deutlicl. Im Zentrum der Anlage sind die Epithelstrïnge dagegen meist dümm und erscheinen stark aufgelockert. Von einem zentralen Parenchymstrang kann man eigentlich nicht melir reden: viel eher von einem zentralen Netz epithelialer Bälkchen, welche das dicht von Lymplıcyten erfüllte Mesenchym durchziehen. Die Grenzmembran gegen letzteres ist meist nicht mehr zu seben. Eine Rekonstruktion der alten epithelialen Anlage allein wäre jetzt nicht mehr möglich.

Die trennendell Mesenchymschichten sind im Gegensatz dazu breiter geworden, was allein schon für eine ak- 
tive Mitbeteiligung spricht, die durch zahlreiche Kernteilungsfiguren nur bestätigt wird. Man kann jetzt direkt das Freiwerden der Zellen beobachten. Zuerst färbt sich das Protoplasma unmittelbar um den Kern herum dunkler und intensiver blau bei Panchrom- und Azur IIEosinfärbung, was der beginnenden Verdichtung und der wachsenden Basophilie des Protoplasmas entspricht. Dabei tritt auch die wabige Struktur des Protoplasmas deutlicher hervor. Dann beginnt die Zelle ihre Fortsätze einzuziehen; es finden sich jetzt neben freien Lymphocyten sehr häufig solche, welche durch einen oder zwei teine Protoplasmafäden noch mit dem Muttergewebe in Verbindung stehen. Man kann diesen Vorgang allenthalben im Mesenchym beobachten, nicht nur in unmittelbarer Nahe des Epithels; doch scheinen die Wanderzellen eine besondere Vorliebe für die Nachbarschaft der Gefüsse zu besitzen; hier findet man sie so häufig und dicht gedrängt, dass sich einem der Gedanke an eine besondere Beziehung zur Gefüsswand aufdrüngt: doch konnte ich niemals ihr Entstehen dirckt aus derselben beobachten.

In den von lymphoidem Mesenchym erfüllten Zwischenräumen zwischen den Epithelknospen findet man jetzt allenthalben Gefässe. Sie haben mehr Raum zur Ausbreitung gewonnen und ziehen tief ins Innere des Organs hinein (T'extfig. 8; vgl. auch Fig. 27) und häufig auch zwischen den Epithelzapfen durch, wie dies in jüngeren Stadien auch schon, aber nur selten der Fall war. Sie sind relativ weit und gut gefüllt; ihre Wand besteht meist nur aus einer einfachen Lage platter Zellen, sie tragen also den Charakter von Kapillaren. Es beginnen aber jetzt einzelne Gefässquerschnitte durch die Ausbildung einer Muskelschicht um das Endothelrohr als Arterien kenntlich zu werden, doch handelt es sich dabei vorwiegend um kleinere Gefässe. $\mathrm{Zu}$ diesem Zeitpunkt beginnt recht eigentlich die Vaskularisierung der Thymus, auf welche ich weiter unten noch zurïckzukommen habe.

Es wurde schon vorher erwähnt, dass eine direkte $\mathrm{Ab}$ stammung der freien Wanderzellen aus den Gefässwandzellen nicht beobachtet werden konnte: da sich letztere aber in der Nähe der Gefässe mit Vorliebe ansammeln, nimmt es nicht Wunder, wenn man vielleicht nach einer Beziehung zum Gefässinhalt sucht. Doch lässt auch hier jeder sichere Anhaltspunkt im Stich. Die Gefüsse sind ja meist gut mit Blut gefüllt; dies gestattet aber böchstens einen Schluss auf einen regen Stoff- 
wechsel zu ziehen, der ebensogut mit der Entwicklung des Organs überhaupt zusammenhängen kann. Jedenfalls sind in den Gefiissen in und um die Thymusanlage weisse Blutzellen durchaus nicht in grösserer Menge vorhanden als in den übrigen embryonalen Gefassen, von der Leber überhaupt ganz abgesehen. Somit bleibt nur die einzige Annahme, die sich wenigstens durch das mikroskopische Bild begründen lässt, dass dem die Gefässe umgebenden Mesenchym eine grössere Fähigkeit, Wanderzellen zu liefern, innewohnt als dem übrigen, sofern man nicht zu ganz hypothetischen Erklärungen seine Zuflucht nehmen will. Nicht nur um die Gefasse, sondern auch noch in der Umgebung des Epithels sammeln sich die Lymphocyten in dichten Haufen an, was Maximow nach Art eines chemotaktischen Reizes von seiten des Epithels erklärt; doch sind die Verhaltnisse hier wiederum ganz eigenartige, so dass sie sich durch diese Hypothese, gegen die an und für sich nichts einzuwenden wäre, nie vollständig erklären lassen. Wie sich aus der Fig. 27 ergibt, ist die Anlockung durch das Epithel keine gleichmässige. Die am weitesten nach der Peripherie zu gelegenen epithelialen Knospen sind von durchwandernden Zellen fast völlig frei und in ihrer Lmgebung zeigt das Mesenchym die bekannte netzige Beschaffenheit mit relativ wenigen freien Zellen. Hier fehlt die chemotalktische Wirkung augenscheinlich ganz. Wesentlich anders sieht es im Innern des Organs aus. Hier liegt Zelle an Zelle, fast so, wie man es in der Rinde des fertigen Organs zu sehen gewohnt ist. Bei schwacher Vergrösserung scheint die Grenze zwischen Epithel und Mesenchym unschwer zu finden sein, da sich die Zellen des letzteren durch ihre dunklere Farbung scharf abheben. Anders bei stärkerer Vergrösserung (Fig. 16). Das Epithel erscheint hier zerklüftet und aufgelockert; überall zwischen seinen Zellen liegen hier die fremden eingewanderten Elemente, die ihren Weg weiter vorzudringen scheinen. Eine Grenzmembran gegen das Mesenchym ist nicht mehr festzustellen; ganz allmählich gehen die Retikulumzellen des einen in das des anderen Gewebes über. Dies ist natürlich nicht so aufzufassen, als ob Mesenchym und Epithel in direkter Verbindung miteinander stünden durch die Fortsätze ihrer Zellen; es findet nur eine innige Durchmengung beider Elemente statt, deren Übersicht durch die reichliche Einlagerung freier Zellen sehr erschwert, ja beinahe unmöglich gemacht wird. 
Das Epithel ist nur mehr kenntlich an dem etwas dichteren rötlichen Protoplasma seiner Zellen, auch liegen hier die Kerne noch nüher beieinander, als in dem Mesenchymnetz; es sind also die Vlaschen noch etwas kleiner und regelmässiger. An anderen Stellen legen sich die freigewordenen Wanderzellen wie ein dicht geschlossener Saum um den noch fest geschlossenen dünnen epithelialen Strang herum, der ihrem Eindringen offenbar Widerstand entgegensetzt. Nicht selten werden dabei ihre Zelleiber zusammengedrückt, so dass auf dem hellen Epithel eine Schicht dunklerer kubischer Zellen aufzusitzen scheint. Hüufiger jedoch sind die Ansammlungen ganz regellos und bestehen meist aus mehreren Schichten. Nach aussen in das Mesenchym geht das lymphoide Gewebe ohne scharfe Grenze über. In diesem Stadium wird der Vergleich mit der Tonsille und der Bursa Fabricii noch näher gerückt. Wieder legt sich lymphocyten lieferndes Gewebe um epitheliale Knospen herum, nur dass hier die Grenzen mehr verwischt sind. Die alte Auffassung v. Ebners, der nur dem Mark der Thymusläppchen epitheliale Abstammung zuerkennt, scheint gerechtfertigt. Wenn man aber die einzelnen Elemente durchmustert, so fallen zwischen den sehr polymorphen Zellen bindegewebiger Herkunft, die nicht selten noch syncrtial zusammenhängen, grosse sternförmige Zellen auf, die ganz den Habitus von Epithelzellen tragen und bei günstiger Lage und Schnittrichtung sich auch bis zum Epithel verfolgen lassen. Sie liefern uns den Beweis dafür, dass das mesenchymatöse Gewebe die durch das Epithel gesetzte Grenze bereits überschritten hat. Die Auflösung des Epithels geht nun sehr rasch weiter, und ist jetzt wohl in erster Linie mechanisch bedingt durch Vermehrung des lymphoiden Gewebes, wie dies auch $\mathrm{Hammar}$ und $\mathrm{Maximow}$ annehmen. Für eine alstive Zerstörung fehlen alle Anhaltspunkte. Es sind keine Degenerationszeichen vorhanden, man findet wohl kleine Epithelkerne, sie sind aber immer gut erhalten und verdanken ihre Kleinheit wahrscheinlich der Schnittrichtung. Die früher erwähnten dunklen Epithelzellen, die $\mathrm{Maximow}$ als "geschrumpfte" bezeichnet, kommen jetzt überhaupt nicht mehr vor. Dagegen findet man manchmal zwischen den Zellen grössere oder kleinere, meist runde strukturlose Körner, die sich stark mit allen Chromatinstoffen färben. Ich halte sie für die von Flemming beschriebenen tingiblen Körperchen, die auch in den 
Lymphdrüsen vorkommen und von vielen Autoren in der Thymus allex Wirbeltiere angetroffen worden sind. Jetzt sind sie noch selten, spatter werden sie viel haufiger und oft auch grösser.

Auf einen Punkt haben wir noch einzugehen, ehe wir die weitere Ausbildung der lymphoiden Elemente in älteren Stadien verfolgen. Es bleiben nămlich einzelne Epithelbezirke merkwürdig kompakt und frei von Lymphocyten und fallen namentlich in den zentralen lymphocytenreichen Partien als helle Stellen auf (Fig. 20). Die Differenzierung in Mark und Rinde scheint hier eingeleitet zu werden. Maximow schildert die Entstehung des Markes als ror allem im zentral gelegenen Hauptstamm auftretende „kleine unscharf begrenzte Inseln von grossen, meistens syncytienartig verbundenen Epithelzellen", welche durch Hypertrophie eine andere Beschaffenheit annehmen, als die ebenfalls spärlich mit Lymphocyten durchsetzte äussere Peripherie des Läppchens. Dies sind die altesten Stadien, die seinen Untersuchungen zugrunde liegen und er hält hiermit die Histiogenese der 'Thymus für im wesentlichen beendet. Auf die genauere Differenzierung von Mark und Rinde werde ich in einem eigenen Abschnitt zurückkommen, nur soviel möchte ich hier schon bemerken, dass weder von einer Hypertroplie einzelner Epithelzellen hier schon die Rede sein kann, noch von einer Hyperplasie bestimmter Bezirke. Witosen sind eher an der Peripherie des Organs hüufiger zu finden, als im zentralen Teil, und die verschiedene Grösse der Zellen auf dem Schnitt beruht vor allem auf der verschiedenen Richtung, in welcher sie getroffen sind.

Was das Verhalten der eingedrungenen Wanderzellen betrifft, so kann ich die Angabe von Maximow bestätigen, dass sie sich alle zunïchst in typische sogenannte grosse Lymphocyten verwandelı. Unter ihnen fallt eine besondere Form auf, von welcher Maximow nur angibt, dass sie mehr in den peripher gelegenen Teilen der Läppchen zu finden seien. Da sie im Gegensatz zu den gewöhnlichen grossen Lymphocyten (Fig. 15 bc) einige Besonderheiten darbieten, habe ich drei von ibnen in Fig. $15 \mathrm{ds}$ gezeichnet. Sie sind sehr auffallend; der Kern ist meist hell mit kräftiger Membran, das gesamte Chromatin zu mehreren grossen Kilumpen zusammengeballt. Der Protoplasmaleil ist gross, immer scharf konturiert, vorwiegend basophil (blau bei Azur- und Panchromfarbung; mehr violett bei Färbung nach Dominici, 
die auch der Zeichnung zugrunde lag), manchmal ganz locker wabig ( $\mathrm{de}$ ), bald mehr homogen und sehr dunkel (c), bald mit mehr oder weniger grossen Vakuolen durchsetzt, zwischen welchen sich das Protoplasma zu dunklen Strüngen verdichtet. Die fast immer vorhandenen zahlreichen Fortsätze lassen auf amöboide Bewegung schliessen. $\mathrm{Zu}$ den gewöhnlichen grossen Thymuslymphocyten finden sich alle Übergänge, so dass die Annahme ihrer Abstammung aus diesen Zellen gerechtfertigt erscheint. Es erübrigt nur, ihr Verhalten im weiteren Verlauf der Entwicklung zu verfolgen, um über ihr Auftreten und ihre Bedeutung Aufschluss zu gewinnen. Im Mesenchym ausserhalb der 'Thymusanlage habe ich nur wenige derartige Zellen finden können.

Das nächste Stadium, das von einem 19 tägigen $28 \mathrm{~mm}$ langen Embryo stammt, bietet noch nicht viel Neues. Nach der Fixierung liess sich die Thymus herauspräparieren. Sie reicht noch ziemlich weit in den Hals herauf und ist an ihrem Kiopfteil in einen spitzen Zipfel ausgezogen. Makroskopisch fanden sich keine Reste eines Verbindungsstranges zur Parathyreoidea mehr; es ist aber nicht ausgeschlossen, dass mikroskopisch noch solche nachzuweisen gewesen wären.

Der Kopfteil der 'Thymus hat jetzt auch einen viel stärker ausgesprochenen lappigen Bau als früher. Er besitzt noch immer Lichtungen, die sich stets nach aussen verfolgen lassen, manchmal klein, schmal und leer, manchmal zum Teil von Mesenchym und selbst von Gefässen erfüllt sind. Bindegewebsfürbungen (Mallory: Pasini) zeigen rings um das Organ herum die Ausbildung einer Faserkapsel, die aber sondelbarerweise nur melr um den Lopfteil deutlich ausgesprochen ist, während sie sich weiter caudal um den Körper mehr und mehr verliert. Das Mesenchym um den Kopfteil ${ }^{1}$ ) ist relativ arm an freien und ruhenden Wanderzellen. Doch sind ziemlich zahlreiche Mitosen ein Beweis für eine rege Tätigkeit desselben. An der Obertäche der Zellen und ihrer Ausläufer sind bereits feine kollagene Fäserchen ausgebildet, die sich um die Gefässe herum zu dichteren Hüllen verflechten. Merkwürdig ist, dass die Grenzmembran des Epithels gegen das Bindegewebe $\mathrm{zu}$, wo sie noch erhalten ist, sich bedeutend verstärkt hat und denselben Fürbcharakter wie die Fibrillen zeigt. Sie fehlt nur an den zentralen Partien des Epithels (Fig. 18).

1) Gemeint ist der cranialste Abschnitt der bleibenden Thymus. 
Gerade mit ihrer Hilfe und der der feinen Fibrillen lässt sich das Mesenchym sebr weit in die Thymusanlage hinein verfolgen und es ist verständlich, dass die Grenzen zwischen beiden Geweben jetzt noch mehr verwischt sein müssen als vorher. Die eingewanderten freien Zellen sind im Kopfteil nicht allzu zahlreich. Doch findet man gerade zwischen der Zone der dichter gedrängten Lymphocyten und del von ihnen fast freien Randzone, die Naximow als eigene Schicht betrachtet haben will, jene eigentümlichen - grossen Zellen, welche selbst bei der Färbung nach Pasini, die andere Lymphocyten nicht differenziert, durch ihre leuchtend roten grossen Chromatinschollen auffallen. Der Körper der 'Thymus unterscheidet sich vom Kopfteil ${ }^{1}$ ) jetzt nur mehr durch die noch stărkere Beteiligung des lymphoiden Mesenchyms, das sich in Form dicker Hüllen um die zentralen Epithelstrïnge herumlegt und in das aufgelöste Epithel eintritt (vgl. Textfig. 8). Die Grenze des lymphoiden Gewebes gegen das Epithel zu ist hier vollständig verwischt und letzteres zugunsten des ersteren fast völlig verdrängt, nur grosse sternförmige Zellen, die noch den Zusammenhang gewahrt haben, oder Gruppen von wenigen Zellen, die noch in epithelialem Verband zusammenliegen und an eventuell in ihnen vorkommenden Mitosen kenntlich sind, erinnern noch an das alte Gefüge. Dagegen beginnt das lymphoide Gewebe sich jetzt gegen das übrige lymphocytenärmere Mesenchym abzuschliessen, indem die oberflachlichsten seiner Zellen sich abplatten und als spindelförmige Elemente die Bindegewebshülle des Läppchens auszuarbeiten beginnen. Ebenso legen sich an der Peripherie der Epithelknospen einzelne Mesenchymzellen der Oberflache flach an, so dass eine kontinuierlich das Lappchen umfassende Kapsel entsteht. Nur ganz in der Tiefe der Septen bleibt diese Kapsel offen und der Verkehr des Mesenchyms mit dem Organparenchym ungestört (Fig. 26). Die Septen selbst werden dadurch schmäler, da ein Teil ibres Gewebes jetzt direkt dem Organ angehört. Sie dienen jetzt vorwiegend den grösseren Gefässen als Bahn ins Innere der Thymus. Dass mit der Ausarbeitung einer Kapsel die Einwanderungsbilder aufhören, ist verständlich; dennoch findet man gerade in der Umgebung der Thymus mehr freie Wanderzellen als sonst im embryonalen Mesenchym. Ihre Vorliebe für die Nähe der Gefässe ist noch ebenso ausgeprãgt wie früher und blëibt es auch dauernd. 
Von dem Verhalten der Lymphocyten im Innern des Organs ist bisher noch kaum die Rede gewesen. Während sie bei Beginn ihrer Einwanderung sich alle nahezu gleich verhielten, macht sich.jetzt die Umwandlung zu den typischen kleinen Thymuslymphocyten bemerkbar. Zunächst färbt sich der Protoplasmaleib dunkler und wird schmäler, die lockere vakuoläre Struktur verdichtet sich; erst allmählich wird das Protoplasma wieder heller, bis es nur mehr als feiner Saum den Kern umgibt. Auf welche Weise die Veründerung zustande kommt, kann ich nicht sicher angeben; Abschnürungen protoplasmatischer Zellbestandteile, wie sie von Weidenreich als charakteristisch für die Entstehung von kleinen Lymphocyten aus grossen angegeben werden, konnte ich jedoch nirgends wahrnehmen, gleichzeitig velăndert sich auch der Kern. Zuerst erscheint die Membran dicker, dann beginnt das Chromatin sich längs derselben in Körnchen aufzureihen, während der Chromatinrest sich in mehreren groben Schollen im Innern zusammenballt. Auch der Kernsaft färbt sich dunkler. Typische Radspeichentiguren, wie sie so oft beschrieben werden, kounte ich manchmal, aber nicht immer deutlich sehen. Es gelingt leicht, alle Übergänge von den grossen Lymphocyten zu den kleinen Thymuszellen zu beobachten.

Dass die Einwanderung ihr Ende erreicht hat, geht schon daraus hervor, dass man nur mehr selten pseudopodienartige Fortsatze an den Zellen wahrnimmt. Die durch die fortgesetzte Vermehrung notwendigerweise bedingte Verschiebung ist wahrscheinlich mehr passiver Art. Die Lymphocyten haben sich in dichter Schicht (Rinde) um ein Zentrum gelagert, das mehr oder weniger frei von ihnen ist und dessen langgestreckte Zellen sich nach Art eines Plattenepithels aneinanderlegen. Jenseits der lymphoiden oder besser lympho-epithelialen Schicht (Jolly), da wir es ja nicht mit rein lymphoidem Gewebe zu tun haben, sondern mit von lymphoidem Gewebe durchsetztem Epithel, bleibt abermals eine geschlossene Epithelschicht, vorerst frei von Lymphocyten und zwar liegt sie der Rinde nicht gleichmassig aussen an, sondern ist dem freien Ende des Läppchens kappenartig aufgesetzt. Hier geht offenbar die Vermehrung sehr rege vor sich, und man findet viele Mitosen, und diese ausserste Schicht ist es auch, welche nach $\mathrm{Rudbe} \mathrm{r} g$ bei der accidentellen Involution am frühesten von den Lymphocyten verlassen wird und von welcher 
ans, wenn die Notwendigkeit und die Möglichkeit dazu gegeben sind, die Regeneration des Organs elfolgt. Hier stehen aber die Zellen radiäl zur Achse des Läppchens, nicht wie im Zentrum parallel.

Bei einem Embryo von 20 'agen besitzt die Thymus bereits einen ganz ausgesprochenen Läppchenbau. Jedes einzelne Läppchen steht noch im Zusammenhang mit einem zentralen Parenchymstrang, ist aber gegen das umgebende Gewebe jetzt scharf abgesetzt. Die Zellen des Mesenchyms haben schon reichlich Fibrillen produziert; sie sind zum Teil in freie spindelige Elemente umgewandelt, die den Fasern anliegen und den echten Bindegewebszellen immer ähnlicher werden. Damit erlischt auch die reichlichere Produktion von Lymphocyten. Von der alten, das ganze Organ zusammenhaltenden Faserkapsel ist kaum mehr etwas zu sehen.

Jedes einzelne Läppchen ist aber wieder durch Bindegewebszüge in einzelne Unterabteilungen geteilt, die vom Rande her schneidend, etwa bis zur Grenze von Mark und Rinde ins Innere eindringen. Es sind dies lieine Neubildungen, sondern ein Teil der alten gefässführenden Mesenchympapillen, welche durch die Verbreiterung der epithelialen linospen zusammengedrückt und mit in den Bereich des Lappphens einbezogen worden sind. Die Zellen sind hier gross und saftig geblieben und jedenfalls einer weiteren Vermehrung fühig, was auch durch Kernteilungsfiguren bestätigt wird. Auch sind sie bei der Faserproduktion beteiligt, denn mit ihnen verlaufen feine blaue Fibrillenzüge (Fürbung nach Pasini) ins Innere, die sich, nach beiden Seiten hin auflösend, auf eine ganz kurze Strecke verfolgen lassen (Fig. 18).

Ebenso lässt sich das Eindringen von blauen Fasern in der Tiefe der breiten bindegewebigen Septen beobachten, wo die Grenze gegen den zentralen Parenchymstrang noch ganz verwischt ist und es auch dauernd in mehr oder weniger hohem Grade bleibt. An solchen Stellen bleibt auch das Mesenchym indifferent und gibt die Lieferung freier Zellen niemals ganz auf.

Die aussere Form des Organs ist.num vollendet. Das einzige, was sich bis zur Geburt des Tieres noch ändert, ist, dass die Septen schmaler und zellärmer werden, wodurch der lappige Bau des Organs noch deutlicher wird, und dass die einzelnen Läppchen an Grösse und Ausdehnung zurehmen; neue werden jetzt nicht mehr gebildet. 
Im Innern der Läppchen ist jedoch die Ausgestaltung noch lange nicht beendigt. Bei einem Embryo von 20 'Tagen $(30 \mathrm{~mm}$ Lünge) ist der am Rande gelegene Epithelsaum immer noch kompakt und frei von Lymphocyten, werm auch schon schmäler geworden, als im vorhergehenden Stadium. Da eine Einwanderung: von ausseu her nicht mehr stattfindet, so muss man annehmen, dass die Lymphocyten in zentrifugaler Richtung vordringen. Nach weiteren $2 \pm$ Stunden umfasst der freeie Rand nur mehr $1-2$ Zelllagen, bis anch diese vollständig von Lymphocyten infiltriert werden, was aber nicht gleichmaissig erfolgt, sondern Heckweise, so dass noch lange kleine kompakte Epithelinseln an den Rändern des Läppchens zu finden sind. Eist 1-2 Tage vor der Geburt verschwinden auch diese.

Die Umwandlung der grossen basophilen Lymphocyten zu den typischen kleinen Thymuszellen findet hauptsichlich erst. dann statt, wenu die Durchdringung der epithelialen Anlage mit lymphoidem Gewebe im wesentlichen beendigt ist, also vom 19. bis zum 25. Tage des Fötallebens ungeführ.

Je alter der Embryo, desto reichlicher sind sie vorhanden. Mit ihrer Vetamorphose verlieren sie jedoch nicht die Fähigkeit, sich selbstindig weiter zu vermehren. Man findet Karyokinesen sowohl in den grossen als in den kleinen Lymphocyten und in den Überongsformen zwischen beiden; auch hierin liegt ein Unterschied gegen die Tonsille, wo der Nachwuchs der Lymphocyten nur von den Keimzentren der Follikel aus erfolgt. Es scheint sogar, als würden sich die kleinen Zellen reger vermehren als die übrigen; doch ist das nicht zu verwundern, da sie gegen Ende der Embryonalzeit in der fertigen Thymus weitaus das grösste Kontingent aller Thymuszellen stellen. Meist liegen sie in Gruppen oder Ketten beisammen, ebenso wie auch die grossen Lymphocyten selten einzeln $z u$ finden sind.

Die früher beschriebenen ganz grossen basophilen Zellen sind noch immer vorhanden, doch treten sie hinter den kleinen Elementen sehr an Zahl zurïck. Meist liegen sie mehr an der Peripherie des Läppchens, nicht selten auch an der Grenze zwischen Rinde und Mark (Fig. 26) und kommen auch im interlobulären Bindegewebe jetzt häufiger vor wie früher. Ihr Bau ist nicht verändert; manchmal zeigt sich der Kern nierenförmig eingebuchtet und liegt dann exzentrisch. Das Cytoplasma fullt 
ausser durch die ausgesprochene Basophilie durch die starke Vakuolisierung auf. Der Zelleib der kleinen Thymuszellen ist meist nur als schmaler heller Ring um den Kern wahrzunehmen und lasst Struktureigentümlichkeiten nur selten erkennen.

Mit der Ausbildung einer kollagenen Faserkapsel um das Läppchen ist eine weitere Beteiligung des aussen liegenden Mesenchyms selbstverständlich ausgeschlossen und hiermit wäre das vorliegende Kapitel eigentlich beendet, wenn nicht gerade der gegenwärtige Stand des Thymusproblems es so besonders interessant erscheinen liesse, sich auch mit dem ins Thymusparenchym einbezogener Mesenchym noch weiter zu beschäftigen. Hieraus ergibt sich vor allem die wichtige Frage, ob ein Teil der eingeschlossenen mesodermalen Zellen dauernd als syncytiales Reticulum erhalten bleibt, also in vollständig undifferenziertem Zustand; dann wäre eine fortgesetzte und unter gewissen Bedingungen gesteigerte Lieferung von Lymphzellen leicht verständlich; auch die Erklälung der Ausbildung eines weit verzweigten Kapillarnetzes in den Rindenteilen würde nicht mehr auf Schwierigkeiten stossen. Wird dagegen das primäre Mesenchymreticulum vollstïndig in seine einzelnen Elemente aufgelöst und diese alle in kleine Thymuszellen verwandelt, denen die Fahigkeit zu selbständiger Vermehrung erhalten bleibt, anders als wir es in den Keimzentren der Lymphfollikel zu sehen gewohnt sind, so müssten die Thymuslymphocyten als eine besondere funktionelle Abart der Zellen des gesamten lymphatischen Apparates betrachtet werden, in welchem Sinne auclı die Untersuchungsergebnisse von Bang (1904) verwertet werden könnten; $\mathrm{Hammar}$ hat wiederholt darauf hingewiesen, dass derartige chemische Verschiedenheiten, wie sie von Bang für die Lymphdrüsen und die Thymus festgestellt wurden, nicht überschatzt werden dürfen und zum mindesten nicht einen histogenetischen Unterschied zweier Zellkategorien zu bedeuten brauchen.

Sieht man sich in der Literatur nach dem Vorkommen eines bindegewebigen Thymusreticulums um, so ist man erstaunt, hierüber sehr wenig Angaben zu finden, abgeseben von jenen Autoren, welche die ganze Thymusrinde als mesodermales Produkt auffassen und hier nicht in Betracht kommen. Entweder wird das Reticulum zwar als lymphoides, aber aus dem Epithel hervorgegangenes betrachtet (Marer 1902, Nussbaum und 
Prymack 1901, 0. Schultze 1897 und Retterer 1913; letzterer vertritt epitheliale Abstammung für sämtliche Lymphocyten des Körpers, indem er ein besonderes aus dem Epithel sich herausdifferenzierendes "angiotheliales Gewebe" annimmt, oder das Reticulum wird als dauernd epithelial bezeichnet (Prenant 1893, 1894, Bell 1906, Fritsche 1910, Mietens 1909, Hammar und Maximow). Die meisten der letztgenannten Autoren lassen wenigstens mit den Gefässen und Septen lockeres Bindegewebe ins Innere des Organs gelangen, schreiben ilm aber für den Bau des Thymusreticulums keine oder nur untergeordnete Bedeutung zu. Mietens erkennt im Endbezirk der Septen die scharfe Grenze zwischen epithelialem und bindegewebigem Reticulum aus der Stellung der Kerne; wie unmöglich das ist, kann man aus meinen Fig. 13 und 17 leicht ersehen. Ausserdem beschreibt er neben dem zelligen Reticulum noch ein Faserreticulum; allein aus seiner Arbeit geht nicht klar hervor, wie eigentlich die Beziehungen beider zueinander aufzufassen sind. Die Fasern sind bindegewebiger Herkunft, dringen von der Kapsel her mit den Gefüssen ein und sollen später in das zellige Reticulum einwachsen; dabei soll sich ein Teil der den Fasern anliegenden Reticulumzellen „bindegewebig“ verïndern und als „Hache platte Kerne ${ }^{*}$ den liasern anliegen. Hier ist wenigstens die Andeutung einer innigeren Durchmischung von epithelialen und mesodermalen Elementen gegeben, wenn sie auch vorerst nur unklar zum Ausdruck kommt. Schaffer und Rabl (1908, 1909) beschreiben in der Thymus von Maulwürfen ebenfalls neben dem zelligen noch ein bindegewebiges Reticulum, welches nicht ausschliesslich von den Gefäßscheiden und Kapillarhülsen bestritten wird, sondern aus selbständigen Fasern und Bündelchen besteht. Es kann sich im Mark und der involvierten Thymus dem Reticulum eines Lymphknotens năhern.

Ganz neuerdings hat Salkind (1912) zwei auch morphologisch verschiedene Arten von Reticulum in der Thymus beschrieben: nämlich ein aus schwach basophilen, locker vakuolär gebauten Protoplasmazügen bestehendes unregelmüssiges Netz und ausserdem ein in mehr regelmässigen Maschen angeordnetes, stärker acidophiles, durch kollagene oder elastische Fasern besonders charakterisiertes Bindegewebsreticulum. Ich habe nun die Methode von Salkind nachgeprüft, sowohl genau nach seinen 
eigenen Angaben, als auch, indem ich die Zusammensetzung der Farblösungen etwas moditizierte; die Bilder, welche ich erhielt, waren durchaus nicht klares als die mit den bisher gebräuchlichen Methoden; zwei als gesonderte erkennbare Netze sind jedenfalls nicht zu sehen, ebenso fehlen elastische Fasern, die ich auch nach der Methode von Weigert in der Thymus nicht darstellen konnte. Sobald eben epitheliales und lymphoides Reticulum innig miteinander vermischt sind, geben selbst Grösse oder Struktur der Kerne, Ausdehnung und Bau des Protoplasmaleibes kein sicheres Kriterium mehr für die Zugehörigkeit ab. Dass Zupfpräparate und Nacerationsmethoden hier nicht zum Ziele fülıren können, ist klar. In diesem Sinne sind die Ausführungen Watneys (1882) hinfällig, auch die Kultur von Thymusgeweben, wie sie Pappenheimer (1913) neuerdings vornahm, kann keinen Aufschluss geben, da es sich ja nicht um das Vorhandensein einzelner bindegewebiger Elemente handelt, was niemand bezweifelt, sondern um den syncytialen Zellverband, dem seine wichtigste Funlition, die Lieferung freier Lymphocyten, erhalten bleibt.

Wit Hilfe verschiedener Fasermethoden hoffte ich, beide Gewebsarten auseinander halten zu können. Mollier (1913) hat gezeigt, dass in der Bursa Fabricii die Fasern des epithelialen Reticulums sich nach $\mathrm{Pasini}$ rot fürben und in direktem $\mathrm{Zu}$ sammenhang stehen mit den blauen Fasern des um das Epithel gelegenen lymphoiden Reticulums. Es müssten also in der 'Thymus l'ote und blaue Fasern nebeneinander vorhanden sein; dies ist bis zu einem gewissen Grade auch der Fall; nur folgen bei neugeborenen oder sehr jungen Tieren die blauen, also bindegewebigen Fasern vorliegend dem Verlauf der Gefässe, während die immer nur sehr zarten roten Fibrillen fast ausschliesslich in der Umgebung der Hassalschen Körperchen zu finden sind. Gerade hier aber also im Epithel kommen auch blaue Fasern vor (vgl. Fig. 12). Über die sehr feinen fädigen Strukturen im Protoplasma ganz junger Thymen lässt sich mit Sicherheit nichts behaupten: dagegen habe ich in der Thymus von äleren ( 7 Monate) Kaninchen, welche bereits die ersten Anfünge der Involution zeigten, bei der Färbung nach Pasini deutlich zweierlei verschiedene Fasern wahrgenommen (Fig. 11a). Die Beobachtung mit monochromatischem grünem Licht lässt die roten Fasern scharf schwarz hervortreten, ebenso wie die rotgefärbten Kerne, während die 
feineren blauen Fasern in dem rötlich violetten Protoplasma verschwimmen (Fig. 11b), die bei gleicher Einstellung gezeichnet wurde, nur unter Verwendung der Quecksilber-Quarzlampe von $Z$ eiss mit dem von $K o ̈ h l e r$ berechneten grünen Filter, anstatt der Zeissschen Mikroskopierlampe. Untersucht man nun mit dem roten Filter, so wird das Bild ganz unscharf, da alle roten Strukturen fast ungefärbt erscheinen, nur die blauen Fäserchen, die übrigens viel feiner sind als die roten und meist sehr wellig verlaufen, werden deutlich, auch die Gefässe fallen jetzt durch die dicke schwarze Umränderung auf. Somit scheint der Beweis für ein zweiwertiges Reticulum in der Thymus erbracht zu sein, wenn nicht durch die Resultate anderer Reaktionen dieses schöne Ergebnis wieder in Frage gestellt würde; man erbalt nümlich nach Mallory auch ein feines fibrillüres Reticulum sowohl im Mark als auch in der Rinde; die gröberen Fasern sind deutlich blau, aber in ihrer Verteilung auf den Verlauf der Gefüsse beschränkt, während die feineren Fibrillen, die sich mit dem zelligen Reticulum verspannen, mehr eine rotviolette Färbung aufweisen. Dies spricht wohl für einen Unterschied gegenüber den fertigen kollagenen Fibrillen des Bindegewebes, wogegen an und für sich nichts einzuwenden wäre, da man sie als präkollagene auffassen könnte; aber die violetten Fibrillen unter sich ergeben ein einheitliches Netz, indem sich weder mit monochromatischem, noch mit weissem Licht Unterschiede herausfinden lassen.

Stehen sie nun zum Epithel oder zum Reticulum in engerer genetischer Beziehung? Weder für das eine, noch für das andere lassen sich sichere Bewreise erbringen, wenn man nicht ihr stärkeres Hervortreten im Mark als Stütze für ihre Herkunft aus Epithelzellen anführen will. Doch liesse sich dagegen wieder einwenden, dass sie in der Rinde durch die zahlreichen kleinen Rundzellen auseinander gedrängt und verdeckt werden.

Kollagene oder ihnen sehr nahe verwandte Fasern lassen sich auch nach anderen Methoden (Hornowsky, Bielschowsky, mit Indulin etc.) in den $\mathrm{Hassalschen} \mathrm{Körperchen} \mathrm{nachweisen;}$ dagegen lässt die Silberimprăgnation bei den Fibrillen des Rindenreticulums im Stich, mit Ausnahme der Fibrillen um die Gefässe.

$\mathrm{Hammar}$ selbst fasst in seinem Referate die selbständig innerhalb des Parenchyms gefundenen Bindegewebszüge nur als Scheinbilder auf, nämlich als ganz obertlächlich getroffenes peri- 
vasculäres Bindegewebe, da man an reinen Gefässquerschnitten ein derartiges Eindringen von Bindegewebszügen in das Parenchym vermisst. Allerdings sind auch die feinsten Kapillaren bei geeigneter Färbung von einer scharf begrenzten Faserhaut umgeben, wie sie auch $\mathrm{Stöhr}$ schon beschlieben hat, der sonst der 'Thymus jede bindegewebige Komponente abspricht. Dies ist aber kein Beweis dagegen, dass nicht doch von den Gefälischeiden aus noch ein weitverspanntes zelliges Reticulum nicht epithelialer Herkunft das Parenchym durchzieht. Wenn man nämlich das lymphoidzellige Reticulum junger Iymphdrüsen zum Vergleiche heranzieht, so gelingt es auch hier, ausser in der Kapsel und den gröberen Septen kaum deutliche kollagene Fasern darzustellen; nur schwer zu definierende selten glatt fortlaufende Fadenstrukturen, die immer intraprotoplasmatisch liegen, sind zu sehen.

Andere Autoren (Prenant 1894, Jonson 1909, Markus 1907, Hammar 1909, Maximow) haben den Formen der Mitosen in der Thymus ihre besondere Aufmerksamkeit zugewandt. Prenant findet die Mitosen in den epithelialen Zellen der jungen Thymus charakterisiert durch deutliche haufig gewundene Chromosomen, Spindel, Sphäre, Polkörperchen und Zentralkörperchen, während er im späteren Stadium nur mehr den "Lymphoblasten" Vermehrung zuerkennt und in ihnen (wie Hansemann in den Mitosen der Lymphdrüsen Lymphoblasten) nur "des caractères négatifs" findet, nämlich die Abwesenheit aller oben zitierten Merkmale. Die letztere Form hat Markus zwar auch gesehen, er erklart sie aber als zustande gekommen durch eine Störung der Kernplasmarelation, wodurch die Zelle in einen Depressionszustand versetzt wird, der eine pathologische Form der Karyokinese zur Folge hat. Hammar und Jonson beschreiben zwei Arten von Mitosen, charakterisiert durch die Lange und Dicke der Chromosomen; aber während sie beide das Vorkommen von Zwischenformen nicht unbedingt in Abrede stellen, unterscheidet Maximow von dem ersten Auftreten der Lymphocyten an zwei deutlich getrennte Formen der Mitose, von welchen die grössere schönere den Epithelzellen, die kleinere „hänfig verklumpte " den Lymphocyten angehört. Dieser Ansicht kann ich mich nicht ohne weiteres anschliessen. In den kleinen Thymuszellen sind die Chromosomen allerdings "verklumpt“, ebenso wie in den kleinen Lymphocyten der Lymphdrüsen. Was jedoch die grossen Lympho- 
cyten der Thymus anbetrifft, so zeigen sie dieselbe scbön ausgebildete Kernteilungsfigur, wie ich sie früher schon für die Mesenchymzellen und die grossen freien Wanderzellen des jungen Bindegewebes beschrieben habe (vgl. Fig. 1, 2 b und 6). Spindel und Polkörperchen sind deutlich zu sehen, und wenn die sich teilende Zelle nicht durch ihr basophiles Protoplasma als lymphoides Element charakterisiert ist, kann man aus dem Bild der Karyokinese allein nicht auf die Herkunft der Zelle schliessen. Dies ist sehr haufig der Fall, da die Basophilie des l'rotoplasmas während der Teilung meist weniger auffallig ist und andererseits die Epithelzelle sich abrundet und scharf konturiert erscheint.

Trotz alledem komme ich am Ende dieses Abschnitts auf Grund der genetischen Beobachtungen zu dem Schluss, dass die Verteilung des Iymphoiden Gewebes in der Thymus eine viel kompliziertere ist, als man bisher angenommen hat; nicht nur frei zwischen den Maschen des epithelialen Reticulums liegende Zellen mesodermaler Abstammung werden zu den Mutterzellen der kleinen Lymphocyten, sondern in den Rindenpartien wenigstens bleibt mesenchymatöses Reticulum als soiches erhalten und es ist wohl nicht zu viel vermutet, wenn man demselben die Lieferung von Lymphocyten als dauernde Funktion zuerkennt. Dafür sprechen ausser dem weitverzweigten Kapillarnetz in der Rinde auch das ständige Vorhandensein von grossen Lymphocyten von ähnlichem Habitus wie die Keimzentrumszellen der Lymphdrüsen. Selbst wenn man mit Maximow zugibt, dass die grossen Lymphocyten unter Umständen wieder aus den kleinen entstehen können, so ist es doch eigentlich naheliegender, die kleinen runden Thymuszellen als die höherdifferenzierten Elemente, die grossen dagegen als die primitiveren Formen zu betrachten. Hiervon später mehr, zunächst haben wir die innere Ausgestaltung des 'Thymuslappchens bis zum definitiven Bau weiter zu-verfolgen.

\section{Entstehung von Mark und Rinde.}

Trotzdem Fig. 21, die einem Embryo von 22 Tagen entstammt, schon ein fest begrenztes, auusserlich fertiges Thymusläppchen zeigt, findet man noch keine Andeutung einer Trennung von Mark- und Rindensubstanz. Dieser Umstand besagt zunächst, dass die Differenzierung in Mark und Rinde erst sehr spät erfolgt; bedenkt man aber, dass bei der Geburt des 'Tieres ein in jeder 
Hinsicht vollwertiges Organ vorliegt, so bleibt der Marksubstanz nur eine ganz kurze Zeit zu ihrer Entwicklung übrig. Es folgt nun weiter die wichtige 'Tatsache, dass wenn die Funktion des Organs in enger Beziehung zu seiner architektonischen Struktur steht, was wohl anzunehmen ist, sie ihre volle Wertigkeit erst nach der Geburt erreichen kann. Damit ist die alte Hypothese von der Thymus als eines vorwiegend wïhrend des Embryonallebens tätigen Organs hinfällig. Hierfür spricht auch, dass bei beginnender Involution sowohl der physiologischen als der accidentellen neben einer Verschmälerung der Rinde zuerst auch die scharfe Grenze zwischen Rinde und Mark verwischit wird. Andererseits aber lalsst sich dagegen einwenden, dass niclit allen Säugetieren eine so markante Trennung von Rinde und Mark eigen ist, sondern der Übergang mehr allmählich erfolgt, so dass das Charakteristische im Bau der Thymus lediglich in den Beziehungen von Epithelgewebe zu lymphoidem Grewebe zu suchen wäre. Anch wird bei vielen Säugetieren schon viel früher, beim Menschen z. B. nach Hammar schon im 4. Fötalmonat, die Differenzierung zwischen Mark und Rinde deutlich, dem Organ also die Möglichkeit gegeben, seinen Funktionen schon während des intrauterinen Lebens nachzukommen. Es ist, wie man sieht, sehr schwer, hierüber etwas Bestimmtes zu sagen, solange man sich über die Physiologie der Thymus noch so im unklaren befindet; nur das eine darf man wohl mit Recht behaupten, dass die Anschauung jener Autoren, welche dem Einfluss der lhymus erst nach der Geburt die grössere Rolle zuweisen, auch in der Morpho- und Histogenese des Organs eine Stütze findet.

Die Angaben, welche man in der Thymusliteratur über die Entstehung der Marksubstanz findet, sind recht wenig präzis. Für die meisten Autoren ist eben das Mark nur "der Rest der alten epithelialen Anlage“, in welcher die Zellen syncytial verschmolzen sind, und welche für die Anhänger der Lehre von der Pseudomorphose frei von bindegewebigen Bestandteilen bleiben, für die Vertreter der Transformationstheorie nicht zur lymphocytoiden Umwandlung gelangen. Nur $\mathrm{Ham}$ mar und seine Schüler erkennen auch den Markzellen leine gewisse Selbständigkeit $\mathrm{zu}$, indem sie die Elemente der ersten Anlage sich erst zu einem Reticulum auflösen und danach durch Hypertrophie zu dem kompakten Marksyncytium zusammenfliessen lassen. In derselben 
Weise aussert sich auch Maximow. Pigache und Worms (1910) dagegen, die auch die Thymus von Kaninchen bearbeiteten, sehen die Begründung für die Terteilung von Mark- und Rindensubstanz im Lrreislauf gegeben. "La substance médullaire suit dans sa repartition exactement le trajet des artères", während in der Rinde sich nur Kapillaren und abführende Venen finden. Sicherlich darf man der Gefässverteilung im Organ einen gewissen Einfluss auf die Entstehung beider Substanzen nicht absprechen, worauf schon Watney hingewiesen hat; aber man muss hierbei doch sehr vorsichtig sein, denn zur Zeit der Markdifferenzierung ist die Thymus zwar schon reichlich von Gefässen durchsetzt, diese selbst abel' besitzen fast nur eine kapillare Wandung und lassen eine Unterscheidung in Arterie und Vene kaum zu. Sehr merkwürdig aber ist der Mechanismus, mit Hilfe dessen beide Autoren die Entstehung der Marksubstanz erklären. Es sollen sich nümlich in den Arterien sehr viel mehr weisse Blutkörperchen befinden, als in den Venen. Diese verlassen das Gefitss per diapedesin, gelangen mitten unter die Thymuszellen hinein und bringen dieselben wahrscheinlich vermittelst ihrer Sekretionsprodukte zum Verschwinden. Für Picache und Worms, obwohl sie sich nicht weiter über die Genese des Organs aussern, besteht demnach das Mark aus lymphoidem, die Rinde dagegen fast ausschliesslich aus epithelialen Zellen, den eigentlichen Thymuselementen. Meine Stellungnahme zu dieser Ansicht, die sich ahnlich nur von Dustin vertreten findet, geht aus dem Vorangegangenen ohne weiteres hervor.

Kehren wir nun zur Entstehung des Markes zurück. Fig. 20 zeigt einen Ausschnitt aus einem 'Thymuslïppchen zu einer Zeit, wo eben das Läppchen durch Ausbildung einer Faserkapsel sich als solches zu charakterisieren beginnt. Durch die Mitte zieht ein hellerer Streifen, der auf den ersten.Anblick als Mark imponiert. Die genaue Untersuchung zeigt aber sofort, dass man es hier mit einem vollstandig in sich geschlossenen Epithel, einem wirklichen Rest der alten Anlage zu tun hat, dessen Zellen eine eigenartige, plattenepithelähnliche Anordnung zeigen. Auch an der Peripherie findet man noch grössere Komplexe von Epithel, welche der netzigen Auflösung noch nicht anheimgefallen sind. Alle derartigen Epithelinseln stehen durch grössere oder feinere Züge von Epithelzellen miteinander in Verbindung, die zwischen 
den Lymphocytenlaufen hindurchziehen. In diesen Stadien ăhnelt die Thymus am meisten der Tonsille; nur vermisst man noch jedes Zeichen einer Degeneration, wenigstens einer ausserlich sichtbaren, die sich in Bildung von Hornsubstanzen oder ibrer Vorstufen kundgeben würde. Auch fehlt die Ausbildung scharf ausgeprägter intracellulärer Fasern. Dass die Proliferation des Epithels selbst ihr Ende noch nicht erreicht hat, beweisen die zahlreichen Mitosen.

Die Thymus eines 2 Tage älteren Embryos (Fig. 21) zeigt insoterne eine Verunderung, als zusammenhängende grössere Epitbelbezirke nur meir in geringer Zaht zu finclen sind, meist nur am Rande der Läppchen. Hier lassen sie sich an den fortlaufenden Schnittbildern als dünne Kalotten an der Peripherie des Lüppchens verfolgen. Doch zeigen sich die Zellen hier nicht plattgedrückt und Hächenhaft ausgebreitet, sondern sie stehen unregelmässig angeordnet, denn ein Schnitt, der die Läppchenobertliche tangential trifft, ergibt keine anderen Bilder als der Querschnitt (Fig. 9). Es ist dies auch nicht anders zu erwarten, da die Oberflache des Lilppchens der Basis des Epithels entspricht und man, da man es mit einem geschichteten Epithel zu tun hat, an dieser Stelle die Hauptwachstumszone desselben suchen muss, wenigstens so lange sich iiberhaupt noch etwas von der architektonischen Struktur der primären Anlage nachweisen linst.

Der Hauptunterschied gegen frither besteht in der grossen Zunabme der lymphoiden Zellen und zwar hat jetzt, wie sich aus der Struktur und Grösse der Kerne in Fig. 21 ohne weiteres ergibt, ihre Umwandlung zu den typischen kleinen Lymphocyten in grösserem Maße begonnen. Sie liegen nicht mehr vereinzelt zwischen den grossen Lymphocyten, sondern sind zu grösseren oder kleineren Haufen gruppiert; und durchsetzen auch die letzten Reste der epithelialen Anlage, indem sie ihrerseits das Gefüge zur Auflockerung im Sinne Maximows bringen.

In den zentral im Lappchen gelegenen Epithelpartien macht sich ein leichter Farbunterschied geltend gegenüber dem peripheren Teil, der vielleicht als erster Ausdruck einer inneren Differenzierung aufgefasst werden kann. Von einer Hypertrophie einzelner epithelialer Elemente kann aber noch nicht die Rede sein, weder was Kern noch Protoplasma anbelangt. Nur ganz vereinzelt findet man, und 
zwar auch schon in jüngeren Stadien, dass sich einzelne Epithelzellen aus dem lockeren netzigen Verband fester zusammenschliessen, indem sie sich zwiebelschalenartig um ein gegebenes Zentrum herumlegen. Man gewinnt beim ersten Anblick den Eindruck, ein $\mathrm{H}$ assal sches Körperchen vor sich zu haben (Fig. 14). Es enthalten diese Gebilde aber keine Lymphocyten oder zeigen sonstige Degenerationserscheinungen, auch trifft man sie in jüngeren Stadien, wo das epitheliale Reticulum noch leichter zu übersehen ist, eber häufiger als später, was mich zu der Anschauung veranlasst, dass sie mehr zufällige Gebilde als bestimmte Differenzierungen darstellen. Im Verlauf der nächsten beiden Entwicklungstage treten die epithelialen Bestandteile der Thymus noch mehr zurück gegen die lymphoiden Zellen, welch letztere jetzt zum weitaus grössten Teil durch die kleinen dunkelkernigen Elemente vertreten sind. Das Thymusepithel besteht jetzt wirklich aus einem weitmaschigen Reticulum, in welchem sich an seltenen, allerdings dann meist im Zentrum des Läppchens gelegenen Stellen mehrere Zellen zu grösseren Knotenpunkten vereinigen. Untersucht man derartige Stellen bei stärkerer Vergrösserung, so fällt die verschiedene Grösse der Kerne besonders auf. Es liegt also sehr nabe, zunichst an eine Hypertrophie der Zellen zu denken. Diese würde aber nur die Kerne betreffen, nicht auch das Protoplasma, da die Entfernung zwischen den einzelnen Kernen gegen früher nicht vergrössert worden ist, auch wären dabei nur einzelne Kerne beteiligt.

$\mathrm{Zu}$ der Volumzunalume der Kerne kommt als weiteres auffallendes Merkmal ihre schlechte Fürbbarkeit. Das zarte schöne Chromatingerüst ist kaum mehr $z u$ sehen; die chromatische Substanz erscheint zu einzelnen Körnern zusammengeballt, die entlang der gut sichtbaren Membran aufgereiht sind. Die Kernvergrösserung steht meiner Meinung nach im Zusammenhang mit. den Veränderungen am chromatischen Apparat, in dem Sinne, dass durch beide Veränderungen eine Degeneration des Kernes. eingeleitet wird.

Schmaus und E. Albrecht (1895), welche die Kerndegeneration experimentell studierten, beschreiben gerade für die Form, die mit einer Zerstückelung des Kernes endigt, als einleitenden Vorgang einen chromatokinetischen Prozess, wobei sich das Chromatin zum Teil mit Vermehrung oder Verminderung- 
seiner Masse auf bestimmte Stellen des Kernes zusammenballt und zu einer „Hyperchromatose der Kernwand oder des Gerüstes“ führt. Andererseits machen sie auf "sogenannte Frühstadien der Mitose" aufmerksam, zu welchen auch Kerne gehören mit mehr oder weniger diffuser Grundfärbung und solche, die statt zahlreicher feiner Chromatinkörner weniger grobe Partikel enthalten. An solche "Frühstadien der Mitose", die nach den Verfassern „nicht unter allen Umständen zur Kernteilung führen müssen, sondern vielleicht eine Bedeutung allgemeinerer Art besitzen, sich eventuell wieder rückbilden oder anderweitig umwandeln können", ist man versucht $z u$ denken; doch lässt sich nicht recht einsehen, warum solche gerade $\mathrm{zu}$ einem bestimmten Zeitpunkt auftreten, nämlich nur bei der endgültigen Lmwandlung des Epithels zum syncytialen Reticulum, nicht schon bei Beginn der Auflockerung überhaupt.

Allerdings sind am Protoplasma keine Veränderungen (Körncheneinlagerung, Vakuolisierung etc.) wahrzunehmen, doch ist es wohl möglich, dass der Kiern allein zugrunde geht. Es steht dies wenigstens im Einklang mit der Tatsache, dass man im definitiven Mark die Kerne viel weiter auseinanderliegend findet und die gesamte Masse der Kerne im Verhältnis zu der des l'rotoplasmas reduziert erscheint.

Über das Protoplasma selbst ist wenig zu sagen. Es zeigt denselben wabig-schaumigen Bau wie früher; vereinzelt finden sich grössere Vakuolen eingesprengt, die bis zu halber Kerngrösse erreichen können. Die Grenzen zwischen den einzelnen Zellen haben sich noch mehr verwischt, so dass man mit Recht von einem Syncytium sprechen kann. An einzelnen dichteren Stellen erscheint der Bau mehr fädig, ohne dass sich jedoch wirkliche Fibrillen nachweisen liessen.

An den spärlichen zwischen den grösseren Epithelkomplexen eingelagerten Lymphocyten sind dagegen deutliohere Degenerationserscheinungen wahrzunehmen, meist in Form einer Pylinose des Kernes, die mit einem Dichterwerden, einer Verkleinerung der ganzen Zelle einhergeht. Schliesslich findet sich an Stelle des Kernes nur mehr ein rundlicher, selten mehrere kleinere, anscheinend homogene Körper, die Kernfarbstoffe intensiv aufnehmen. Wahrscheinlich sind sie identisch mit dem von Flemming in Lymphdrüsen beschriebenen "tingiblen Körperchen", die v. Schu - 
macher (1904) auch in der Bursa Fabricii der Vögel gefunden hat und bei denen es sich wohl auch um Reste degenerierter Lymphocyten handelt. Dass ihr Vorkommen nicht auf das Mark beschränkt bleibt, sondern sie auch in der Rinde zu finden sind, braucht kaum erwähnt zu werden.

Die weitere Entwicklung, die nunmelr sehr rasch fortschreitet, lehrt, dass die oben beschriebenen grösseren Knotenpunkte des epithelialen Netzes tatsächlich die ersten Anfünge der Markentwicklung darstellen, d. h. von ihnen aus geht die Bildung der definitiven Marksubstanz. Diese wird also im Imnern des Läppchens in Form eines nach drei Richtungen verspannten Netzes angelegt, dessen Stränge durch Verbreiterung die zwischen ilınen liegende Substanz zurückdrängen, bis sie zu einem kompakten Ganzen zusammentliessen. Dieser Zustand wird am 27. Tage des Fötallebens, also kurz vor der Geburt, erreicht. Bei schwacher Vergrösserung zeigt das Läppchen zunächst den Bau der fertigen Thymus, nur ist auffallend, dass die Rinde an vielen Stellen sehr schmal erscheint und das Mark hăufig mit breiter Fläche an das interstitielle Bindegewebe grenzt (Fig. 26). Letzteres hat dann keine Faserkapsel ausgearbeitet, sondern den lockeren mesenchymartigen Bau beibehalten; zahlreiche freie Zellen aller Art, die sich in seinen Maschen finden, zeugen von fortgesetzter blutbildender Tatigkeit. Manchmal sind gerade an solchen Stellen die weissen Blutzellen $\mathrm{zu}$ dichten Haufen zusammengelagert, in welchen die kleinen Lymphocyten vorwiegen (Fig. 26). Man kann sich des Gedankens nicht erwehren, dass man es hier mit kleinen Herden lymphoiden Gewebes zu tun hat, die noch nachtrïglich der Thymus einverleibt werden, zumal da eine scharfe Grenze gegen das Thymusläpchen zu fehlt und benachbarte kleine Lymphdrüsen, die zu dieser Zeit in der Nähe entstehen, noch keine Lymphocyten zu liefern vermögen und ein ganz anderes Aussehen zeigen.

Untersucht man zunächst die zellulären Bestandteile der Rinde ganz im allgemeinen, so zeigt sich, dass sie bereits zum weitaus grössten Teil aus typischen kleinen Lymphocyten besteht, sie liegen noch nicht so dicht gedrängt wie in der fertigen Thymus, namentlich gegen den Rand des Lappchens zu werden sie allmählich spärlich. Die Grenze ihrer Ausbreitung gegen das Mark $\mathrm{zu}$ ist ziemlich scharf, nur an vereinzelten Stellen ragen 
Züge von Lymphocyten keilförmig ins Mark hinein und lösen sich dann allmählich auf (Fig. 26). Man liat hier aber nicht. den Eindruck, als ob die Rindenzellen dem Mark zustrebten, das selbstverständlich niemals ganz frei von ihnen ist, sondern eher als ob es sich um eine Wanderung in zentrifugaler Richtung handle.

Neben den kleinen Lymphocyten finden sich noch zahlreiche grosse mononukleäre Zellen der lymphoiden Reihe, welche die Übergangsformen zu erstel'en liefern. Sie finden sich gerne in der Nähe von Gefüssen, ohne jedoch eine eigentliche Scheide um dieselbe $\mathrm{zu}$ bilden, wie ich ausdrücklich gegen Pigache und Worms hervorheben möchte. Zwischen ihnen sind netzartig verspannt die Epithelzellen, kenntlich an den grossen blassen Kernen von eimem zarten, schwach acidophilen Protoplasmamantel umgeben. Sie bilden am Rand des Läppchens noch ein verhältnismässig dichtes Netz, das in der Tiefe der Septen, wo keine deutliche Kapsel ausgebildet ist, ohne Grenze in das Reticulum des Mesenchyms übergeht. Ausserdem findet man gleich nach der Geburt zwischen den Zellen der Rinde verstreut granulierte Elemente verschiedener Art, auf welche ich später noch ausführlich zurïckkommen muss, daher ich sie jetzt nur erwähne. Sie kommen in etwas geringerer Zahl auch im Mark vor.

Letzteres zeigt, mit etwas stilikerer Vergrösserung betrachtet, ein eigenartig fleckiges Aussehen (Fig. 28), das von der eigentümlichen Verteilung des Zellmaterials herrührt. Vor allem interessieren die Epithelzellen, die in der 'Tat manche Besonderheiten zeigen. Ein Teil derselben hat den alten Charakter noch beibehalten und verhält sich genau wie die Reticulumzellen der Rinde. Sie bilden ein engmaschiges $\mathrm{Netz}$, das die lymphoiden Zellen umschliesst. Wo mehrere Epithelzellen zusammenkommen, treten charaliteristische Veränderungen auf, die zunächst durch die Vergrösserung einzelner Zellen imponieren. Am auffallendsten werden sie an den Kernen, wo die Vorgänge am chromatischen Apparat noch ausgesprochener sind als früher. Die ohnehin schon sehr blassen Kierne sind jetzt fast ungefïrbt, nur die feine Membran und einige dunkle Schollen im Innern bleiben deutlich. Sie bebalten im allgemeinen ihre Form und zeigen nur selten grobe Ausbuchtungen. In dem schwach acidophilen feinwabigen Protoplasma treten an einzelnen Stellen, meist in geringer Entfernung: 
der grossen Kerne, feine fibrilläre Strukturen hervor, besonders nach der Färbung nach Pasini.

Hammar und Maximow bezeichnen die Vergrösserung als Hypertrophie und erblicken in ihr das kausale Moment für die Entstehung der Marksubstanz. Sicher ist, diss nach dem Auftreten der ebengenamnten Erscheinung die Scheidung des Thymusparenchyms in zwei morphologisch getrennte Bestandteile sichtbar wird, die wahrscheinlich auch physiologisch nicht als gleichwertig aufgefasst werden dürfen; ob aber hiermit der Differenzierungsprozess wirklich erst eingeleitet wird, bleibt zum mindesten fraglich, denn in die Vorgünge des inneren Zellgescbehens, welche vom ursprünglichen Zustand der embryonalen Zellen angefangen auf deren endgültige Struktur determinierend einwirken, bleibt uns vorerst noch jeder Einblick versagt. Ausserdem muss man die Frage aufwerfen, ob hier wirklich eine echte Hypertrophie einzelner Zellen vorliegt, die lediglich einer quantitativen Änderung der Zellmasse entspricht, ohne Einfluss auf ihre qualitativen Besonderheiten. Dies muss jedoch verneint werden, denn die Veränderung del morphologischen Zellcharaktere ist offenkundig und lässt daher wohl den Schluss zu, dass auch in funktioneller Hinsicht Umwandlungen stattgefunden haben, wenı wir auch über deren Natur nur Vermutungen hegen können. Der Versuch, die Vorgänge der endocellularen Histiogenese an bestimmte, angeblich in allen Embryonalzellen vorhandene Gebilde, den Vitochondrialapparat, zu knüpfen, ist auf die Säugerthymus bisher noch nicht ausgedehnt worden. Nach Stöhr und Schridde sollen Mitochondrien in den Thymuszellen fehlen. Beide Autoren führen dies als Beweis für die Nichtlymphocytennatur derselben an, denn echte Lymphocyten enthalten Mitochondrien. Dagegen hat Pappenheimer (1913) sowohl in den kleinen Thymuszellen, als in den Reticulumzellen mit Gentiana- und Kristallviolett darstellbare Körner gefunden, ebenso wie Prenant, allerdings in der Froschthymus. Ich habe die Methode von Benda auch auf die Kaninchenthymus angewendet und in ihren Zellen Körnchen darstellen können, doch sind die Bilder so unregelmässig und so unklar, dass ich nichts aus ihnen herauslesen möchte. Die Granuladarstellung nach Altmann gibt kaum befriedigendere Resultate: Feine rotbraune Körnchen finden sich in allen freien und fixen Mesenchymzellen, ebenso in den Lymphocyten des Markes. 
und der Rinde, nur sind sie in letzterer wohl wegen der dichteren Lagerung der Zellen nur schwer zu sehen. Sie sind nicht sehr zahlreich, oft nur auf einer Seite des Zelleibes angehäuft, immer in unmittelbarer Nähe des Kernes und von spezifischen Leukocytengranulationen gut zu unterscheiden. Sie scheinen mir den von Schridde (1905) in den Lymphocyten beschriebenen Körnchen zu entsprechen. In den Reticulumzellen des Markes scheint ihr Vorkommen viel weniger konstant, sie sind viel spärlicher mit einem ausgesprochen roten Ton und von ungleicher Grösse; auch lassen sie sich manchmal in die Fortsätze hinein verfolgen. Sehr selten findet man sie in Hassalschen Körperchen, ausser weln Leukocyten darin eingeschlossen sind. Man sieht aus alledem, wie vorsichtig man sein muss, sobald man aus jenen Reaktionen Schlussfolgerungen ziehen will.

Es bleibt noch ein Ausweg ïbrig, nümlich die Vergrösserung einzelner Reticulumzellen des Markes nicht als einen Wachstumsprozess aufzufassen infolge gesteigerten Stoffwechsels, sondern als einen Vorgang, der zum langsamen Tode der Zellen fïhrt. Ich habe schon darauf hingewiesen, dass die erste bemerkbare Vergrösserung der Zellkerne mit Veränderungen am chromatischen Apparat Hand in Hand geht. Diese sind jetzt noch viel auffallender; manche Kerne verlieren ihr Chromatin fast vollständig und verbleiben als leere eben noch bemerkbare Lücken im Gewebe liegen (Fig. $8 \mathrm{a}$ und b). Das Chromatin wird dabei zum Teil im Kern selbst aufgelöst (Fig. 8b), zum Teil geht es in das Cytoplasma über und bleibt in Form von feineren oder gröberen Schollen lange in demselben nachweisbar (Fig. $8 \mathrm{a}, \mathrm{c}$ und d). Ausserdem geht aus Fig. $8 \mathrm{a}$ und $\mathrm{b}$ hervor, dass es auch seine chemische Zusammensetzung ïndern kann, indem die saure Komponente stärker hervortritt. Einzelne Zellen lösen sich aus dem syncytialen Verband los. An diesen wird die gleichzeitig im Protoplasma stattfindende Degeneration gut sichtbar, die sich vor allem in einer streifigen Verdichtung der Randzone aussert (Fig. $8 \mathrm{c}$ ).

Der Rest der Epithelzellen, die ihren ursprünglichen Charakter vorläufig noch beibehalten, gruppieren sich um die degenerierenden Elemente herum entweder regellos oder durch den im Innern der sich vergrössernden Zellen vorhandenen Quellungsdruck zusammengepresst in konzentrischen Schichten. Hier kommt der Plattenepithel- 
charakter wieder zum Vorschein. Das Hassalsche Körperchen ist fertig. Tatsüchlich lassen sich beim Kaninchen die ersten Hassalschen Körperchen in eben diesem Stadium nachweisen; ich werde auf sie weiterhin noch zurïckkommen.

Dass die sogenannten hypertrophischen Markzellen wirklich degenerierende Elemente sind, lässt sich auch anderweitig feststellen. Unterwirft man die Thymus junger Kaninchen einer mässigen accidentellen Involution durch Hunger oder Bebandlung mit Röntgenstrahlen, so sind jene Formen häufiger zu finden und viel ausgesprochener als im normalen Organ gleichaltriger Tiere. Dies geht schon aus den Versuchen von $\mathrm{Rudberg}$ (1907) und Jonson (1909) hervor und neuerdings von Regaud und Crémieu (1912), Jolly (1912) und Levin (1912), welche eine Zunahme der Hassalschen Körper nach Hunger und Röntgenbestrahlung konstatierten und daraufhin die Hassalschen Körper direlit als Involutionszentren ansprechen. Warum sollte dies nicht auch für das normale Mark gelten. Allerdings möchte ich mich ausdrücklich dagegen verwahren, in dem gesamten epithelialen Reticulum der ${ }^{\circ}$ Marksubstanz ein der Degeneration verfallenes Gewebe zu erblicken, sondern nur an einzelnen circumskripten Stellen, meist wo mehrere Epithelzellen zusammentreffen, werden solche Degenerationszentren sichtbar, die sich langsam vergrössern. Mollier (1913) betont die Ähnlichkeit des Vorganges mit der Ablösung und Degeneration des Epithels in den Krypten der Tonsillen. Dass die Hassalschen Körperchen eine gewisse Grösse nicht überschreiten werden und sich am Ende anders darstellen müssen als der Balghöhleninhalt, der entbehrt werden kann, liegt im architektonischen Aufbau beider Organe begründet.

Dunkel bleiben die Ursachen, welche zur Degeneration des Epithels führen und damit auch der Grund, warum dieselbe nur im Mark zu finden ist, nicht aber auch in der Rinde. Die Verteilung des Epithels hier anzuführen, würde nichts zur Lösung der Frage beitragen, eher noch die Anordnung der Gefăsse. Um diese Zeit beginnt in der Rinde ein dichtes Netz von Kapillaren sich zu entwickeln, während die relativ weiten Gefässe des Markes, welche bis dahin nur eine endotheliale Wand besassen, jetzt eine kräftigere bindegewebige Hülle erhalten und somit das Mark in seiner Ernährung gegen die Rinde scheinbar zurückgesetzt wird. 
Die lymphoiden Zellen des Markes sind bis jetzt vollständig ausser acht gelassen worden; dennoch bilden sie weiter einen sehr wesentlichen Anteil desselben. In dichten Zügen durchsetzen sie das epitheliale Netz, indem sie gleichsam ein Negativ desselben geben (Fig. 28). Ihre Verteilung ist daher sehr unregelmässig Dies hängt wahrscheinlich mit der rasch einsetzenden Umgestaltung des Epithels zusammen, wodurch sie zu ungleichen Haufen zusammengeschoben werden; andererseits aber auch damit, dass die kleinen echten Lymphocyten fast alle das Mark verIassen. Spater wird die Verteilung der Lymphocyten im Mark wieder etwas mehr ausgeglichen. Analysiert man die Zellen nach ihren Formen, so findet man im Gegensatz zur Rinde vorwiegend grössere Lymphocyten. Sie haben einen relativ chromatinreichen Kern, verglichen mit den Mesenchymzellen des interstitiellen Gewebes und einen deutlich basophilen schaumig gebauten Protoplasmaleib. Ganz vereinzelt kommen auch noch grosse mononukleäre Zellen vor. Gegen die Rinde zu werden die kleinen Lymphocyten häufiger; die hier viel zalılreicheren Teilungsfiguren in denselben sprechen für eine vorwiegende Entstehung in loco.

Wichtig ist, dass auch unter den Lymphocyten jetzt Degenerationserscheinungen häufiger vorkommen wie früher', zum Teil unter dem Bilde des Kernzerfalls, zum leil in Form der Piknose. Fig. $8 \mathrm{e}-\mathrm{g}$ geben verschiedene solche Figuren wieder. Durch Hunger und Röntgenbestrahlung kann ihre Zahl bedeutend gesteigert werden. Es ist erstaunlich, wie wenig Aufmerksamkeit dieser Degenerationserscheinung bisher geschenkt wurde. Maxim ow in seiner ausführlichen Arbeit erwähnt sie gar nicht, obwohl er von blasig aufgetriebenen und deformierten Kernen der Markreticulumzellen spricht, die er aber für eine spezifische Differenzierung jener Zellen hält. Der Umstand, dass man keine direkten 7erfallsprodukte von Zellen findet, ist an sich noch kein Beweis gegen eine Degeneration. Diese kann so langsam fortschreiten und mehr in Form einer allmählichen Auflösung erfolgen, so dass sie morphologisch wenig sichtbar wird, namentlich wenn für eine Resorption der Abbauprodukte gesorgt ist. Dass eine solche nicht immer genügend rasch zustande kommt, beweisen die detritusartigen Massen, die hăufig genug im Innern grösserer Ha s s a l scher Körper zu finden sind. Bei anderen Tieren, z. B. bei Hunden, werden cystenähnliche Bildungen erfüllt mit zerfallenden Zellen gefunden. 
Erst Pigache und Worms (1910) haben degenerierende Zellen als einen integrierenden Bestandteil auch der nolmalen Thymus hingestellt. Sie gehen nur wieder zu weit, indem sie das ganze Markreticulum als eine von Leukocyten gelieferte kolloidühnliche Masse ansehen, die ihrerseits den Verfall ihrer Produzenten nach sich zieht, während die spezifischen Thymuselemente nach der Rinde zu wandern. Sie deuten aber das Vorhandensein einer Wechselwirkung zwischen Epithel und Leukocriten an.

Nach Maximow veranlassen die hypertrophischen Markzellen die Lymphocyten, sich aus ihrer Nähe zu entfernen. Sie entfalten also ihre Wirkung gerade in umgekehrter Richtung wie zum Beginn der Entwicklung, wo sie einen deutlichen positiv chemotaktischen Einfluss auf die Mesenchymzellen zeigten. Tatsache ist, dass grössere Epithelkomplexe nahezu frei von Lymphocyten sind, wie man es sich auch erklüren mag, und dass hierin vorhandene Zellen mesodermaler Ablunft bald zugrunde gehen, so wie dies von anderen durch das Epithelgewebe hindurchwandernden Lymphocyten bekannt ist (vgl. Mollier 1913, Spuler 1911, Jolly 1911, v. Schumacher 1904). Für die Thymus ist dabei charakteristisch, dass die Durchmischung des Epithels mit Lymphocriten nicht gleichmässig bleibt, sondern die in der 'Tonsille und der Bursa Fabricii gleichmässig vor sich gehende physiologische Degeneration hier durch eine bestimmte regressive Metamorphose einzelner Epithelzellen auf circumscripte Stellen des Markes beschränkt wird; während dazwischen immer wieder eine Neubildung beider Gewebe statt hat; daran vermag auch der Umstand nichts zu ändern, dass man auch in der Rinde hin und wieder Degenerationsprodukte von Lymphocyten findet, denn diese kommen überall vor, wo lymphoides Gewebe in grösseren Mengen angehäuft ist, z. B. den Lymphdrüsen und der Milz. Selbstverständlich darf auch die Degeneration der Epithelzellen im Thymusmark nicht als pathologischer Vorgang aufgefasst werden, sondern als ein notwendiges für die Thymus spezifisclies Geschehen; das beweist auch die Tatsache, dass bei der Involution, sei es der normalen oder accidentellen, trotz der absoluten Zunahme der H as salschen Körper, die Grenze zwischen Mark und Rinde wieder verwischt wird und unter Verschmälerung des Rindenanteils die Marksubstanz mit kleinen dunkelkernigen Lymphocyten überschwemmt 
wird. Ausserdem behält sowohl der epitheliale wie der lymphoide Bestandteil des Markes seine selbständige Vermehrungsfahigkeit. Karyokinetische Figuren kommen zwar sparlicher als im embryonalen Organ, aber in vollkommen normaler Weise auch bei alteren Kaninchen noch vor und lassen sich dann viel leichter als einer bestimmten Zellart zugehörig identifizieren. Es ist wohl nicht erstaunlich, dass Mitosen in der Rinde häufiger sind als im Mark.

Zum Schlusse müssen noch ein paar Worte gesagt werden über die Verteilung der Marksubstanz im gesamten Organ. Was Ha mmar (1912) für die menschliche Thymus nachgewiesen lat, dass numlich das Mark im allgemeinen die Form des ganzen Organs nachahmt, gilt auch für das Kaninchen. Es entsteht aber, wie gezeigt, nicht als kontinuierlicher zentraler Strang, sondern durch Verschmelzung selbständig angelegter Markinseln. Gerade durch diese grob anatomischen Verhältnisse, die einen Vergleich mit der Tonsille und Bursa Fabricii von neuem nahe legen, wird man wieder an die Anschauung v. Ebners erinnert, der nur im Mark die alte epitheliale Komponente sab, um die sich aussen lymphoides Gewebe herumlegt. Die Entwicklung lehrt aber, dass dem nicht so ist. Andererseits lässt sich schwer einsehen, dass die baumartige Verästelung des Markes, die sekundăr die Form der ursprünglichen Anlage wieder erreicht, durch blossen Zufall zustande gekommen sein soll. Noch schwieriger gestaltet sich das Problem, sobald man erfahrt, dass bei den einzeinen Klassen der Vertebraten (vgl. Maximow 1909, 1912, 1913, Dustin 1911, 1913, Hamilton 1913, Helgesson 1913) verschiedene Verhältnisse vorliegen, es sich also sowohl bei der primitiven Formgestaltung als auch bei der histogenetischen Differenzierung um streng spezifische Vorginge handelt. Selbst wenn man, wie es zunächst am wahrscheinlichsten erscheint, in der Markdifferenzierung einen mehr regressiven Prozess erblickt, wie sich solche an der Oberfläche sehr vielschichtiger Epithelien auch sonst abspielen, mit einzelnen kleinen Degenerationszentren, den $\mathrm{Hassalschen}$ Körperchen, so kann diese Anschauung nicht mehr als eine blosse Vermutung bleiben, die nur eine Seite des Problems beleuchtet, niemals aber den Kernpunkt der Sache selbst trifft.

Dasselbe gilt, sobald nach einer Erklärung für das Verhalten des lymphoiden Gewebes gesucht wird. Warum stellt es sich in der 'Thymus anders dar, als in anderen lympho-epithelialen Organen, 
in der 'Tonsille und in der Bursa Fabricii? Hier erfolgt die Vermehrung und Nachlieferung der Zellen durch die Bildung typischer Follikel, während dort vorwiegend einzelne freie Zellen, die vorwiegend schon den Charakter der kleinen Lymphocyten tragen, sich immer wieder teilen und Ersatz für zugrunde gegangenes Material liefern. Auch mit der Theorie der Wechselwirkung жwischen epithelialem und lymphoidem Gewebe, die eben nichts weiter ist als eine Umschreibung unklarer Vorstellungen, kommt man hier nicht weiter und wir müssen uns vorläntig begnügen, die Entstehung des Markes einfach so zu beschreiben, wie sie erfolgt ohne einen Einblick in die Bedingungen des Geschehens zu erzwingen suchen.

4. Die Vaskularisierung der 'Tymus.

Den Thymusgefässen ist bisher wenig Beachtung geschenkt worden, wenigstens nicht in dem Sinne, der ihnen als intraepithelial gelegenen Gefüssen eine besondere Stellung zuerkennt. Erst Mollier (1913) hat unlängst darauf lingewiesen und die Stellung der Thymus in der Reihe der lympho-epithelialen Organe damit als eigenartige und noch nicht völlig gesicherte begründet. Unter den früheren Thymusforschern hat Watney (1882) die Gefässe in der Thymus genauer beobachtet, melr mit Rücksicht auf die die Gefüsse begleitenden Lymphscheiden, die den kleinen Thymuszellen als Abschlussbahn dienen sollten. Dustin (1913) bringt die jährliche Evolution und Involution der Amphibienthymus mit den Gefassen in Zusammenhang und Pigache und Worms (1910) erklären aus dem Verlauf und der Entwicklung der Gefässe in der Thymus der Sänger die Entstehung von Mark und Rinde, allerdings in einer Weise, die, wie ich schon früher betonte, meinen Anschauungen vollständig widerspricht. Die Angaben, die Maximow (1909) über die Vaskularisierung der Thymus macht, sind sehr spärlich; bei ungefähr $15^{1 / 2} \mathrm{~mm}$ langen Embrỵonen werden die Gefässe mit dem Mesenchym in die Furchen der Oberfläche hineingesenkt "und an einzelnen, allerdings noch sehr seltenen Stellen sieht man sogar, wie von ihnen junge Sprossen abgehen." Später, wenn die zuliünftige Marlisubstanz aufzutreten beginnt, werden die Beziehungen zwischen Thymusparenchym und Blutgefaissen als innigere beschrieben. Von der Tiefe der Bindegewebssepten aus, viel seltener von der Peripherie des Läppchens Archiv f. mikr. Anat. Bd. 86. Abt. I. 
sinken Gefäßschlingen tief in das Thymusparenchym selbst ein; ob es sich dabei um einen mehr passiven oder aktiven Vorgang handelt, wird nicht erwähnt; "sie (die Gefässschlingen) werden dabei manchmal von einzelnen Mesenchymzellen begleitet, meistens verwandeln sich aber diese letzteren früher oder später in Lymphocyten und dann erscheint das Endothelrohr unmittelbar in dem mit Lymphocyten infiltrierten Epithelgewebe gelegen." Hier gibt Maximow die Einbeziehung von undifferenziertem Mesenchym in das Thymusepithel selbst $z \mathfrak{n}$; allerdings schränlt er dieses Eingeständnis sofort wieder ein. Hierzu wäre zu bemerken, dass theoretisch die Umwandlung aller Mesenchymzellen in Lymphocyten sehr wohl denkbar wäre, dann müssten sich von den wenigen zuerst eingedrungenen nackten Endothelröhren aus die weitere Vaskularisation der gesamten Thymus entwickeln; dazu müssen aber die Endothelzellen sich die Fähigkeit zur Vermehrung bewahrt haben, sie vermögen also neues Endothel-Mesenchym zu liefern; ebenso muss vom Endothel aus die Adventitia der grösseren Ciefässe geschaffen werden. Wenn nun aber vom Endothel aus die Neubildung von Mesenchym erfolgen kann, so kann auch die Möglichkeit nicht ausgeschlossen werden, dass von hier aus stets einzelne Zellen sich loslösen und zu Lymphocyten werden. Morphologisch ist der Beweis hierfür kaum zu erbringen, da sich mesenchymatöses und epitheliales Reticulum nicht voneinander unterscheiden lassen.

Will man dagegen die Neubildung von Gefässen in der Thymus nicht durch Aushöhlung bestimmter vom schon vorhandenen Endothel gelieferter Mesenchymstränge vor sich gehen lassen, so muss man für die Lieferung der neuen Gefässwände die Rückdifferenzierung lymphoider Thymuszellen zu Hilfe nehmen; einen solch umständlichen, sonst nirgends im Körper vorkommenden Bildungsgang anzunehmen, liegt jedoch gar kein Grund vor, auch lässt sich nicht die Spur eines Beweises dafür erbringen. Es ist interessant, dass gerade die eifrigsten Vertreter der Transformationslehre, Stö hr, Cheval und Marcus, die Gefäss ein der Thymus nur nebenbei erwähnen oder ganz mit Stillschweigen übergehen, nachdem v. Ebner sich gerade durch das Vorhandensein derselben von der Auffassung des Reticulums als eines epithelialen abschrecken liess. Wie gelangen. nun zunăchst die Gefässe in das Epithel? Untersuchen wir die Thymus zu einer Zeit, wo sie äusserlich schon ein kompliziertes Organ darstellt, histologisch 
aber noch einheitlich gebaut ist, also etwa von einem Embryo von 16 Tagen ('Textfig. 5), so finden wir das Epithel noch überall gefiissfrei, selbst im kaudalen Brustteil, wo eben die Einwanderung der Lymphocyten beginnt. Während aber früher die weiten Kapillaren das Organ nur von aussen in ein weitmaschiges Netz einhüllten (Fig. 22), dringen sie jetzt auch tief in die Bindegewebssepten ein (Textfig. 7 und 8 ) und durchsetzen in diesen bindegewebigen Strassen die ganze epitheliale Anlage, indem sie manchmal bis dicht gegen das Epithel vordringen (Fig. 19).

Sicherlich haben sie jetzt bereits Einfluss auf die weitere Formgestaltung der Thymus. Man könnte sich dies auf zweierlei Weise erklären. Es wird entweder das Epithel, sobald es auf ein Gefäss stösst, hier an seiner weiteren Ausdehnung gehindert und gezwungen, nach rechts und links auszuweichen und das Gefäss zu umwachsen (Fig. 19), oder aber es nimmt das Gefüss Anteil an der Auflösung und Vakuolisierung des Epithels, indem es mit dem Jymphoiden Material aktiv weiter vordringt und so ins Innere gelangt (Fig. 27). Die Verwischung der scharfen Grenze zwischen Epithel und Bindegewebe spricht zugunsten der letzteren Auffassung, doch lässt sich erstere auch nicht absolut von der Hand weisen. Ich glaube, dass beide vorkommen können und berücksichtigt werden müssen.

Noch deutlicher wird das Vordringen der Gefüsse in den folgenden Tagen; es sind jetzt nicht mehr weite, dünnwandige Kapillaren, sondern die meisten erscheinen von einer deutlichen Hïlle von lymphocytoiden Zellen umgeben, welche mit ihnen in das Parenchym einzudringèn versuchen (Fig. 27 und Textfig. 8). Ausserdem wird jetzt eine Verschiedenheit in der Weite der Röhren immer auffälliger, sowie ein Unterschied im Bau der Wand, so dass man bis zu einem gewissen Grade zwischen Arterien und Venen unterscheiden kann. Erstere beginnen glatte Muskelzellen auszubilden, sie liegen meist mebr an der Peripherie des Organs.

Was den Inhalt der Gefässe betrifft, so zeigt er nichts Besonderes, jedenfalls keine Vermehrung der weissen Blutzellen gegenüber anderen Gefässen, so dass von einer Zufuhr von Lymphocyten auf dem Blutweg nicht die Rede sein kann, was bereits von $\mathrm{Stöhr}$ betont wurde.

Das Epithel selbst ist immer noch gefussfrei. 
Nach 2 Tagen der Entwicklung (20 Tage alter Embryo) scheint dies nicht mehr der Fall zu sein. Wenigstens finden wir auch das eigentliche Parenchym von Kapillaren durchsetzt. Wie ein Blick auf Fig. 20 lehrt, erfolgt aber das Vordringen der Gefässe auch jetzt noch in Begleitung bindegewebiger Stränge, welche das schon früher aufgelockerte epitheliale Gefüge immer mehr zerklüften. Es gelingt fast immer deutlich, den Weg des Gefässes za verfolgen und niemals dringt es in Partien fest geschlossenen Epithelgewebes ein (Fig. 20 und 21). Wenn man also will, so kann man auch jetzt noch die Thymus als gefïssfrei bezeichnen; es handelt sich nur um die Auffassung, welche Gewebe man nunmehr als zum eigentlichen Thymusparenchrm zugehörig erachtet haben will. Nicht nur manchmal, wie Maximow sagt, sondern immer, ist das Gefiss von einer dichten Schicht mesenchymatösen Gewebes umgeben.

Diese letztere bleibt als solche nicht erhalten. Ein 'T'eil ibrer Zellen wird für die grösseren Gefüisse wenigstens zum Aufbau der Gefasswand mit verbraucht, ein anderer löst sich als frei gewordene Lymphocyten ab und wandert tiefer in das Epithel ein, aber einzelne Zellen haften den jungen Gefassen wohl auch weiter noch an, und sind dann als undifferenzierte, für den Nachschub nicht univichtige Elemente aufzufassen. Marchand (1901) fand die Endothelien regelmässig von Zellen bekleidet, die Lymphocyten $z u$ liefern vermögen.

Ob diese Zellen dauernd durch feine Fortsätze miteinander verbunden bleiben, und so auch morphologisch den embryonalen Habitus behalten, gelang mir leider nicht nachzuweisen. Wie schon oben erwähnt, versagte auch hier die ron Salkind angegebene Methode. Aber selbst wenn alle Verbindungen zwischen diesen Zellen gelöst sein sollten, so ändert diese Tatsache nichts an der Bedeutung des Mesenchyms als solchem für das Thymusgewebe. Es ist ja gerade für dieses Organ charakteristisch, im Gegensatz zur Tonsille, dass hier "unreife“, noch ganz jugendliche Stadien zur Einwanderung in das Epithel kommen, während das epitheliale Reticulum der Tonsillen von typischen, kleinen Lymphocyten durchsetzt wird, selbst im embryonalen Zustand des Organs. Dass in diesen Lymphocyten hin und wieder auch Teilungsfiguren beobachtet werden, andert nichts an der Sache, sie kommen auch bei den kleinen Lymphocyten der Thymus und 
sogar sehr viel häufiger vor. Etwas anders liegen die Verhaltnisse bei der Bursa Fabricii der Vögel. Jolly hat hier ebenfalls die Einwanderung jugendlicher Lymphocytenformen beobachtet, doch schï̈tzt die basale Schicht derselben, die ein fest geschlossenes Gefüge bewalhrt, das epitheliale Reticulum vor dem Eindringen der Gefüsse.

Fig. 21 zeigt die Gefïsse schon in das epitheliale Reticulum eingeschlossen, an welches sie jetzt stellenweise direkt anzugrenzen scheinen. Dies wird mit der weiteren Differenzierung der mesenchymatösen Septen immer auffälliger, bis endlich das beliannte Bild der fertig vascularisierten Thymus entsteht.

Es braucht nach dem Vorhergesagten wohl nicht mehr eigens hervorgehoben zu werden, dass von den einmal ins Innere des Thymusparenchyms verlagerten Gefäsen aus anch nene weitere gebildet werden können, aus denen sich dann vor allem das Iiapillarnetz der Rinde entwickelt.

Die kompakten Epithelinseln, von welchen aus die Marksubstanz ihre Entstehung nimmt, wehren sich auch weiterlin gegen das Einwuchern von Gefüssen und Mesenchym. So kommt es, dass auch im fertigen (Organ in der Marksubstanz die Ciefïsse stets in grösserer Entfernung voneinander liegen ohne kapillare Anastomosen; ferner darf es nicht mehr wundernehmen, dass die Gefässe des Markes meist ein weiteres Lumen und eine liriftiger ausgebildete Wand besitzen, stellen sie doch die am frïhesten eingedrungenen Schlingen dar.

Auch ist der Gedanke nicht abzuweisen, dass die spurtiche Verteilung dünnwandiger Gefüsse im Zentrum des Läppchens ihrerseits Einfluss gewinnt auf die weitere Entwicklung des Markes, vielleicht sogar dazu in ursïchlicher Beziehung steht. Sicherlich wird dadurch die Bildung kleiner Herde mit zentraler Degeneration begünstigt, von welchen aus die $\mathrm{H}$ assalschen Körperchen ihren [rsprung nehmen. Denn dass ibre Entstehung mit einem Mangel an Ernäbrung zusammenbängt, wird durch die Versuche von Jolly (1911) und Levin (1911) bewiesen, die bei hungernden Tieren ihre Zahl vermehrt und ihr Volumen vergrössert fanden. Dafür spricht auch, dass die erste Entstehung ausgedehnterer Markinseln zeitlich mit dem Eindringen der Gefüsse zusammenfällt.

Andererseits muss man sich fragen, warum es in der Thymus zu einem bestimmten Zeitpunkt überhaupt zur Einwanderung von Gefässen kommt. Maximow erklärt den Vor- 
gang dadurch, dass die gefässhaltigen Bindegewebszüge vom Epithel direkt umwachsen, also scheinbar passiv eingezogen werden. Dies ist zum Teil auch sicherlich der Fall, namentlich in den jüngeren Stadien, wo die Vergrösserung der Thymusläppchen lediglich auf Kosten des epithelialen Wachstums geschieht; hiermit wird aber nur das Vorhandensein derjenigen Gefässe aufgeklürt, die in den bindegewebigen Strassen zwischen den Epithelbalken verlaufen, und vielleicht noch das Vorkommen grösserer Gefässe an der Grenze zwischen Rinde und Mark, nicht aber das von Kapillaren und Venen in der Rinde selbst. Man könnte nun denken, dass, sobald das Lappchen einen gewissen Durchmesser erreicht, die Ernährung mittels eines Saft- und Lymphstromes nicht mehr ausreicht; die zahlreichen Mitosen, die der Ausdruck einer energischen proliferativen Taitigkeit sind, scheinen dies zu bestätigen. Dass schon Gefässe vorhanden sind, ehe die Ausgestaltung des definitiven Läppchens erfolgt, spricht nicht dagegen, denn Mesenchym muss vorhanden sein, um den weiteren Aufbau des kapillaren Systems zu ermöglichen. Dies müssen selbst diejenigen Forscher zugeben, die in den kleinen Thymuszellen nicht Elemente mesodermaler Abkunft, sondern umgewandelte Epithelzellen sehen. Wir müssen aber andererseits auch bedenken, dass auch in der Tonsille epitheliale Netze vorkommen, die auf weite Strecken hin gefüssfrei sind und dass die einzelnen Knospen der Bursa Fabricii manchmal eine ganz beträchtliche Dicke erreichen. Somit komme ich zu der Überzeugung, dass es nicht die Ausdehnung der Thymusläppchen allein sein kann, die eine so eminente Gefüssversorgung benötigt und veranlasst, sondern dass die Ursachen hierzu mit in der eigenartigen Ausgestaltung des Organs selbst zu suchen sind, insofern es hierin seinen funktionellen Leistungen angepasst sein muss und letztere in der eigenartigen Architektonik morphologisch zum Ausdruck gebracht werden. Vielleicht ist auch der Umstand, dass die Thymus nicht wie die Tonsille oder Bursa Fabricii direkt an den Darmkanal angeschlossen ist, damit in Beziehung $\mathrm{zu}$ bringen. Es bleibt nun nur noch übrig, über die Gefässanordnung in der Thymus ein paar Worte zu sagen und sie mit der Entwicklung in Einklang $\mathrm{zu}$ bringen.

Mollier (1913) hat unlängst den Gedanken ausgesprochen, dass man möglicherweise die Erklärung hierfür in dem Verhalten 
der Gefässe eines geschichteten Plattenepithels finden köune. In del Tonsille wenigstens bleibt nach seinen Untersuchungen die für die Papillen der bindegewebigen Unterlage charakteristische Gefässanordnung erhalten, selbst wenn das Epithel zum Reticulum umgewandelt und durch Auflösung der Membrana propria die scharfe Grenze gegen die Unterlage verloren geht.

Die Blutgefüsse in der Haut verlaufen nun folgendermassen: Aus dem subpapillaren arteriellen Netz steigen feine Zweige in den Papillen auf, die erst an der Spitze der Papille sich zum venösen Netz auflösen und in das subpapilläre Venennetz übergehen (Spalteholz). Ich habe versucht, das gesamte Gefässsystem einer embryonalen Kaninchenthymus zu rekonstruieren, musste aber wegen der technischen Schwierigkeiten davon absehen und mich mit der Durchsicht von Schnittserien begnügen; doch lisst sich auch auf diese Weise ein ganz guter Einblick in den Aufbau des Systems gewinnen, vorausgesetzt, dass alle Gefässe prall gefüllt sind.

Die Zufuhr des Blutes erfolgt durch Gefässe, die von den interlobulär gelegenen abzweigen und meist von einer ziemlich

derben Bindegewebsscheide umgeben sind (Textfig. 10 und 9). ${ }^{1}$ ) Sie dringen bis zur Marksubstanz vor und beginnen erst hiel sich in feinere İste aufzulösen. Textfig. 10 lässt das Eindringen

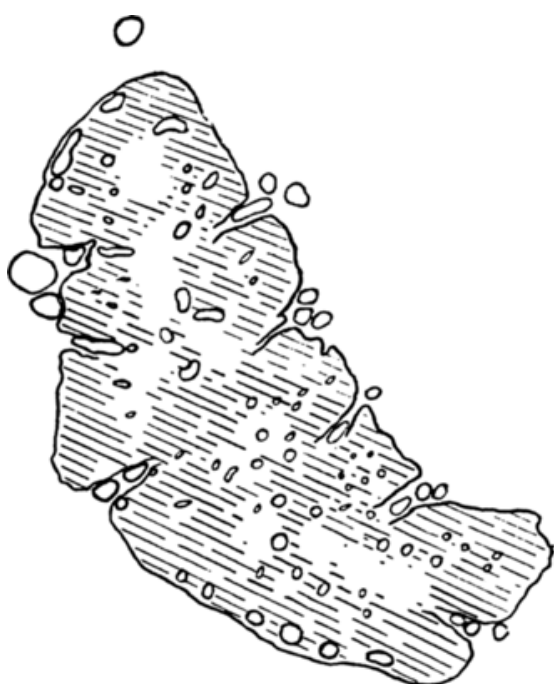

Fig. 9. des Bindegewebes in Form von Papillen erkennen, nur sind diese

1) Textfig. 9-13 entstammen der Thymus eines 22 tägigen Embryos. Sie wurden in der Höhe des Mikroskoptisches mit dem A b be schen Zeichenprisma entworfen unter Verwendung von Apochromat $16 \mathrm{~mm}$ als Objektiv und Compensations-Ocular 6. Zur Reproduktion wurden sie um ein Drittel verkleinert mit Ausnahme von Textfig. 13, welche die natürliche Grösse zeigt. 
hier sehr dünn und lang gestreckt und erreichen die Marksubstanz nicht immer, so dass das Gefass über sie hinausgeht. $O b$ die Gefässe der Marksubstanz, die aus den Arterien hervorgehen, alle netzförmig untereinander verbunden sind, lässt sich auf diese Weise nicht genau feststellen. Es ist aber nicht undenkbar, denn die Gelegenheit zur Anastomose ist geboten, solange noch keine zusammenhängende Marksubstanz vorhanden und nur einzelne

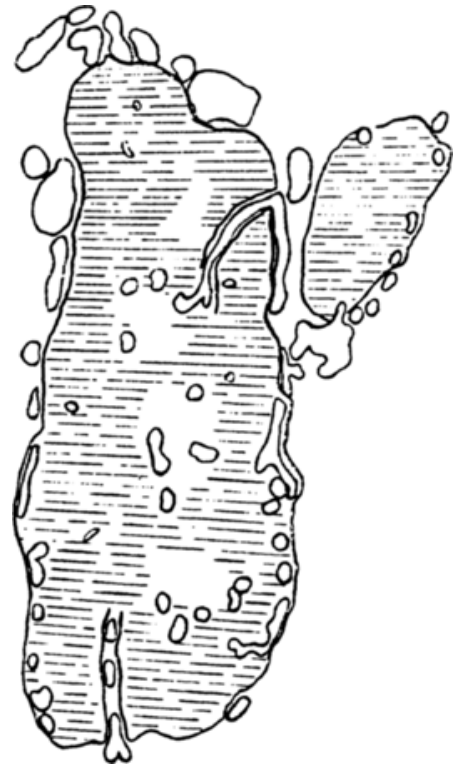

Fig. 10 . feste Epithelinseln zu umgehen sind. Selbstverständlich sind auch die Papillen nicht immer als drehrund zu denken; sie können auch in Form schmaler Leisten rorhanden sein; doch sind letztere

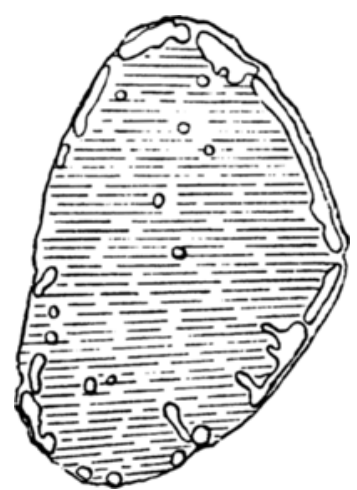

Figg. 11.

sicher viel seltener und meist da zu suchen, wo zwei alte Epithelknospen aneinander gestossen sind.

Die grossen Gefässe des Markes kehren nun nicht mehr auf demselben Wege zurück, sondern lösen sich in ein feines und sehr dichtes Kapillarsystem auf, dessen feinste Zweige auf der bei ganz schwacher Vergrösserung gezeichneten Textfig. 9 nicht mehr zur Geltung kommen konnten. Aus ihnen wird das Blut in relativ weite Venen gesammelt, die dicht unter der Kapsel, aber noch innerhalb des Läppchens liegen (Textfig. 11), und wie ein Tangentialschnitt durch die Lüppchenoberfläche zeigt (Textfig. 13), netzförmig angeordnet sind. Von Stelle zu Stelle durchbrechen sie die Kapsel und münden in die interlobulär gelegenen Gefässe 
ein (Textfig. 12 und 13). Sie sind übrigens in der fertigen Thymus sehr viel kleiner und daher weniger auffällig.

Die Vermutung Molliers hat sich demnach als richtig erwiesen und die besondere Anordnung der Gefässe in der Thymus wird dadurch auf relatir einfache Weise erklärt. Es musste sich dieses Verhalten aber auch aus der Entwicklung des Organs

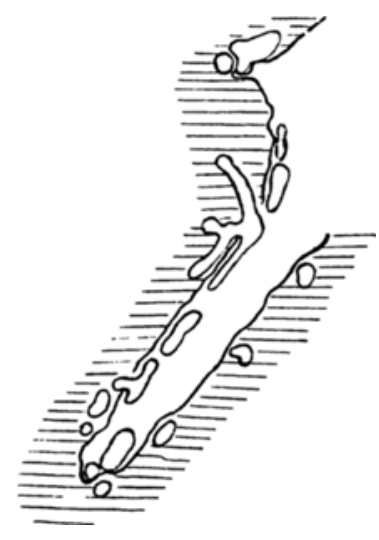

Fig. 12.
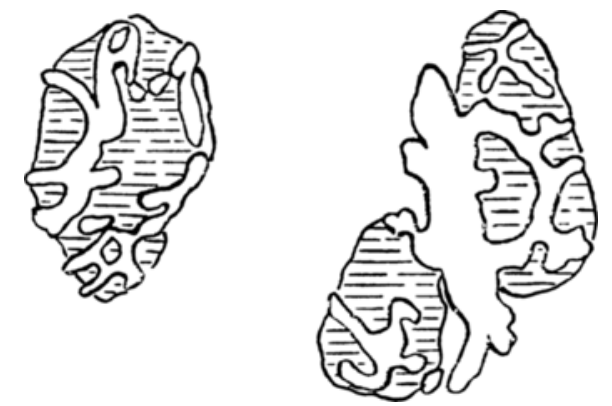

Fig. 1:3.

ergeben, das solide Epithelknospen in das gefässhaltige Mesenchym vordiingen laisst, die erst nachtrïglich vaskularisiert werden. Die anfangs sehr breiten bindegewebigen Septen werden dann durch die weitere Entfaltung des Organs zusammengedrïngt und zu den schmalen Papillen reduziert, während andererseits durch die lebhafte Mitbeteiligung des Mesenclyms an der histogenetischen Differenzierung die Möglichkeit zur Ausbildung des Kapillarnetzes gegeben wird.

5. Hassalsche Körperchen und andere Differenzierungsprodukte.

Unter all dem merkwürdigen, was die Thymus in ihrem Bau darbietet, sind wohl am auffallendsten die $\mathrm{Hassalschen}$ Körperchen; daher ist es auch nicht zu verwundern, dass gerade diese Gebilde vielfach beschrieben und gedeutet worden sind. Ohne auf die verschiedenen Theorien, welche über sie schon geäussert wurden und die man der Hauptsache nach wohl als bekannt voraussetzen darf, naher einzugehen, möchte ich hier nur ein paar Worte über ihre Entstehung sagen, sowie über ihre 
Beziehungen zu den verschiedenen Komponenten des Thymusparenchyms. Daraus wird sich die Stellungnahme zur Literatur dann von selbst ergeben.

Zuvor muss noch der Begriff des Hassalschen Körperchens festgelegt werden. Ha m mar unterscheidet zwischen mehrzelligen und einzelligen Hassalschen Körperchen, indem er zu den letztereı sehr grosse hypertrophische Reticulumzellen rechnet, die bei den Säugern den Ausgangspunkt für die Bildung mehrzelliger Körper abgeben und bei anderen Vertebraten durch Ausarbeitung ganz bestimmter Strukturen zu den sogenannten myoiden Zellen führen, über deren Herkunft allerdings noch grosse Meinungsverschiedenheiten herrschen. Fibrillare Strukturen mit ausgesprochener Querstreifung kommen beim Kaninchen nicht vor; selbst bei Katze, Hund und Meerschweinchen, wo die Hassalschen Körperchen sehr gross sind, konnte ich höchstens Andeutungen davon findelı. Die myoiden Zellen können also hier ausser acht gelassen werden. Wie bei allen anderen Siugetieren, so fehIt hier auch die Umwandlung von Epithelzellen zu Schleimzellen oder ein schleimiger Zerfall von Reticulumzellen, der zur endgültigen Auflösung führt.

Ebensowenig finden sich beim Kaninchen grössere Cysten, deren Wand deutlich epithelialen Bau aufweisen; es fehlt demnach den Epithelzellen die Gelegenheit, Bürstensüume oder Flimmern auszuarbeiten, da ein diesbezüglicher Reiz nur an einer freien Oberflache zustande kommen kann. Aus demselben Grunde lässt sich auch keine Cuticulabildung beobachten. Zum Studium der Hassalschen Körperchen ist die Thymus des Kaninchens überhaupt wenig geeignet, da diese Gebilde hier selten sehr gross werden und selbst im fertigen Organ nur relativ spärlich vorhanden sind.

Trotzdem die Bildung eines $\mathrm{H}$ assalschen Körperchens meist mit einer Volumzunahme der betreffenden Zellen einsetzt, darf man nicht a priori alle hypertrophischen Zellen in der Thymus als einzellige Hassalsche Körperchen ansprechen, da eine Vergrösserung der Reticulumzellen noch nicht notwendig zur Entstehung eines Hass al schen Körperchens führen muss. Ich werde daher als einzellige Hassalsche Körperchen nur solche hypertrophischen Markzellen betrachten, in welchen ausser der Grössenzunahme noch eine besondere Differenzierung irgendwelcher Art 
nachweisbar ist. Es wird sich aus dem folgenden ergeben, dass diese sehr verschiedener Natur sein kann.

Die ersten $\mathrm{H}$ as s alschen Körperchen treten beim Kaninchen erst unmittelbar vor der Geburt in Erscheinung, also etwa am 27. Tag des Fötallebens; man kann aber selbst dann noch viele Schnitte durchmustern, olıne ein einziges mehrzelliges zu finden (Fig. 26). Nach der Geburt sind sie dagegen immer vorbanden. Mit zunehmendem Alter werden sie etwas zahlreicher und glösser, sobald jedoch die Involution der Drüse einsetzt, scheinen sie beim Kaninchen im Gegensatz zu anderen Tieren wieder abzumelımen. Diese Beobachtung steht in Einklang mit den experimentellen Befunden von Rudberg (1907) und Jonson (1909). Es wäre jedoch verfehlt, daraus den Schluss ziehen zu wollen, dass die Bildung der Hassalschen Körperchen nicht mit regressiven Vorgängen in Beziehung stände. Denn es brauchen die beiden Prozesse, welche bei der Involution des Organs durch Verminderung des Gesamtparenchrms auch zu einer Abnahme der Hassalschen Körperchen und auf der Höhe der Entwicklung durch lokale besondere Einflüsse zur Bildung derselben führen, durchaus nicht gleichartiger Natur zu sein, trotzdem in beiden Fallen ein degenerativer Vorgang mit im Spiele sein kann.

Ehe man nun auf den Vorgang der Entstehung selbst näher eingeht, wird man sich fragen müssen, welche Zellen dabei beteiligt sind, besonders, wenn man sich überzeugt hat, dass zwei verschiedenwertige Gewebe in dem Organ stecken. Es wird nun ziemlich allgemein als feststehend angenommen, dass es grosse blasse sternförmig verästelte Elemente, also Reticulumzellen sind, welche die Grundlage der $\mathrm{Hassalschen} \mathrm{Körperchen} \mathrm{liefern.} \mathrm{Nur}$ über die histologische Natur derselben gehen die Meinungen weit auseinander. Rein morphologisch mit Hilfe tinktorieller Unterschiede lässt sich hier nichts erreichen; trotzdem die Entwicklungsgeschichte lehrt, dass man ein Eindringen mesenchymatösen Reticulums nicht von der Hand weisen darf, lassen sich, wie gezeigt, epitheliale und bindegewebige Reticulumzellen später nicht mehr voneinander unterscheiden. Selbst der Nachweis von Fasern in diesen Zellen hat keinen Unterschied artspezifischer Fibrillen ergeben, die uns ein diagnostisch sicheres Hilfsmittel bieten würden. Man ist also gezwungen, alle Möglichkeiten theoretisch gegeneinander abzuwägen und die bereits ge- 
sammelten Erfahrungen einer strengen Kritik zu unterziehen.

Zunächst ist merkwürdig, dass $\mathrm{H}$ as s a lsche lï̈rperchen nur im Mark rorkommen, dessen Reticulum sicher zum grössten Teil epithelialer Herkunft ist. Es kommen zwar auch in der Rinde sternförmig verästelte Epithelzellen vor, sie liegen daselbst aber weit auseinander gedrängt durch die dichtgehäuften Lymphocyten, so dass sie sich gegenseitig schwer beeintlussen können. Für die Entstehung der $\mathrm{Hassalschen} \mathrm{Körperchen} \mathrm{ist} \mathrm{aber} \mathrm{ein} \mathrm{solches}$ Zusammenarbeiten mehrerer Zellen mindestens wahrscheinlich. Andererseits bleibt zu bedenken, dass die Verteilung des mesenchymatösen Reticulums im Mark niemals eine sehr ausgedehnte sein kann, und wenn es daselbst überhaupt als solches vorhanden ist, auf die Begleitung del Gefüsse beschränkt bleibt. Mit den Gefüssen aber haben die Hassalschen liörperchen nichts zu tun, wovon man sich schon nach obertlächlicher Cntersuchung überzeugen kann, selbst wenn es natürlich vorkommt, dass ein Hassalsches Körperchen einem Gefäss sehr nahe anliegt. Nur wenn man sie also aus epithelialen Zellen ableitet, ist es verständlich, warum sie nur im Mark zu finden sind und diese Anschauung wird noch weiter gerechtfertigt durch die in ihnen auftretenden Differenzierungsprodukte. Dass alle diejenigen Forscher, welche dem Thymusreticulum eine bindegewebige Herkuntt zuschreiben (Watney, Prenant u. a.), eine solche auch für die Hassalschen Körperchen annehmen müssen, ist klar, sofern sie nicht in den Hassalschen Körperchen Reste der alten epithelialen Anlage sehen; nur Dustin nimmt hier eine Sonderstellung ein, indem er sie zwar von grossen verästelten Zellen ableitet, in welchen er aber sekundar in das Organ eingewanderte Bindegewebszellen erblickt. Ebenso sind auch über den Bildungsprozess selbst die Meinungen noch sehr geteilt. Zwar steht jetzt fest, dass es zunichst die Vergrösserung einer oder mehrerer Zellen ist, welche zur Entstehung eines Hassalschen Körperchens führt, allein es ist noch strittig, ob wir das Wesentliche des Vorganges in der Hypertrophie zu suchen haben oder in der sie begleitenden oder ihr folgenden Degeneration. Auch beim Kaninchen liegt die Sache so, dass man zuerst einzelne "hypertrophische" Zellen findet (Fig. 8), die ihren Zusammenhang mit dem syncytialen Verband schon gelöst haben können (Fig. $8 \mathrm{c}$ ), und erst etwas später treten 
durch Anlagerung einer oder mehrerer Zellen jene charakteristischen Bildungen auf, die so bekannt sind, dass sie nicht näher beschrieben zu werden brauchen. Hammar sieht in der von einem Ausgangspunkt ausgehenden Hypertrophie, die "excentrisch um sich greifend successive neue Zellen betrifft", das Wesentliche des Vorganges und betrachtet von diesem Gesichtspunkt aus die konzentrische Lagerung der Zellen als von selundärer Bedeutung. Das letztere ist sicher der Fall; da für die Zellen keine Möglichkeit vorhanden ist, auszuweichen, müssen sie sich erst enger zusammenschliessen und endlich entsprechend dem Druck und Gegendruck inre Form verändern, sei es, dass sie selbst an der Hypertrophie teilnelımen oder nicht. Ich habe schon trüher hervorgehoben, dass kein Grund vorliegt, in der Hypertrophie oder besser Grössenzunahme einzelner Markzellen den morphologischen Ausdruck einer gesteigerten ouer wenigstens nach einer bestimmten Richtung erfolgenden Lebenstätigkeit zu sehen; man kann sie ebensogut als erstes Anzeichen der im Innern der Zelle erfolgenden degenerativen Yorgänge auffassen und hierin den Grund für die Entstehung dieser merkwürdigen Gebilde suchen. Man braucht deshalb noch nicht so weit zu gehen, die im Innern der Hassalschen Körperchen auftretenden Degenerationsprodukte als das Wichtigste bei ihrer Erscheinung und für die Funktion des Organs überhaupt zu sehen, was auch ich für sehr unwahrscheinlich halte. Einen Beweis für meine Ansicht kann ich naturlich ebensowenig erbringen wie Hammar, ich vermag höchstens anzuführen, dass fast niemals alle Zellen der $\mathrm{H}$ as S alschen Körperchen an der Hypertrophie beteiligt sind und dass, sobald das Hassalsche Körperchen eine gewisse Grösse erreicht hat, d. h. sobald eine gewisse Zeit seit seinem Auftreten verflossen ist, immer unzweifelhafter Degenerationserscheinungen im Innern desselben auftreten, welche auch auf Zellen der Peripherie übergreifen können, die keine Anzeichen ron Hypertrophie dargeboten hatten (Fig. 12). Ausserdem liegen schon manche Beobachtungen vor, welche eine Zunahme der Hassalschen Körperchen bei einer allgemeinen Schädigung des Organs anführen (Rega ud und Cremieu 1912, Jolly und Levin 1912, Lucien und Parisot 1908, Ruräh 1903). Selbstverständlich kann ich mich auf Grund dieser Ansicht auch nicht zu der Anschauung jener Autoren bekennen, welche in den fraglichen Bildungen den Ausdruck der sekretorischen Tätigkeit der 
Drüse sehen. Über die Faktoren, welche zur Bildung der Hassalschen Körperchen führen, sind wir so wenig unterrichtet, wie über diejenigen, welche die Trennung von Mark und Rinde überhaupt veranlassen. Hier könnten vielleicht systematische vergleichende und experimentelle Untersuchungen eher Aufschluss bringen als das Studium ihrer Entstehung. Soweit sich die Verhältnisse bis jetzt übersehen lassen, erscheint es mir, als ob es sich dabei gar nicht um zwei verschiedene Prozesse handeln würde, sondern als ob die $\mathrm{H}$ assalschen Körperchen lediglich einer "intensiveren Markbildung “, wenn man so sagen darf, ihre Entstehung verdankten. Dass sie mit dem übrigen Markretikulum in kontinuierlichem Zusammenhang bleiben, lïsst sich auch für das Kaninchen leicht feststellen.

Was die Hassalschen Körperchen so besonders auffallend macht, und sie in gewisser Beziehung auch wieder vom übrigen Markretikulum scheidet, sind die in ihnen auftretenden Differenzierungen. Sie lassen sich in zwei Gruppen trennen: Einmal solche, welche normalerweise in jedem geschichteten Plattenepithel vorkommen können und dann solche, welche ausschliesslich degenerativer Natur sind. $\mathrm{Zu}$ den letzteren rechne ich vor allem Chromatinschollen verschiedener Form und Grösse, die aus den zugrundegehenden Zellkernen stammen und häufig auch verschiedene Farbreaktion geben (vgl. Fig. 8). Fett und fettälınliche Substanzen sollen nach Holmström (1911) beim Kaninchen gerade in den $\mathrm{H}$ ass alschen Körperchen fehlen. Dagegen habe ich ebenso wie Ciaccio in ihnen mit dessen Methode (1909), sowie in den grossen Reticulumzellen des Markes ziemlich reichlich Lipoidkörnchen verschiedener Grösse nachweisen können (Fig. 10).

Was die normalerweise von Epithelzellen gelieferten Produkte anbetrifft, so käme hier zunächst die Bildung von Hornsubstanzen in Betracht, die schon früher von Letulle und Nattan-Larrier (1902) u. a. erwäbnt worden sind. Man findet in der Tat auch beim Kaninchen in nach Pasini gefarbten Schnitten in den Hassalschen Körperchen rote Schollen (Fig. 12), welche man ihrem Aussehen nach als Vorverhornung deuten könnte; doch sind sie niemals sehr ausgedehnt, was wohl damit zusammenhängt, dass die Hassalschen Körperchen des Kaninchens überhaupt selten eine grössere Ausdehnung erreichen. Wenn es sich hier wirklich um Keratinbildung bandelt, so würde dies wiederum für ein $\mathrm{Zu}$ - 
grundegehen der Zellen sprechen, da Verhornung stets den Tod der Zelle nach sich zieht.

Sehr interessant und schwierig zu beurteilen sind die im Hassalschen Körper fast immer auftretenden Fasern, welche das Zentrum meist konzentrisch umspannen. An und für sich hat diese Erscheinung nichts Befremdendes, da wir das Vorkommen von Fibrillen in jedem Plattenepithel kennen. Es ist nur sehr merkwürdig, dass diese Fibrillen die Rekationen kollagener Fasern geben. Dies war wohl auch für manche Autoren (Watney, Prenant, Dustin u. a.) der Grund, sie von Bindegewebszellen abzuleiten. Mit der Methode von Pasini lassen sich in fast allen grösseren $\mathrm{Hass}$ al schen Körperchen sowohl rote als blaue Fibrillen darstellen (Fig. 12), die nicht immer leicht zu unterscheiden sind. Dass es sich tatsächlich um differente Gebilde handelt, lehrt die Lintersuchung mit monochromatischem Licht. Es scheint mir aber doch, als ob Übergänge zwischen ihnen bestünden, gewöhnlich sind die roten feiner und mehr nach immen gelegen, die blauen kiäftigeren mehn gegen die P'eripherie; doch lasst sich hierfür keine Regel aufstellen. Man kann auch nicht sagen, dass die blauen aus den roten hervorgehen, da letztere, als im Zentrum gelegene, doch eher als die alteren anzusprechen sind. Wir stehen hier vor denselben Schwierigkeiten, die sich auch für die Fibrillen des Markretikulums ergeben haben; nur in einer Hinsicht sind Unterschiede festzustellen; es lassen sich nämlich die starken Fibrillen des Hassalschen Körperchens auch nach Bielschowsky, Wo ronin u. a. Methoden imprägnieren, was bei den zarten Fasern des Markretikulums nicht gelingt. Einen gewissen Unterschied darf man demnach wohl annehmen, doch lässt sich natürlich nicht sagen, ob er mehr chemischer oder physikalischer Natur ist.

Es wäre vielleicht noch ein Wort zu sagen über die schon früher erwähnten und in Fig. 19 und 20 abgebildeten kompakten Epithelstränge. Sie finden sich in dieser Art in der fertigen Thymus niemals und haben demnach auch mit der Entstehung der Hassalschen Körperchen nichts zu tun. Offenbar gelingt es den vereinzelt eindringenden Lymphocyten doch allmählich, den netzigen Verband zur Auflösung zu bringen. Sie stehen natürlich auch in keiner Beziehung zu den häufig beschriebenen (vgl. das Ref. Hammars), in der Thymus fast aller Tiere vorkommenden irregulären Zellverbänden, die nach $\mathrm{Hammar}$ durch sekundäre 
Aneinanderlagelung der verzweigten Epithelzellen zustande kommen sollen, wobei dann meist auch die Zellvergrösserung eine Rolle spielt. Es ist leicht einzusehen, dass derartige Verbande niemals das Aussehen eines geschichteten Plattenepithels zeigen werden und dass sich andererseits alle Übergänge ron ihnen zu den Hassalschen Körperchen finden lassen müssen. Ich habe solche Komplexe auch beim Kaninchen gesehen, nur sind sie hier nicht sehr ausgedehnt, wie ja auch die Hassalschen Körperchen nur selten grössere Dimensionen annelimen.

Auf einen Punkt, der vielfach Beachtung gefunden hat, bin ich bisher noch nicht eingegangen, nümlich auf das Vorkommen von granulierten Leukocyten und leukocytoiden Zellen in den $\mathrm{H}$ as $\mathrm{Sa}$ lschen Körperchen. Stellen sie hier mehr einen zufälligen Befund dar, oder sind engere physiologische Beziehungen zwischen ihnen und dem Epithel anzunelimen? Hielauf lüsst sich eine bestimmte Antwort nicht geben. Es kommen auch beim Kaninchen in jeder Thymus spezialgranulierte und eosinophile Zellen ror, zuweilen in sehr grosser Zahl; da ist es natürlich nicht zu verwundern, wenn sie auch zwischen den sich zusammenschliessenden epithelialen Retikulumzellen der Marksubstanz gefunden werden und hier wie diese, nur meist etwas langsamer. der Degeneration anheimfallen. Freilich, ob es sich dabei nur um eine Folge handelt oder um eine Ursache für weitere Prozesse, bleibt der Beobachtung vorläufig entzogen. Es liegt hielin aber noch ein weiterer Anklang an die enge genetische Zugehörigkeit der Thymus zu der Mundhöhle und zum Darmkanal im allgemeinen, die bei ihren übrigen Derivaten (Thyreoidea, Epithelkörperchen etc.) in ausgewachsenem Zustande gar nicht mehr manifestant wird (vgl. Mollier 1913).

Selbstverständlich werden anch grössere und kleinere Lymphocytenformen mit in die Hassalschen Körperchen eingeschlossen und degenerieren hier ebenfalls meist unter dem Bilde der Pyknose mit oder ohne Kernzerfall. Das Protoplasma ändert seinen Färbecharakter; es verliert allmählich die Basophilie, wird mehr bomogen und löst sich schliesslich auf. Zerfall unter Valiuolenbildung konnte ich gerade hier nicht beobachten.

Auffallend ist, dass man in den $\mathrm{Hassalschen} \mathrm{Körperchen}$ granulierte Zellen eigentlich häufiger findet als ungranulierte, wo doch gerade das Umgekehrte zu erwarten wäre. Ich vermag 
hierfür keine Erklärung zu geben; denn dass mononucleäre lymphocytoide "primitive" Formen gleichsam im letzten Moment noch Granula auszuarbeiten beginnen, ist eine Hypothese, die sich durch nichts begründen lässt. Dagegen spricht schon das Verhalten des Kernes, der in ihnen fast immer polymorph, d. h. gelappt erscheint. Man könnte sich höchstens denken, dass das Epithel vielleicht gerade durch das Auftreten von Zerfallsproduliten eine besondere Anlockung auf die Granulocyten ausübt; doch birgt diese Erklärung in sich einen Widerspruch, der sich gegen die Genese selbst richtet. Vielleicht hängt das relativ seltenere Vorkommen von Lymphocyten in den Hassalschen Körperchen nur mit der Kleinheit der letzteren beim Kaninchen zusammen. Am besten ist es, auch hier einfach den Befund zu notieren und die Erklärung der Zukunft zu überlassen.

\section{Die Thymus als Lymphocyten lieferndes Organ und ihre Stellung unter den übrigen blutbildenden Organen.}

Sobald man zu der Überzeugung gelangt ist, dass die Thymus neben der von Anfang an vorhandenen epithelialen Komponente noch als zweiten ebenso wichtigen Bestandteil echtes lymphoides, d. h. Lymphocyten lieferndes Material enthält, so wird man diesen Gedanken und die sich daraus ergebenden Konsequenzen auch rechtfertigen müssen. Dabei ist es vielleicht von einigem Interesse, in aller Kürze auf die morphologische, genetische und histogenetische Stellung der weissen Blutzellen, soweit sie für die Thymus in Betracht kommen, einzugehen, namentlich bei der Wichtigkeit, welche diese Fragen heutzutage gewonnen haben. Selbstverständlich gehört es nicht in den Rahmen dieser Arbeit, eine erschöpfiende Übersicht zu geben auch nur über die wichtigsten strittigen Punkte der modernen Hämatologie; ich setze diese als bekannt voraus; man kann sich darüber auch leicht aus den einschlägigen grösseren Referaten orientieren.

Es müsste vor allem möglich sein, den Begriff der lymphoiden Zelle festzulegen. Das ist aber jetzt und voraussichtlich auch in allernächster Zeit nicht erreichbar. Man kann hierüber nicht im Zweifel sein, dass zur Zeit noch die Möglichkeit für so ganz verschiedene Auffassungen gegeben ist, wie sie in der Lehre der völlig arteinheitlichen Zelle mit allerdings sehr verschiedener 
ausserer Form und in der Lehre vom grossen Stamm der lymphoiden Zellen, der wohl von einer Stammutterzelle ausgeht, aber in artverschiedenen Endgruppen sich differenziert und endlich in der Auffassung von Anfang an getrennter selbständiger Zellgruppen zum Ausdruck kommt.

Die Möglichkeit so grundverschiedener Vorstellungen kann nur in dem Mangel an verschiedenen Erkenuungsmerkmalen liegen. Diese sind auf physiologisch-biologischem Gebiet noch so völlig unzulänglich, dass ein Versuch, die lymphoiden Zellen zu charakterisieren, kaum gemacht werden kann.

Wir möchten hier davor warnen, die spärlichen bisherigen Beobachtungen über Vital- und Supravitalfärbung, die Reaktion auf Oxydase, Lipase, Protrolyse etc. schon jetzt dazu zu verwenden. Das kann erst nach viel ausgedebnteren Versuchen auf viel breiterer Basis versucht werden.

So bleibt nur die morphologische Beobachtung übrig, welche uns aber mit einem so ungemein wechselnden Bild der lymphoiden Zellen bekannt gemacht hat, ohne die Beziehungen dieser vielen verschiedenen Zellformen bündig feststellen zu können, dass wir entschieden Gefahr laufen, sehr verschiedenwertige Elemente unter einem Namen zu vereinigen. Ich vertrete hier eine Ansicht Molliers, die er früher bereits selbst geäussert hat: „Ich halte die wichtige Frage, ob es unter jenen vielen Zellformen, die wir als Lymphocyten (grosse und kleine) bezeichnen könnten, eine stabilere Form gibt, oder ob sie alle indifferente Elemente sind, denen nach jeder Richtung die Entwicklung offen steht, noch für unentschieden." Wăhrend Pappenheim bereits eine Spezialisierung dieser Zellen anbahnt und dies auch in der Nomenklatur zum Ausdruck zu bringen versucht, verstehen Maximow und Weidenreich unter Lymphocyten alle jene Formen, welche in der Lymphe und in der Gewebstlüssigkeit überhaupt frei vorkommen und durch kein besonderes Merkmal gekennzeichnet sind. Dagegen wäre an und für sich nichts einzuwenden, wenn sie damit nur sagen würden, dass in der Lymphe Zellen vorhanden sind. Wir sind aber gewohnt, mit einem Namen auch einen bestimmten Begriff zu verbinden; so ist es natürlich, dass mit der Erkenntnis einer feineren Differenzierung anch unsere begrifflichen Vorstellungen von den freien Zellen in der Gewebsflüssigkeit sich andern und spezialisieren mussten, während der 
Name sich unverändert erhalten hat, so dass wir jetzt in der unangenehmen Lage sind, mit einer einzigen Bezeichnung keine einheitliche Vorstellung zu verbinden.

Wir müssen sagen, dass wir der Lehre von der Artgleichheit des so sehr polymorphen Lymphocytenstammes schon deshalb zurzeit nicht gerne beitreten würden, weil sie eine Vereinfachung der Betrachtungsweise anstrebt, die zu einer gewissen Befriedigung führt und damit rom Problem ablenkt, während sie doch noch nicht genügend gesichert erscheint.

Es wäre vielleicht das Richtigste, den Namen Lymphocyt so lange ganz frei zu geben, bis er in allgemein erkanntem bestimmtem Sinne gebraucht werden kann.

Wenn ich nun hier die frei gewordenen Mesenchymzellen in der Umgebung der Thymus trotzdem als lymphoide Elemente bezeichne, obwohl ich aus ihnen allein für die weitere Entwicklung nichts herauslesen kann, so war ich dazu gezwungen, um mich bei den jetzt herrschenden ohnehin schon sehr wenig präzisen Vorstellungen über die Lymphocyten nicht völlig unverständlich $\mathrm{zu}$ machen. Die Entwicklung des Thymusmesenchyms führt ja schliesslich zu jenen Formen, die morphologisch den ursprünglich als Lymphocyten bezeichneten Zellen gleich sind. Die funktionelle Gleichheit bleibt eine andere Frage, die vorerst nicht zu entscheiden ist. Ich möchte aber nochmals betonen, dass die von mir zunïchst als lymphoide Zelle beschriebene Form nichts weiter ist als eine völlig indifferente embryonale Zelle, frei in der GewebsHüssigkeit gelegen, deren rundlicher Kern mit feiner Chromatinstruktur und ein bis zwei Nukleolen von einem relativ breiten, schaumig wabig gebauten, basophilen Protoplasmamantel umgeben ist (Fig. 24).

Diese Form deckt sich morphologisch mit der von Mollier (1909) beschriebenen Hämogonie, der ruhenden Wanderzelle Maximows, dem Lymphoidocyten Pappenheims (grosser Lymphocyt, Hamatogonie), dem grossen Lymphocyten Weidenreichs und dem Lymphoblasten der Dualisten. Auch histogenetisch hat sie mit allen eben genannten Zellen dasjenige gemeinsam, dass sie eine sogenannte indifferente Form darstellt, sie ist mit keinem besonderen Merkmal ausgestattet, das die Entwicklungsrichtung, welche die Zelle einschlägt, kennzeichnen würde. Damit können wir wohl als wahrscheinlich annehmen. 
dass noch alle Differenzierungsmöglichkeiten latent in ihr vorhanden sind, aber absolut beweisen lässt sich dies selbstverständlich nicht. Mollier betont 1911 ausdrücklich, dass seine Hämogonie nicht als solche als Stammzelle der Erythrocyten erkenubar ist, sondern dies erst am Ort der Entstehung wird; sie vermag also an anderer Stelle oder unter anderen Bedingungen ebensowohl kleine Lymphocyten und Granulocyten zu liefern wie andere aus den definitiven Stützgeweben bekannte Formell. Mollier hat deshalb ganz neuerdings (1913) denselben Namen auch auf die grossen Keimzentrumszellen des lymphoiden Gewebes in der Tonsille übertragen. Auch Pappenheim, der sich sonst den extremen Unitariern Maximow und Weidenreich nicht anschliesst, hebt gegen die Dualisten hervor, dass der „lymphoide Plasmazustand" kein eigentlich spezifisches Artmerkmal sei, auch nicht Unreife schlechtweg bedeute, sondern nur die Fühigkeit zu weiterer Differenzierung anzeige. Nach der Ansicht Molliers ist aber die Vorstellung von der Reife oder Cureife einer /elle eine gan\% willkürlich von den Hämatologen auf die weissen Blutzellen übertragene; da wir ja diese Zellen jeweilig immer nur auf einer einzigen Entwicklungsstufe fassen können, niemals aber den Verlauf ihrer Evolution verfolgen; wir lassen also den Begriff der Reife fallen. Dasselbe gilt für das Alter der Zelle. Eine Ausnahme hiervon macht die Reihe der Erythrocyten, wenigstens von einem bestimmten Stadium ab, alleil gerade sie kommt für die T'hymus nicht weiter in Betracht.

Die unmittelbare Beobachtung lelurt, dass diese indifferenten Zellen durch Einziehung ihrer Fortsätze und Verdichtung ihres Protoplasmas direkt aus dem Mesenchym entstehen (Mollier, Waximow, Dantschakoff, Weidenreich und bis zu einem gewissen Grade auch Pappenheim), und zwar gilt dies nicht nur für die früheste Embryonalperiode, sondern für die ganze Dauer des postfötalen Lebens, wenn natürlich auch mit Abnahme der Gesamtleistungsfähigkeit dieser Prozess herabgesetzt wird. Hierin liegt auch der Gegensatz gegen die Anschauung der Dualisten (Nägeli, Schridde, Helly u. a.), sowie der amerikanischen Schule, die in letzter Linie ja auch eine gemeinsame Stammzelle für alle Blutelemente annehmen müssen (Min ots Mesamöboide); sie stammt aber ausschliesslich von den Zellen des Dotterangioblastes, die sich dann bei der Teilung in bestimmte Stämme spezialisieren. 
Dieser auf den ersten Blick sehr plausibel scheinenden Theorie haften aber zwei Mängel an; entweder muss man annehmen, dass jede erste 'leilung sofort zur Differenzierung führt, dann wären die Angioblastzellen sehr bald verbraucht und überhaupt kein primitives Ersatzmaterial mehr vorhanden, dagegen sprechen die Befunde der obengenannten Autoren, wie der klinischen Erfahrung; oder aber es vermehren sich diese primitiven Elemente eine Zeitlang als solche, dann können sie aber später von anderen ahnlichen Formen nicht mehr getrennt werden, es fehlt also der Beweis für ihre Identitat und die Theorie wird zur Hypothese.

Die Faktoren selbst, welche zur Loslösung einzelner Zellen aus dem syncytialen mesenchymatösen Verband fübren, sind uns völlig unbekannt; von einem hämoblastischen Reiz kann man hier in der Umgebung der Thymus sicherlich nicht sprechen.

Die eben freigewordenen Zellen sind ihrem Aussehen nach sehr polymorph (Fig. 24); dies könnte dazu verleiten, im Sinne Pappenheims in ihnen keine "arteinheitlichen", sondern nur "artverwandte" Zellen zu sehen. Solchen Anschauungen gegenüber vertritt Mollier den Standpunkt, dass es sehr gefährlich ist, sich durch geringfïgige morphologische Unterschiede, über deren Bedeutung man sich nicht im klaren sein kann, verleiten $\mathrm{zu}$ lassen, bestimmte funktionelle und genetische Beziehungen anztunehmen, die beeinflusst durch die vorgefasste Meinung immer nur hypothetischen Charakter haben werden. Man kann sich seiner Ansicht nach nicht energisch genug klar machen, dass wir über die Funktionen der weissen Blutzellen ganz ungenügend unterrichtet sind und dass die Morphologie allein uns hierfür einen Anhaltspunkt nicht geben kann und die Embryologie nur bis zu einem gewissen Grade. Hier fehlen aber noch die einschlägigen Untersuchungen.

Gerade an der Histiogenese der Thymus lasst sich dies in sehr schöner und klarer, aber auch wenig erfreulicher Weise zeigen.

Die indifferenten Iymphoiden Zellen wandern also in das epitheliale Thymusreticulum ein, bringen dasselbe za weiterer Auflösung und fallen zunächst einer lebhaften Proliferation anheim, nachdem sie vorher alle annähernd gleiche Form angenommen hatten. Aus dieser regen Vermehrung resultiert eine Unsumme 
kleiner, dunkelkerniger, schmalleibiger, basophiler Elemente, welche schliesslich die Hauptmasse des fertigen Thymusparenchyms ausmachen und die morphologisch sich von den kleinen Lymphocyten der Lymphdrüsen und des übrigen lymphadenoiden Gewebes nicht unterscheiden lassen. Da sie auch dieselbe Genese zeigen wie letztere, ist kein Grund vorhanden, ihnen diese Bezeichnung zu verweigern.

Daneben finden sich alsbald nach Beginn del Einwanderung noch jene grossen oben beschriebenen Formen (Fig. 15d, e, f). Entstehen dieselben durch Vermehrung oder wachsen sie einfach aus den primitiven Formen heraus? Ich bin geneigt, das letztere anzunehmen, trotzdem gelegentlich vorkommende Hitosen auch auf selbstandige Vermehrung hindeuten; diese Zellen unterscheiden sich von den primitiven Formen lediglich durch die Grösse des Kernes und die starke Vakuolisierung des Protoplasmas. Sie kommen auch in den Lymphdrüsen des Kaninchens vor, und hier lïsst sich auch die direkte Entstehung aus dem Mesenchym beobachten.

Ganz ahnliche Zellen hat Wallgren im strömenden Blute des Kaninchens beschrieben; er erinnert an ihre Ähnlichkeit mit den „blasigen Polyblasten“ Maximows, die ich zugebe; nur kann ich die Anordnung der Vakuolen an der Peripherie nicht so regelmässig finden. Die Beobachtung, dass diese Zellen bei hungernden Tieren sich vermehrt finden, kann ich für die Thymus wenigstens nicht allgemein bestütigen.

Ich halte sie also lediglich für eine Variante der Hämogonie Molliers, die nicht einmal für die Thymus, wo man doch lokale Einflüsse geltend machen könnte, spezifisch ist. Wie spïter noch zu erörtern sein wird, sind diese Zellen in ihrer Erscheinung äusserst variable Elemente.

Nach Weidenreich sind die kleinen Lymphocyten (im Sinne Ehrlichs) nichts als der „Ausdruck einer besonders lebhaften Artproduktion, die zur Verkleinerung der Zelle, zur Verdichtung des Kernes und zur Abnahme des Plasmaleibes führt". Die zablreichen in ihnen vorkommenden karyokinetischen Figuren scheinen dies für die Thymus $\mathrm{zu}$ bestatigen. Weidenreich lässt sie dann wieder zu grösseren Formen heranwachsen, und auch Maximow vertritt diese Anschauung. Nachdem sie eine Zeitlang im "Kleinlymphocyten- 
stadium" verharrt sind, fangen sie wieder an sich zu vergrössern und bilden den Ausgangspunkt für neue anderswertige Elemente.

Diesen Standpunkt kann ich nicht teilen. Nan findet in der Thymus namentlich im fertigen Organ alle nur denkbaren Formen zwischen den grossen lymphoiden Zellen und den kleinen Lymphocyten. Dass die kleinen aus den grossen hervorgehen, ist klar, da ja anfangs nur grössere Formen vorluanden waren, ebenso geht aus der weiteren Entwicklung hervor, dass diese Umwandlung nur sehr allmühlich geschieht. Man dart sie aber auch nicht so auffassen, als ob jedesmal dieselbe Zelle den einmal vorgezeichneten Weg einschlüge und ihn bis zum Ende rerfolge, sondern die Differenzierung erfolgt gradatim auf dem Wege häutiger Zellteilungen und selbst die kleinen Lymphocyten haben sich das Vermögen selbständiger Teilung in hohem Maße bewahrt, wovon man sich an jeder Thymus leicht überzeugen kann. Wir hätten es hier demnach mit einem "Keimzellmeristemgewebe" im Sinne von Pappenheim und Ferrata $z u$ tun; jedoch nimmt Pappenheim an, dass es sich dabei nicht um einen reversiblen Prozess handelt, die Stammformen werden dabei verbraucht und die aus ibnen hervorgegangenen Tochtergenerationen vermögen weder $\mathrm{zu}$ einer primitiven Form zurïckzukehren, noch auf einer niedrigeren Stufe stehen zu bleiben; daher ist er auch gezwungen, komplizierte Stammbäume mit verschiedenen Alterstormen für jede einzelne Zellform anzunehmen.

Für eine derartige theoretische Anseilauung lisst sich aber ein Beweis weder aus den Lymphdrïsen noch aus der 'Tlymus erbringen. Wenngleich in der fertigen 'Tlymus die kleinen Lymphocyten an Zahl überwiegen, sind doch die mittelgrossen und grossen Formen noch so reichlich vorhanden, dass selbst ein ganz allmählicher Verbrauch derselben damit nicht in Einklang $z u$ bringen wäre. Oder der Nachschub an indifferentem Material (entweder aus dem Mesenchym oder durch Vermehrung der Hämogonien) müsste ganz aussergewöhnlich kiäftig sein, was sich durch die Beobachtung an der normalen Thymus nicht bestätigen lässt. Oder aber man muss mit $\mathrm{Vaximow}$ und Weidenreich annehmen, dass die kleinen Formen wiedel heranwachsen. Dies ist möglich, lässt sich aber nicht beweisen.

Damit soll natürlich eine weitere Entwicklungsmöglichkeit für die kleinen Lymphocyten nicht geleugnet werden; aber es 
ist unmöglich, den Zwischenformen anzusehen, nach welcher Seite hin sie sich weiter entwickelt hätten. Einen morphologischen Beweis dafür, dass sie wieder heranwachsen, gibt es in der Thymus jedenfalls nicht. Wenn lymphoides Zellmaterial aus der Thymus ausgeführt wird, so geschieht dies in Form kleiner Lymphocyten. Dies berechtigt zu der Annahme, dass die Produktion kleiner Lymphocyten in der typischen Form wenigstens mit in den Wirkungskreis der Thymus einbezogen werden darf; gerade deswegen rechnet Maximow auch die Thymus zu den blutbildenden Organen. Aber es muss natürlich auch stets die Möglichkeit zugegeben werden, dass die 'l'hymuslymphocyten durch das eigenartige Milieu, in dem sie sich entwickelı, iı gewissem Sinne beeinflusst werden und dass dieser Einfluss sich auch nocl ausserhalb der Thymus bei ihnen geltend maclien kann. Es ist überhaupt sehr zu bezweifeln, ob der biologisclie Wert aller Lymphocyten auf dieselbe Grössc zurïckgeführt werden kann. Der Beweis hierfür ist wiederum niclıt au erbringen, doch glaube ich, dass Weill und Weidenreich recht haben, wenn sie daror warnen, die Thymus als Lymphdrüse aufzufassen.

Die chemischen Unterschiede, die Bang gegenüber den Lymphdrüsen-Lymphocyten gefunden hat, liessen sich vielleicht dadurch erklären, ebenso die verschiedenen Resultate von Ritclies Komplementablenkungsversuchen.

Wir rechnen mit einer bestimmten Konstanz der organischen Form und wir dürfen dies selbstverständlich auch, da ohne dieselbe eine morphologische Wissenschaft nicht denkbar würe. Gerade der Wechsel in der Erscheinung ist uns ein Ausdruck für die Vorgänge innerhalb der Materie und die regelmässige Wiederkehr derselben Erscheinungsform erlaubt uns mit einem gewissen Recht auf Beziehungen zwischen Form und Funktion zu schliessen. Dennoch darf die Konstanz der organischen Form nicht als ein gegebener absolut starrer Faktor betrachtet werden, um so mehr, als wir noch weit entfernt davon sind, die feinsten, die Form einer Zelle bedingenden Strukturen zu kennen, sondern uns an relativ grobe Merkmale (Granula, Faden, Vakuolen etc.) halten müssen. Diese brauchen aber unter Umständen gar nicht etwas für die Zelle Spezifisches zu bedeuten, sondern können einem momentan durch äussere Faktoren bedingten Zustand ebenso gut entsprechen, als der in der Struktur der Zelle 
durch ihre besondere Funktion begründeten Erscheinungsmannigfaltigkeit.

Wenn ich nun aus dem oben Gesagten heraus die Stellung der kleinen dunkelkernigen, schmalleibigen Lymphocyten charakterisieren soll, so möchte ich mich in erster Linie der Anschauung Molliers anschliessen, dass man nämlich in diesen Zellen weder Elemente erblicken darf, die alle bereits ein Endstadium erreicht Laben, also mit einer bestimmten Funktion verknüpft sind (D ualisten und vielleicht auch Pappenheim), noch aber solche, die ausschliesslich Stammformen neuer, besonders gekennzeichneter Arten darstellen (Weidenreich, Maximow). Hierzu fehlen vorerst noch die Möglichkeiten der Identifizierung. Sie sind eben lediglich eine Erscheinungsform der weissen Blutzellen überhaupt, wahrscheinlich in bestimmter funktioneller Abhängigkeit $\mathrm{zu}$ den Geschehnissen im Organismus stehend, aber ohne morphologische Nachweisbarkeit dafür. Erst wenn eine Erkenntnis ihrer Funktion möglich wird, werden sie vielleicht aufhören, eine Erscheinungsform zu sein und $z u$ einer bestimmten Zellart werden.

Aus den bereits vorliegenden Beobachtungen (Mollier in der Tonsille, ebenso Spuler, Maximow bei der Entzündung u. a.) geht hervor, dass ihre Rolle eine sehr vielseitige sein kann und dass gleichzeitig auch ihre Form grossen Variationen unterworfen ist. Dass sie darnach wieder zu ihrer alten Gestalt zurückkehren können, ist wohl denkbar, aber nicht zu beweisen, da dies unserer Beobachtung entzogen bleiben muss.

Die Frage, ob die in der Thymus aus den Hämogonien hervorgehenden Zellen alle zu kleinen Lymphocyten werden und ob sie dann dauernd oder nur vorübergehend sich in dieser Erscheinungsform darstellen, muss also noch weiter offen bleiben.

Vergleicht man Lymphdrüsen junger Kaninchen (zirka 4 bis 6 Wochen) mit der zugehörigen Thymus, so sind die Bilder denn doch nicht gleichartig, von dem Reticulum in den beiden Organen ganz abgesehen. In der Thymus ist der Reichtum der Formen, die zwischen der grossen. indifferenten lymphoiden Zelle, der freigewordenen Reticulumzelle, und dem typischen kleinen Lymphocyten liegen, noch weit grösser als in der Lymphdrüse und zwar betrifft dies nicht nur die Grösse, Form und Struktur des Kernes, sondern ebenso die Menge, den Bau, die Gestalt 
und die tinktoriellen Unterschiede des Protoplasmas, ohne dass sich jedoch scharf konturierte greifbare Reihen aufstellen liessen. Die Übergänge sind so subtil, dass sich spezifische Artcharaktere nicht fassen lassen, ein neuer Beweis dafür, wie wenig Wert auf Grösse und Zahl der Nukleolen, Dicke und Feinheit der Kernmembran und der Chromatinfäden, ihre Verteilung (Radstruktur), Vakuolen und dergleichen gelegt werden darf (Pappen heim, Nägeli, Schridde u. a.) bei der Beurteilung der verschiedenen Arten von Blutzellen. Zudem darf nicht vergessen werden, dass man Thymuszellen eigentlich nur an Schnittprüparaten studieren kann.

Es wäre vielleicht noch zu bemerken, dass die ganz grossen basophilen lymphoiden Zellen in Lymphdrüsen sehr viel seltener zu finden sind und dass ibre Zahl auch in der Thymus sehr grossen individuellen Schwankungen unterworfen ist.

Die Empfindlichkeit der Thymus für Röntgenstrahlen und Einflüsse, welche die Ernährung treffen, ist bekannt. Wie aus den Untersuchungen von Rudberg, Regaud, Jonson, Jolly und anderen hervorgeht, und ich aus gelegentlichen eigenen Beobachtungen bestiltigen kann. sind es auch hier die kleinen Lymphocyten, welche zuerst unterliegen und so eine Verminderung der Rindensubstanz vortänschen; ich glaube, dass es sich zunächst nur um eine Hinausscaiebung und Verwischung der MarkRindengrenze handelt und erst bei andauernder schädigender Wirkung um eine Herabsetzung des Cesamtparenchyms. Die grossen lymphoiden Zellen widerstehen viel länger. Sobald man dem Organ nur kurze Zeit zur Erholung und Restitution gönnt (vorausgesetzt selbstvel'ständlich, dass der angerichtete Schaden ein gewisses $M a ß$ nicht überstieg), zeigt sich die Thymus ganz erfüllt von grossen basophilen Zellen (Fïg. 25), von welchen sich viele in Teilung befinden. Sie tragen also durch ihre Vermehrung sehr wesentlich zur Regeneration der lymphoiden Thymuskomponente bei. Leider lassen sich auch aus den erwähnten Experimenten keine Schlüsse ziehen für die Bedeutung der Lymphocyten im Organismus, die dann wiederum eine klare Erkenntnis ihrer Stellung unter den verschiedenen Elementen des strömenden Blutes ermöglichten. Die Folgerung Levins, dass die Lymphocyten vielleicht ein stickstoffhaltiges Reservematerial wegen ihres Reichtums an Nukleoalbuminen darstellen, ist doch etwas problematisch und entbehrt jeder Grundlage. 
Der früher vielfach gemachte Einwand, dass echte Lymphocyten nur aus den Keimzentrumszellen der Lymphdrüsen-Follikel entstehen könnten, ist nun ebenfalls hinfällig geworden, seitdem Weidenreich und Downey nachgewiesen haben, dass ,Keimzentrumszellen“, d. h. die grossen Stammformen der Lymphocyten, auch ausserhalb der Follikel vorkommen. Auch Nollier hat gezeigt, dass bei der Geburt und im embryonalen Leben im lymphoiden Gewebe der 'Tonsille die Follikelbildung fehlt und dass dieser Umstand noch nicht als Beweis für eine rerminderte Lymphocytenproduktion angesehen zu werden braucht. Es ist ja eigentlich leicht ersichtlich, dass es in der 'Thymus schon aus rein topographischen Verhältnissen, die sich aus der Entwicklung ergeben haben, nicht zur Follikelbildung kommen kann, selbst im postfötalen Leben und trotzdem müssen wir die Thymus als ein Organ ansehen, das neben seinen anderen Funlitionen auch Lymphocyten zu liefern vermag; dass sie also nicht nur an Ort und Stelle bleiben, um mit dem Epithel in Symbiose zu leben. Interessant und hier zu verwerten ware vielleicht eine Beobachtung Lindbergs, dass nämlich der Höhepunkt der Furve, welche die Mengenverhältnisse der weissen Blutkörperchen im strömenden Blute des Kaninchens angibt, zeitlich ganz nahe zusammenfällt mit dem Gipfel der Gewichtskurve des Thymusparenchyms (Thymus vierter Monat; weisse Blutzellen, speziell Lymphoçten fünftel Monat).

Wie sich die grösseren Lymphocytenformen zur Ausfuhr verhalten, vermag ich nicht mit Sicherheit anzugeben. Nan findet sie wohl gelegentlich in den perivaskulären Lymphräumen, doch nur relativ selten, während diese meist mit kleinen Lymphocyten dicht erfüllt sind. Als Hauptausfuhrweg dieneı also die Lymphbahnen. Die Gefässe, wenn sie überhaupt hierfür in Betracht kommen, sind jedenfalls nur wenig beteiligt; eine auffallende Vermehrung der weissen Blutzellen in den ausfülurenden Venen konnte ich wenigstens nicht feststellen. Viel eher noch wäre das umgebende Bindegewebe zu beachten. Hier ergibt sich jedoch eine grosse Schwierigkeit, die vorerst nicht zu beseitigen sein wird. Es ist bekannt, dass das perithymische Bindegewebe stets reichlich mit freien Zellen aller Art infiltriert ist; nur kann man es denselben leider nicht ansehen, ob sie sich auf dem Wege zur Thymus hin oder davon fort bewegen. Letzteres lasst sich jedenfalls nicht 
völlig ausschliessen, denn an kleinen Stellen in der Tiefe der Septen steht das Mark auch in der reifen Thymus noch in offener Verbindung mit dem lockeren Bindegewebe, und auch die die einzelnen Lappchen umgebende Kapsel ist so dünn und zart, dass sie als Hindernis für eine Auswanderung nicht in Betracht kommen kann.

Als Lymphocyten lieferndes Organ wäre die 'Thymus demnach unter die blutbildenden Organe zu rechnen; nun sind aber neuerdings auch Stimmen laut geworden, die ibr auch einen Anteil zuerkennen an der Bildung von Granulocyten (Weill, Weidenreich, Maximow und Regaud) und selbst von Erythrocyten (Schaffer, Retterer und Lelievre). Allerdings werden hiergegen von dualistischer Seite Einwände erhoben. Was die Erythropoese anbetrifft, so konnte ich niemals weder in der embryonalen noch in der fertigen Thymus Anzeichen einer solchen entdecken, was auch bereits von Maximow und anderen hervorgehoben worden ist.

Anders liegt die Sache für die granulierten Leukocyten. Wie in der Thymus fast aller untersuchten Saugetiere, so findet man auch in der des Kaninchens stets Granulocyten in mehr oder weniger grosser Zahl. Die kardinale Frage, die sich daraus ergibt, ist die, ob diese Zellen von aussen eingeschwemmt wurden, also für das Organ fremde Elemente sind oder ob sie in loco aus ungranulierten Formen entstehen und aus welchen. Könnte der Nachweis erbracht werden, dass ihre Mutterzellen in den kleinen Thymuslymphocyten zu suchen sind, so dürfte die Anschauung der Dualisten ( $\mathrm{Nag}$ geli, Schridde, Helly, Ziegler u. a.) endgültig als erledigt gelten. Es ist mir aber nicht gelungen, diesen Nachweis zu erbringen. Ich möchte auf Grund der mir vorliegenden Präparate nicht absolut zu behaupten wagen, dass sie immer an Ort und Stelle aus ungranulierten Vorstufen entstehen, eben wegen der ausserordentlich variablen Verbältnisse, die sie zeigen. Nur soviel steht fest, dass es in der embryonalen Thymus beim Kaninchen wenigstens eine Granulapoese im Sinne der Knochenmarkblutbildung nicht gibt. Erst unmittelbar vor der Geburt und in vielen Fällen erst später lassen sich Granula in einzelnen Zellen nachweisen.

Am einfachsten liegen die. Dinge noch für die eosinophilen Zellen, die in ihren Körnchen ein gutes Charakteristikum besitzen. 
Sie sind auch am frühesten beobachtet worden (Schaffer, Scbridde, Hart u. a.). Während aber Schridde und Hart auf dem Standpunkt beharren, dass sie stets von aussen einwandern, treten jetzt die meisten Autoren (M a i mow, Weill, Weidenreich) für die Entstehung in loco ein. Es ist allerdings wahr, dass das Vorkommen von rundkernigen, eosinophilen Zellen (sogenannten eosinophilen Myelocyten) den Gedanken an eine autochthone Entstehung nahelegt, aber bewiesen wird dadurch noch nichts. Allmülulich und anfangs in geringer Zahl in Erscheinung tretende Körnchen lassen sich nicht beobachten. Auch die Weidenreichsche Hypothese von der Entstehung der eosinophilen Granula wird durch die Befunde in der Thymus nicht gestützt. Zerfallende rote Blutkörperchen findet man im normaleı Organ gesunder 'Tiere nur sehr selten; es hat auch $\mathrm{Hammar}$ schon mehrfach darauf hingewiesen, dass bei der Beschreibung hämoglobinführender Elemente vielfach Verwechslungen mit unterlauten sind.

Lässt sich schon für die Entstehung der eosinophilen Zellen kein sicherer Entscheid treffen, so gestaltet sich die Frage nach der Herkunft der übrigen granulierten Elemente noch viel schivieriger und komplizierter, denn ausser den in ihnen vorkommenden Granula haben wir kein Merkmal, die zusammengehörigen Formen zu erkennen und auf einander zu beziehen. Die Körnchen sind aber hier sehr wechselnd in bezug auf ihre Grösse, Form, Zahl, Verteilung, Reaktion und tinktorielles Verhalten, so dass sie weit mehr als etwas Zufulliges, ausserst Labiles imponieren, entsprechend einer momentan fixierten rasch vorübergehenden Funktionsphase des gesamten Organs oder der einzelnen Zelle, denn als etwas Spezitisches, das dauernd festgelegt bleibt, sobald es einmal in Erscheinung getreten ist. Es kann sich also bei ihrer Beschreibung auch nur um eine Registrierung verschiedenartiger Befunde handeln, nicht aber, wenigstens vorläufig noch, um die Aufstellung einer logisch zusammenhängenden Reihe. Mollier hat für die Entwicklung der Erythrocyten in der Leber eine kontinuierliche Serie vou Zellen gegeben, deren einzelne Glieder getrennt herausgegriffen einen sehr verschiedenen Habitus zeigen und vor der Hämoglobineinlagerung durchaus nicht als Vorstufen eines roten Blutkörperchens erkannt werden können. So lassen sich z. B. alle in seiner Fig. 8 (Taf. XXIII) No. 1-S 
abgebildeten Formen auch überall da finden, wo mesenchymatöses retikuläres Gewebe zur Lieferung freier Zellen, Lymphocyten schlechtweg, schreitet, ohne dass es zur Hämoglobinspeicherung d. h. zur Bildung von Erythrocyten zu kommen braucht. Trotzdem ist hier die Aufstellung einer Entwicklungsreihe vollständig gerechtfertigt, da einmal in der Ausarbeitung von Hämoglobin ein charakteristisches und sehr konstantes Kennzeichen gegeben ist und man andererseits am Orte der Entwicklung; wie Mollier selbst sagt, "geleitet durch die erstmalige Reihenfolge der Geschehnisse bei der Histiogenese auch die nicht einseitig charakterisierten basophilen Vorstufen, hier die Hämoblasten und Hämogonien, dem Stammbaume der Erythrocyten einreihen" darf.

Drei Dinge müssen demnach bei der Aufstellung eines Stammbaumes berücksichtigt werden :

1. Es muss ein bestimmtes konstantes Erkennungsmerkmal der Endglieder vorhanden sein;

2. müssen sowohl die indifferenten Vorstufen als auch die spezifisch gekennzeichneten Endglieder alle mit ihren Zwischenstufen nachweisbar am Orte ibrer Entstehung beisammen liegen und fremdes Zellmaterial muss als solches kenntlich und leicht auf seine Ursprungsformen zurückzuführen sein und

3. muss die Reihenfolge der einzelnen Glieder auch dadurch bewiesen werden, dass sie sich eben immer in derselben Weise aufstellen lässt.

Für die Histiogenese der Granulocyten in der Thymus ist keiner der drei oben genannten Faktoren voll und ganz verwirklicht.

Was zunächst das charakteristische Artmerkmal anbetrifft, so habe ich bereits früher auf die grosse Variabilität hingewiesen, welche die Körnchen nicht nur in einem Punkte, sondern in sehr verschiedenen aufweisen. Es sind allerdings beim Kaninchen die Granula der spezialgranulierten Zellen schwer zu beurteilen, indem sie meist eine grössere Affinităt $z u$ der sauren Komponente des Farbstoffgemisches zeigen, mitunter aber auch basischen Charakter haben können. Immerhin bleibt es für die granulierten, nicht eosinophilen Zellen der Thymus merkwürdig, dass man nicht zweierlei Granula in einer Zelle findet (amphophile Körnchen) und dass einmal vorwiegend acidophil granulierte Zellen vorhanden sind und das andere Mal fast ausschliesslich basophil granulierte 
bei gleicher Fixierung und Färbung. Dass natürlich die Fixierung hier auch ron Einfluss sein muss, ist klar.

Die Entstehung der Granula in den Zellen selbst $\mathrm{zu}$ beobachten, ist manchmal unmöglich; in anderen Fällen scheint dies wieder leichter zu sein. Bei den eosinophilen Zellen ist es mir niemals gelungen; hier sind entweder Körnchen vorhanden oder sie fehlen. Bei den acidophilen (pseudoeosinophilen) Körnchen lässt sich insofern noch ein Unterschied feststellen, als sie in einzelnen Zellen in sehr grosser, in anderen in sehr geringer Zabl vorhanden sind, abgesehen von ihrer Grösse, die mit der Zahl nicht immer parellel geht. Am ehesten lässt sich noch für die basophilen Körnchen ein allmähliches Herausdifferenzieren aus dem Protoplasma beobachten und zwar scheint sich der Prozess in folgender Weise abzuspielen: die Knotenpunkte des stark basophilen, sehr locker wabig gebauten protoplasmatischen Netzes verdichten sich und treten schliesslich als schwach gekrümmte, nicht immer scharf konturierte kurze Stabchen in Erscheinung, die sich allmahlich zu immer schärfer hervortretenden Kügelchen abrunden. Gleichzeitig verliert das Protoplasma fast vollstăndig seine Fürbbarkeit. Wo noch ein feines Netz erkennbar ist, sieht man, dass die Granula immer intervakuolär liegen. Die fertigen Körnchen zeigen bei Panchrom- und Kardosfarbung einen Stich ins Bläuliche.

Ein Stückchen derselben Thymus, mit Alkohol fixiert und alkoholischer Thioninlösung auf Mastzellen gefärbt, zeigte, dass keine basophil metachromatischen Elemente vorhanden waren.

Hand in Hand mit der Ausbildung der Granula geht eine Umformung des Kernes unter Verkleinerung des Gesamtvolumens der Zelle. Die grössten Formen zeigen den hellen runden oder eingedellten oder nierenförmigen Kern, der sich unter Verdichtung seines Chromatinnetzes immer mebr abbiegt, bis er die bekannte, mehrfach gelappte Form erreicht. Dies gilt übrigens in gleicher Weise für die acidophil granulierten Zellen und hier kann man auch beobachten, dass die Körnchen der rundkernigen Formen mehr bläulichen Farbton zeigen, während sie in den kleineren polymorphkernigen Elementen glänzend rot sind, wenn auch nicht von so leuchtend roter Farbe, wie die eosinophilen Granula.

Für die eosinophilen Zellen schien es mir auch möglich, zwischen trachychromatischen kleineren und amblychromatischen 
grösseren Formen im Sinne $\mathrm{Pappenheims}$ zu unterscheiden und zwar gilt dies für kompakt- und gelapptkernige Formen; aber scharf waren die Differenzen nicht.

Darf man nun Beziehungen zwischen den eben beschriebenen Formen annehmen oder nicht? Etwas Positives lässt sich kaum sagen; aber jedenfalls möchte ich die basophil gekörnten nicht ohne weiteres als Vorstufen der acidophil gekörnten auffassen, eben weil beide Formen gleichzeitig die gleichen Veründerungen am Kerne zeigen, trotzdem die Entstehung und Ausbildung der Granula und die Verïnderungen am Protoplasma so verschieden sind. Vielleicht ist gerade dies hier ein schönes Beispiel dafür, dass dieselbe Zelle unter verschiedenen äusseren, für uns unkontrollierbaren Bedingungen auch ein scheinbar ganz verändertes Aussehen annehmen kann.

Als Mutterzellen der Thymusgranulocyten (die eosinophilen Zellen ausgenommen) kommen nur die grossen lymphoiden Zellen in Betracht. Der charakteristische Bau ihres Protoplasmas und die eigentümliche Struktur des Kernes lassen sich noch in den bereits gekörnten rundkernigen Formen deutlich erkennen. Es soll aber hier noch hervorgehoben werden, dass die Kernumformung auch in nicht granulierten Elementen auftreten kann, wenngleich sie dann selten sehr weit geht, ohne dass degenerative Erscheinungen hinzutreten. Gelegentlich kann man aber doch auch kleine, sehr polymorphkernige Lymphocyten finden, namentlich in der Nähe der Hassalschen Körperchen. Sie erleiden hier denselben Zerfall, wie ihn Mollier für die ins Epithel eindringenden Lymphocyten in der Tonsille und der Bursa Fabricii beschrieben hat. Dass man sie in der Thymus in seltenen Fällen auch in grösseren Häufchen beisammentindet, zeigt nur wieder, dass die Bedeutung der äusseren, lokalen Einflüsse nicht unterschätzt werden darf.

Nun ergibt sich für die Thymus noch eine besondere Schwierigkeit. Man findet nämlich alle die granulierten Formen nicht nur innerhalb des Parenchyms, sondern auch allenthalben im umgebenden Bindegewebe und bei dem regen Verkehr der Thymus mit ihrer Umgebung lasst sich eine Einwanderung von aussen niemals völlig abschliessen. Zudem kommen die grossen lymphoiden Zellen, ihre Mutterzellen, auch im Bindegewebe vor, von wo sie ja herstammen. Wenn schon sehr vieles für die lokale 
Entstehung der granulierten Zellen in der Thymus selbst spricht, so muss doch in vielen Fällen die Frage der nachträglichen Einwanderung noch offen bleiben und kann daher noch nicht als erledigt gelten.

Für den dritten Punkt, der bei der Aufstellung einer Entwicklungsreihe zu berücksichtigen wäre, dass nämlich die stufenweise erfolgende Entwicklung auch durch die stete Wiederkehr immer derselben Formen bewiesen werden muss, fehlen in der 'Thymus ebenfalls die Belege, wie sich zum Teil schon aus dem Vorangegangenen ergeben hat. Zwar tindet man in derselben Thymus meist annähernd die gleichen Elemente, die sich teilweise auch aufeinander beziehen lassen; sobald man aber die Thymus verschiedener Individuen sogar derselben Tierart untersucht, ergeben sich so grosse Schwankungen, dass man in dieser Hinsicht kaum zwei Organe miteinander vergleichen kann. Nicht nur das Alter und der Ernalurungszustand der Tiere sind hier massgebend. Diese beiden Faktoren können, wie schon längst bekannt ist, ganz grobe, nicht $\mathrm{zu}$ verkennende Unterschiede bedingen. Selbst bei Tieren, welche von demselben Wurf stammend, im gleichen Stall gehalten worden waren, also unter annähernd den gleichen $\mathrm{Be}-$ dingungen ist die Variabilitat sehr gross. Hier ist vielleicht noch die Beobachtung von Interesse, dass auch die Entwicklung des perivaskulären Bindegewebes in der Thymus eine sehr wechselnde ist und es scheint mir, als ob gewisse Beziehungen zwischen der Ausbildung dieses Bindegewebes und der Menge der vorhandenen granulierten Zellen nicht abzuleugnen wärell, in dem Sinne, dass mit der Ausdehnung des Bindegewebes auch die Lieferung von Granulocyten zunimmt. Hier kanı natürlich nur die Untersuchung der Organe einer sehr grossen Menge von Tieren derselben Art sicheren Aufschluss bringen, welche die Ergebnisse der Befunde aus den verschiedenen Lebensaltern und unter den verschiedensten Bedingungen registriert und miteinander vergleicht. Aus wenigen zufälligen Bildern lassen sich keine Schlüsse ziehen.

Merkwürdig bleibt, dass diese grossen Verschiedenheiten erst nach der Geburt in Erscheinung treten. Man wundert sich dann aber nicht mehr, wenn man von den vielseitigen und sich zum Teil ganz widersprechenden Resultaten hört, welche die Thymusforschung auf physiologischem Gebiete zu verzeichnen hat (W i es e I und L a mpé).

Archiv f. mikr. Anat. Bd. 86. Abt. I. 
Es liisst sich in wenig Worten zusammenfiassen, was sich aus dem letzten Kapitel für die Stellung der Thymus unter den blutbildenden Organen ergibt:

Sie muss diesen zugerechnet werden, denn in ihr entstehen Lymphocyten aus echtem lymphoiden Gewebe und werden auf dem Lymphwege abgeführt. Sie darf aber nicht mit einer Lymphdrïse, auch nicht mit dem adenoiden Gewebe einer Schleimbautpropria verglichen werden, da die Lieferung von Lymphocyten sicher nicht ihre einzige, wahrscheinlich nicht einmal ihre hauptsiichlichste Funktion ist. Es ist auch nicht auszuschliessen, dass die Thymuslymphocyten besonders modifizierte Gebilde darstellen.

Gekörnte weisse Blutzellen kommen in der Thymus vor und zwar finden sich eosinophile Zellen konstant einzeln oder in kleineren Gruppen.

Spezialgranulierte Zellen sind zuweilen in grösserer Menge vorhanden, so dass man von "myeloischen Herden“ sprechen kann; hänfig sind sie sehr vereinzelt und können selbst ganz fehlen. sie bedeuten jedenfalls immer melır einen zufälligen Befund. Ob sie in der Thymus selbst entstehen, ist als wahrscheinlich anzunehmen, doch nicht als vollständig bewiesen zu erachten.

Plasmazellen habe ich gelegentlich, Mastzellen nur äusserst selten beobachtet.

\section{Zusammenfassung:}

Fassen wir die Resultate der vorliegenden Untersuchungen noch einmal kurz zusammen, so ergibt sich zunächst für die Entwicklung der Thymus folgendes:

Ein solider Epithelzapfen wächst in die Tiefe in lockeres embryonales Mesenchym hinein, indem er an seinem distalen verbreiterten Ende dicke, sich weiter ver$z$ weigende Knospen treibt. Das proximale Ende schnürt sich bald vom Mutterboden ab; es wird zur Thymusbildung nicht mehr verwendet, sondern bildet die Parathyreoidea, die noch lange mit der Thymus in Verbindung bleibt.

Das Epithel des verzweigten dicken Thymusendes erleidet gewisse Veränderungen; die Zellen der inneren Partien, den oberflächlichen Schichten des Pharynxepithels entsprechend, werden in ihrem $\mathrm{Zusammenhang}$ aufgelockert, dadurch dass Saftlücken zwischen ihnen auftreten, 
die sich alsbald vergrössern und das Epithel zu einem primären, unregelmässigen, sehr engmaschigen Netzs yncy tium umgestalten.

Gleichzeitig lösen sich in dem umgebenden Mesenchym zahlreiche Zellen aus dem syncytialen Verbande los und sammeln sich in der Umgebung der Epithelbalken an. Sie dringen dann in das Epithel ein, vorwiegend vonder Spitzeder zwischen den kompakten Knospen gelegenen Mesenchympapillen aus, wo das Epithel am lockersten erscheint. Sie bringen dasselbe dann zu weiterer Autlösung, indem sie durch lebhafte Vermehrung ihre Zahl rasch vergrössern.

Ganzallin ällich erfolgt dann innerhalb des Epithels ihre Umwandlung zu den typischen kleinen Lymphocyten.

Die Einwanderung von einzelnen Wanderzellen allein in das Epithel genügt sehr bald nicht mehr. Wührend sich einerseits die epitheliale Anlage der Thymus durch weitere Ausbreitung der Knospen sowie durch ihre Dickenzunahme rasch vergrössert, wird das zwischen deneinzelnen Knospen liegende gefässführende Mesenchymgewebe $z$ u einem wahrhaft ly $\mathrm{mphoiden} \mathrm{umgewandelt.} \mathrm{Hier} \mathrm{liegt} \mathrm{jetzt} \mathrm{Zelle} \mathrm{an} \mathrm{Zelle,}$ ganz ähnlich wie in den spüter auftretenden Lymphdrüsen. Die zahlreichen, ausserst polymorphen, freien Formen liegen in den weiten Maschen eines mesenchymatösen Reticulums, das sich wie ein dichter Mantel um die Epithelbalken herumlegt, doch immer so, dass die äussere Peripherie der Thymusknospen frei davon bleibt. Hier zeigt auch das Bindegewebe seinen gewöhnlichen Charakter, d. h. die freien lymphoiden Zellen treten an Zahl sehr gegen die sternförmigen Formen des Reticulums zurück und die Faserbildung steht im Vordergrund.

Es bleibt jedoch nicht bei einer einfachen Anlagerung des lymphoiden Gewebes an das epitheliale Reticulum, wie in der Tonsille und der Bursa Fabricii, sondern indem beide Gewebe sich gegenseitig $z u$ durchdringen suchen, wird die Grenze zwischen ihnen bald vollstandig verwischt. Es ist klar, dass hierdurch das epitheliale Reticulum eine sehr viel weiter gehende Auflockerung erfahren muss, als durch einfache Einwanderung 
einzelner Zellen, und in der Tat gelingt es, was das Reticulum anbetrifft, sehr bald nicht mehr seine Komponenten mit Sicherheit auseinander zu halten, wenn nicht irgend ein Merkmal ihre Identifizierung ermöglicht.

Erst wenn der gewebliche Bestand der Thymus in dieser Weise festgelegt ist, beginnt die weitere histologische Differenzierung gleichzeitig mit der Ausbildung der Thymuslappchen. Letztere entstehen einfach dadurch, dass eine Lage mehr oberflächlich gelegener, junger Bindegewebszellen, die einen bestimmten Bezirk abgrenzen, sich abplatten und eine faserige Hülle um denselben bilden. Dieser Mantel schneidet aber niemals vollständig durch, so dass auch später wie im embryonalen Organ die einzelnen Lappchen miteinander verbunden bleiben.

Ein guter Anteil des Septenbindegewebes wird damit zu dem Organparenchym geschlagen und gerade an diesen oberflächlichen Bezirken der alten Epithellknospen findet man später am reichlichsten die Ausbildung von granulierten Zellen (Leukocyten).

Durch die Einbeziehung der Septen in das Organ erklart sich das Eindringen der grösseren Gefässe in dasselbe; das Vorhandensein eines mesenchymatösen Reticulums im Innern, mag dasselbe durch fortgesetzte Lymphocytenlieferung auch noch so sehr aufgelöst werden, ermöglicht eine Verteilung der Gefässe im Innern des Organs und lässt uns eine Neubildung von Kapillaren, die scheinbar im Epithel gelegen sind, nicht mehr befremdlich erscheinen. Dabei ist klar, dass die Verteilung des Mesenchymreticulums sich in der Verteilung der Gefässe widerspiegelt.

Eine ausgesprochene Markbildung wird beim Kaninchen erst gegen Ende des Fötallebens deutlich. Dieselbe geht aus von kleinen circumscripten Bezirken, in welche Lymphocyten nicht oder nur in ganz geringer Zahl eingedrungen waren. Wahrscheinlich erleidet das Epithel hier gewisse innere, uns völlig unbekannte und unverständliche Umwandlungen, die weiter um sich greifend allmählich grössere Strecken des epithelialen Reticulums erfassen und in bestimmter Weise auf die Lymphocyten Einfluss gewinnen, indem sich die kleinen Lymphocyten zum grössten Teil wieder aus den Markpartien entfernen. In gewisser Hinsicht kommt die Veränderung auch morphologisch zum Aus- 
druck in dem Auftreten von „Degenerationsvorgängen“, die, wenn sie ein gewisses $M a ß$ erreicht haben, zur Bildung der Hassalschen Körperchen führen. Ähnliche Prozesse fehlen im epithelialen Reticulum der Rinde. Ich kann mich daher der Maximowschen Lehre nicht vollstïndig anschliessen, welche die Trennung von Mark- und Rindensubstanz nur durch ungleichmässige Verteilung der eingewanderten Lymphocyten gegeben sieht.

Auf Grund der entwicklungsgeschichtlichen Tatsachen muss also die Thymus den lympho-epithelialen Organen zugerechnet werden; denn sie besitzt ein epitheliales Reticulum, in welches freie Lymphocyten eingewandert sind und ein bindegewebiges Reticulum, welches für die Nachlieferung der lymphoiden Zellen Sorge zu tragen hat. Ich möchte aber hier nochmals hervorheben, dass man das Freiwerden von Mesenchymzellen in der Thymus selbst nicht beobachten kann; dies liegt aber begründet in den strukturellen Eigenheiten des Organs, und es ist daher kein Grund vorhanden, dem mesenchymatösen Reticulum in der Thymus die Fahigkeit der Lieferung von Blutzellen abzusprechen, die man ihm sonst überall im Körper zuerkennt. Nur sind in der Tonsille und der Bursa Fabricii beide Netze rüumlich getrennt, während sie in der Thymus sich gegenseitig durchflechten. Die Beziehungen zwischen beiden Geweben sind also hier womöglich noch inniger. Eine weitere Ähnlichkeit ist gegeben in der Degeneration der Lymphocyten, die in allen den drei Organen unter dem gleichen Bilde verläuft, wenn sie auch nicht überall mit gleicher Intensităt auftritt. Vielleicht ist sie gerade deshalb in der Thymus weniger auffallend, weil hier für eine Abführmöglichkeit der Lymphocyten gesorgt ist, die in der gefässlosen, rein epithelialen Marksubstanz der Bursa Fabricii fehlt und in der Tonsille, die eine freie Oberflache gegen das Darmlumen zu hat, in ganz anderer Weise gegeben ist.

Über die Funktion der Thymus kann natürlich die embryologisch-histologische Untersuchung niemals Aufschluss geben. Hier haben auch zahlreiche Experimente mit ihren widersprechenden Resultaten (Friedleben, Basch, Klose und Vogt und viele andere; vgl. das Referat von Wiesel) keine Aufklärung gebracht.

Es scheint jetzt als feststehend zu gelten, dass die Funktion der Thymus in Beziehung steht zum Kalkstoffwechsel und Knochen- 
wachstum, zum autonomen System (Herabminderung des Tonus), zu der Funktion der Sexualdrüsen, sowie zu der des gesamten Iymphatischen Apparates im Körper. Letzteres wird nicht wundernehmen, da ja die Thymus echtes lymphoides Material enthalt; es ist aber interessant, dass gerade in neuerer Zeit sich immer mehr das Bestreben geltend macht, auf Grund der pathologischen histologischen Bilder verschiedene Zustände anzunehmen, wenngleich sie sich klinisch noch nicht scharf trennen lassen. Man unterscheidet $z$ wischen einem reinen Status lymphaticus mit einer fast ausschliesslich lymphoiden Thymus, verwischter Markrindengrenze und zahlreichen granulierten Zellen (Pappenheimer) und einem reinen Status thymicus, wo die Hyperplasie der epithelialen Elemente gegenüber der der lymphatisclien im Vordergrund steht; die Hassalschen Körperchen sind sehr zahlreich, die Rinde erscheint verschmälert (Wiesel). Dagegen findet sich beim Status thymico-lymphaticus eine Hyperplasie beider Komponenten und neben einer lebhaften mitotischen Vermehrung an den Lymphocyten auch hiufig Destruktionsvorgänge (Pappenheimer, Wiesel). Hieraus ergeben sich doch gewisse Beziehungen zwischen Morphologie und Physiologie, freilich nur eben angedeutet, die für eine verschiedene Wertigkeit der Thymuselemente sprechen, aber ebensosehr auch für die funktionelle Einheit des gesamten Parenchyms. Viel schwieriger, eigentlich unmöglich ist es für die anderen oben genannten physiologischen Beziebungen, eine morphologische Stütze $\mathrm{n}$ finden. Hier gehen die Meinungen der Autoren auch dementsprechend auseinander. So legen z. B. Wiese l, Hed inger, Hess u. a. den Gedanken nahe, in den eosinophilen Zellen den Träger des gegen das Adrenalin gerichteten Hormons zu suchen. Lu cien und Pa r is o t machen die kleinen Thymuszellen dafür verantwortlich. Auch für Dustin und Pappenheimer sind die kleinen Zellen die sekretorischen Elemente und zwar kommt die Sekretion in der Abstossung von Kernpartikeln zum Ausdruck. Hammar, Hart u. a. sehen dagegen in dell Epithelzellen die spezifisch funktionierenden Elemente. Auch die Hassalschen Körperchen sind hier schon genannt worden. Für all diese Theorien lăsst sich schliesslich irgend eine Beobachtung anführen; trotzdem müssen vorderhand alle als unwahrscheinlich zurückgewiesen werden, solange es nicht gelingt, die einzelnen Komponenten des Paren- 
chyms ganz getrennt experimentell in Angriff zu nehmen. Es ist aber kaum denkbar, dass dies jemals erreicht werden wird. Man hat bis jetzt die Thymus entweder als lymphoides oder als epitheliales Organ betrachtet und von dem einen oder anderen Gesichtspunkt aus die Bearbeitung des Organs in Angriff genommen. Es ist dies aber unrichtig und muss notwendigerweise zu falschen Schlüssen führen, denn die Thymus ist weder lymphoid, noch epithelial, sondern beides zusammen. Beide Gewebsarten lassen sich hier nicht trennen, sondern müssen als einheitlich aufgefasst werden und nur in dem gleichmässigen Zusammenwirken beider kann eine vollwertige Leistung des Organs zur Geltung kommen. Es ist das Verdienst Jollys, auf diese engen Beziehungen zwischen Lymphocyten und Epithel aufmerlsam gemacht zu haben.

Es ist mir eine liebe PHicht, meinem hochverehrten Chef und Lehrer, Herrn Professor Dr. Mollier, für die Anregung zu dieser Arbeit sowie für die jederzeit geleistete Unterstützung meinen ergebensten Dank auszusprechen.

Nachdem ich meine Untersuchungen bereits beendet batte, erschien eine Arbeit von Salkind über feinere Strnkturen und rerschiedene Funktionsformen der 'Thymus bei Säugetieren (Archives danat. microsc, tome $X V, 1913$ ), von welcher ich mir eine genauere Darlegung der Beziehungen zwischen epithelialem und bindegewebigem Reticulum erwartet hatte, entsprechend der früheren Mitteilung des Autors. Leider gibt Salkind auch hier nur eine eingehende Beschreibung der Epithelzellen bei verschiedenen tunktionellen Zuständen der Thymus (Hunger und C̈berernährung). ohne auf die Herkunft und den Bau des lymphoiden Reticulums nüher einzugehen; er erkennt ihm jedoch dauernd leucopoetische Eigenschaften zu. Bei der Überernahrung soll das epitheliale Jetz allmählich zugrunde gehen infolge einer übermässigen Proliferation des adenoiden Gewebes und der freien Wanderzellen und auf diese Weise eine zweite Art der Involution bewirkt werden, die im Gegensatz steht $z u$ der bisher bekannten von der Lymphocytenverarmung. Die Art der Involution versucht Salkind durch eine "mathematische" Formel auszudrücken (formule thymique), indem er die einzelnen Zellkomponenten zahlt und durcheinander dividiert. Es liegt auf der Hand, dass eine 
derartige Formel keinen besonderen Anspruci auf Exaktheit oder wissenschaftlichen Wert machen kann, da sie ganz willkürlich aufgestellt ist und ibre Abfassung von den subjektiven Anschauungen des jeweiligen Beobachters abhängt.

Neujahr 1914.

\section{Literaturverzeichnis.}

A imé, P.: Note sur les Glandules parathyreoidiames et parathymiques de la Tortue Grecque. Compt. rend. Soc. Biol., t. 70, 1911.

Derselbe: L'Evolution périodique du Thymus des Chéloniens. Compt. rend. Soc. Biol., t. 73, 1912.

Aukarsvärd und Hammar: Die Thymus der Ganoiden. Zool. Jahrb., Bd. 36, III, 1913.

Bang, J.: Chemische Untersuchungen der lymphatischen Organe. (Vier Mitteilungen.) Beitr. z. chem. Phys. u. Path., Bd. IV und V.

Basch, K.: Beiträge zur Physiologie und Pathologie der Thymus. Jihrb. f. Kinderheilk., Bd. 64 (III. F., Ed. 14), 1906.

Derselbe: Beiträge zur Physiologie und Pathologie der Thymus. Die Beziehung der Thymus zur Schilddrüse. Zeitschr. f. exper. Path. u. Therap., Bd. XII, II, 1913.

Beard: The Origin and Histogenesis of the Thymus in Raja batis. Zool. Jahrb., Bd. XVII, 1903.

Bell: The Development of the Thymus. The Amer. Journ. of Anatomy; Bd. $V, 1906$.

B öh m und David off: Lehrbuch der Histologie des Menschen. 3. Auflage.

Cheval: Recherches sur les Lymphocytes du Thymus. Bibliogr. anatom., Bd. XVII, 1908.

Ciaccio: Ricerche istologiche e citologiche sul timo degli ucelli. Anat. Anz., Bd. 29, 1906.

Derselbe: Contributo alla conoscenza dei lipoidi cellulari. Anat. Anz., Bd. 35, 1909.

Dantschakoff, W.: Über das erste Auftreten der Blutelemente im Hühnerembryo. Folia haemat., Bd. 4, Suppl. 2, 1907.

Derselbe: Über die Entwicklung des Knochenmarks bei den Vögeln und über dessen Veränderungen bei Blutentziehungen und Ernährungsstörungen. Arch. f. mikr. Anat., Bd. 74, 1909.

Downey, H. und Weidenreich, F.: Über die Bildung der Lymphocyten in Lymphdrüsen und Milz. Arch. f. mikr. Anat., I. Abt., Bd. 80, II, 1912.

Dustin, A. P.: Contribution à l'Etude du Thymus des Reptiles. Arch. de zool. exper. et génér., Sér. 5, t. 2, 1909.

Derselbe: Le Thymus de l'Axolotl. Arch. de Biol., t. 26, 1911. 
Derselbe: Recherches d'histologie normale et experimentale sur le Thymus des Amphibiens Anoures. Arch. de Biol., t. 28, 1913.

Derselbe: Greffes thymiques. Assoc. des Anatomistes, Congrès de Paris, 1911.

Ebner, v.: Kapitel Thymus. Koellikers Handbuch der Gewebelehre des Menschen. Bd. 3, 6. Auf lage, Leipzig 1902.

Ferrata: Sui Globuli bianchi mononucleati. Arch. per le Scienze MIed,, Bd. 30, 1906.

F l e m $\mathrm{m}$ ing: Schlussbemerkungen über die Zellvermehrung in den lymphoiden Drüsen. Arch. f. milkr. Anat., Bd. 24, $188 \overline{\text {. }}$

Derselbe: Über Teilung und Kernformen bei Leukocyten und über deren Attraktionssphüren. Areh f. mikr. Anat., Bd. 37, 1891.

Fritsche, E.: Die Entwicklung der Thymus bei Selachiern. Jenaische Zeitschr., Bd. 46, 1910.

Grosso: Zur Unterscheidung der pseudo-eosinophilen Spezialzellen des Kaninchens von dem echt acidophilen durch die simultane direkte Färbung mit einem Methylgrün-Pyronin-Orange-Gemisch. Folia haemat., Bd XIV, 1913.

Gull and, G. L.: Zitiert nach $\mathrm{H}$ a mmar 1909.

Halpenny und Thompson: On the Relationship between Thyreoid and Parathyreoids. Anat. Anz., Bd. 34, 1909.

Hamilton: Die Thymusentwicklung bei der Ente nebst einigen Beobachtungen über die Kiemenspaltenorgane dieses Tieres. Anat. Anz., Bd. 44, 1913.

Hammar, J. A.: Zur Histogenese und Involution der Thymusdrüse. Anat. Anz., Bd. 27, 190 ó.

Derselbe: Über die Natur der kleinen Thymuszellen. Arch. f. Anat. u. Entwicklungsgesch., 1907.

Derselbe: Zur Kenntnis der Telenstierthymus. Arch. f. mikr. Anat., Bd. 73, 1909.

Derselbe: Der gegenwärtige Stand der Morphologie und Physiologie der Thymusdrüse. Wiener med. Wochenschr., 59. Jahrg., H. 47-50, 1909.

Derselbe: Fünfzig Jahre Thymusforschung. Erg. d. Anat u. Entwicklungsgeschichte, Bd. 19, 1909.

Derselbe: Zur Kenntnis der Elasmobranchierthymus. Zool. Jahrb., Bd. 32, II, 1911.

Derselbe: Zur gröberen Morphologie und Morphogenie der Menschenthymus. Anat. Hefte, Bd. 43, 1911.

IT anson, R.: Über die Entwicklung der Parathyreoideae accessoriae und der Thymus beim Kaninchen. Anat. Anz., Bd. 39, 1911.

Hart, K.: Thymusstudien. I. Über das Auftreten von Fett in der Thymus. Virchow s Arch., Bd. 207/208, 1912.

Derselbe: Thymusstudien. II. Thymuselemente. Virchow s Arch., Bd. 210, 1912.

H e in ecke: Über die Einwirkung der Röntgenstrahlen auf Tiere. Münchener med. Wochenschr., Nr. 48, 1903.

Derselbe: Über die Einwirkung der Röntgenstrahlen auf innere Organe. Münchener med. Wochenschr., Nr. 18, 1904. 
Derselbe: Experimentelle Untersuchungen über die Einwirkung von Röntgenstrahlen auf inmere Organe. Mitteil. aus d. Grenzgeb., 1905.

Helgesson: Zur Embryologie der Vogelthymus. I. Die Thymusentwichlung beim Sperling. Anat. Anz., Bd. 43, 1913.

Herrmann und Tourneux: Zitiert nach Hammar, 1909.

Hertwig, O.: Lehrbuch der Entwicklungsgeschichte des Menschen und der Wirbeltiere. 8. Auf lage, 1906.

His, W.: Zitiert nach Hammar, 1909.

Holmström, R.: Über das Vorkommen von Fett und fettähnlichen Substanzen im Thymusparenchym. Arch. f. mikr. Anat., Bd. 7it, IV, 1911.

Jolly, J.: Histogenèse des Follicules de la Bourse de Fabricius. Compt. rend. Soc. Biol., t. 71, 1911.

Sur la Fonction hématopoiétique de la Bourse de Fabricius. Compt. rend. Soc. Biol., t. 71, 1911.

Sur l'Involution de la Bourse de Fabricius. Compt. rend. Soc. Biol., t. 71, 1911.

Derselbe: Sur les Organes lympho-épithéliaux. Compt. rend. Soc. Biol., t. $74,1913$.

Jolly und Levin: Evolution des corpuscules de Hassal dans le Thymus de l'animal jeûneur. Compt. rend. Soc. Biol., t. 72, 1912.

J on s o n, A.: Studien über die Thymusinvolution. Die akzidentelle Involution bei Hunger. Arch. f. mikr. Anat., Bd. 73, 1909.

Kardos: Zur Kenntnis der neutrophilen und azurophilen Körnung nebst einer neuen Färbemodifikation. Folia haematologica, Bd. 12, 1911.

L ampé: Die Bedeutung der Thymusdrüse für den Organismus. Fortschr. d. naturw. Forsch., Bd. 9, 1913.

Levin: Recherches expérimentales sur l'Involution du Thymus. Thèse Paris, Nr. 25̄6, 1912.

Letulle, M. und Nattan-Larrier: Identification de certains éléments constitutifs du Thymus. Compt. rend. Soc. Biol., t. 51, 1902.

Lindberg, G : Zur Kenntnis der Alterskurve der weissen Blutkörperchen des Kaninchens. Folia haemat., Bd. 9, 1910.

Lucien, M.: Étude anatomo-pathologique sur l'hypertrophie du Thymus. Compt. rend. Soc. Biol., t. 60, 1908.

Thymus et athrépsie. Compt. rend. Soc. Biol., t. 60, 1908.

Marchand: Wundheilung. Deutsche Chirurgie, Bd. 16, 1901.

Marcus, H.: Über die Thymus. Lebenslauf einer Thymuszelle. Verh. d. Anat. Ges., Würzburg 1907.

Maurer: Die Entwicklung des Darmsystems. Handb. d. vergl. u. exper. Entwicklungsgesch. der Wirbeltiere. Herausgegeben von 0 . Hertwig, 1902.

Maximow, A.: Experimentelle Untersuchungen über die entzündliche Neubildung von Bindegewebe. Zi iegle rs Beitr., Suppl. 5-6, 1902-1904.

Derselbe: Beiträge zur Histologie der eitrigen Entzündung. Zieglers Beitr., Bd. 38, 1905.

Derselbe: Über die Entwicklung der Blut- und Bindegewebszellen beim Säugetierembryo. Folia haemat., Bd..4, 1907. 
Derselbe: Über die embryonale Entwicklung der Blut- und Bindegewebszellen bei den Säugetieren. Verh. d. Anat. Ges., Berlin 1908.

Derselbe: Untersuchungen über Blut und Bindegewebe. I. Die frühesten Entwicklungsstadien der Blut- und Bindegewebszellen beim Säugetierembryo, bis zum Anfang der Blutbildung in der Leber. Arch. f. mikr. Anat., Bd. 73, 1907.

Derselbe: II. Histiogenese ter Thymus bei Saugretieren. Arch. f. mikr. Anat. Bd. 74, 1909.

Derselbe: IV. Die Histiogenese der Thymus bei Amphibien. Arch. f. milir. Anat., Bd. 79, 1912.

Derselbe: V. Über die embryonale Entwicklung der Thymus bei Selachiern. Arch. f. mikr. Anat., Bd. SO, 1912.

Derselbe: Über Blutmastzellen. Arch. f. mikr. Anat., Bd. 83, 1913.

Meves: Zur Einigung zwischen Faden- und Granulalehre des Protoplasmas. Beobachtungen an weissen Blutzellen. Arch. f. mikr. Anat., Bd. 75, 1910.

II ietens: Zur Kenntnis des Thymusreticulums und seiner Beziehungen zu dem der Lymphdrüsen, nebst einigen Bemerkungen ïber die Winterschlafdrüse. Jenaische Zeitschr., Bd. 44, N. F. 37, 1909.

Minot: Die Entstehung des Angioblasts und die Entwicklung des Blutes. In $\mathrm{Ke}$ ibel-Mall: Handbuch der Entwicklungsgesch. des Menschen, Bd. II, 1911.

Mollier: Die Blutbildung in der embryonalen Leber des Menschen und der Säugetiere. Arch. f. mikr. Anat., Bd. 74, 1909.

Derselbe: Über den Báu der kapillaren Milzvenen. Arch. f. milir. Anat, Bd. $76,1911$.

Derselbe: Die lympho-epithelialen Organe. Sitzungsber. d. Ges. f. Morph. u. Phys. zu München 1913.

Na egeli: Blutkrankheiten und Blutdiagnostik. Leipzig 1908.

Nussbaum und Prymak: Zur Entwicklung der lymphoiden Elemente der Thymus bei den Knochenfischen. Anat. Anz., Bd. 19, 1901.

Pappenheim, A.: Von den gegenseitigen Beziehungen der verschiedenen farblosen Blutzellen zueinander I. Virchows Arch., Bd. 159, 1900.

Derselbe: Von den gegenseitigen Beziehungen der verschiedenen farblosen Blutzellen zueinander II und III. Virchow s Arch., Bd. 160, 1900.

Derselbe: Über Lymphocyten und aktive Lymphocytose. Folia haemat., Bd. 3, 1906.

Derselbe: Bemerliungen über artliche Unterschiede und die gegenseitigen genetischen Beziehungen zwischen den verschiedenen lymphoiden Zellformen des Blutes. Über die Azurkörnung in den lymphoiden Blutzelien. Folia haemat., Bd. 9, 1910.

Derselbe: Über verschiedene Typen von Lymphocyten und Monocyten, zum Teil in scheinbar normalem Blut. Folia haemat., Bd. 12, 1911.

Derselbe: Färbungsvorschriften mit $P$ appenheims Panchrom. Folia haemat., Bd. 11 und 12, 1911.

Pappenheim und Ferrata: Über die verschiedenen lymphoiden Zellformen des normalen und pathologischen Blutes. Folia haemat., Bd. 10, 1910. 
Pappenheim: Further Studies on the Histology of the Thymus. Amer. Journ. of Anatomy, Vol. 14, 1913.

Parisot et Lucien: Etude physiologique et anatomique du Thymus dans l'athrépsie. Compt. rend. Soc. Biol., t. 60, 1908.

Pigache und Worms: I. Circulation du Lobule thymique. II. Les Dégenérescences cellulaires du Thymus. Bull. de la Soc. des Anat. de Paris, Bd. 85, 1910.

Dieselben: Considérations sur l'état histologique du Thymus. I. Action de la Thyroidectomie. Arch. d'anat. microsc., Bd. 12, 1910.

Prenant: Developpement organique et histologique du Thymus de la Glande thyreoide et de la Glande carotidienne. La Cellule, t. 10, 1894.

Rabl, H.: Die Entwicklung der Derivate des Kiemendarmes beim Meerschweinchen. Arch. f. mikr. Anat., Bd. 82, 1913.

Rega ud und Crémien: Donneés relatives aux petites cellules, ou lymphocytes du parenchyme thymique, d'après les résultats de la Röntgénisation du Thymus chez le Chat.

Sur la suppression définitive du tissu thymique par la Röntgentherapie. Compt. rend. Soc. Biol., t. 72, 1912.

Dieselben: Sur la formation temporaire de tissu myeloide dans le thymus, pendant l'involution de cet organe consécutive à l'action des Rayons X.

La Leucocytose polynucléaire dans le Thymus röntgénisé. Compt. rend. Soc. Biol., t. 74, 1913.

Retterer und Lelièvre: Origine épithéliale et évolution des follicules clos tégumentaires des oiseaux. Journ. de l'Anat., Bd. 48, 1912.

Dieselben: Evolution histogénétique du thymus de boeuf. Hématopoièse dans le thymus.

Homologies de la Bourse de Fabricius.

Nouvelles recherches sur la Bourse de Fabricius. Compt. rend. Soc. Biol., t. 74, 1913.

Ritchic, W. T.: The specificity and potency of adrenolytic and thymolysic sera. Journ. of pathol. and bact., Vol. 12, 1908.

Ruben: Zur Embryologie der Thymus und der Parathyreoidea beim Meerschweinchen. Anat. Anz., Bd. 39, 1911.

Rudberg: Studien über die Thymusinvolution. I. Involution nach Röntgenbestrahlung. Arch. f. Anat. u. Phys., 1907, Suppl.

Rubräh: The relation of the Thymus gland to Marasmus. The Lancet, 48. Jahrg., 1903.

Salkind: Sur l'organisation des Thymus. Anat. Anz., Bd. 41, 1912. (Färbungsvorschriften in Compt. rend. Soc. Biol., t. 72, 1912, p. 117.)

Schaffer: Eosinophile Zellen in der Thymus. Zentralbl. f. d. med. Wiss., Bd. 29, 1891.

Derselbe: Thymus und Plasmazellen. Zentralbl. f. Phys., Bd. 22, 1908.

Derselbe: Die Plasmazellen. 8. Heft d. Samml. anat. u. phys. Vorträge u. Aufsätze, 1910.

Schaffer und Rabl, H.: Das thyreo-thymische System des Maulwurfs und der Spitzmaus. I. Sitzungsber. d. k. k. Akad. d. Wiss., Wien. Math.-Naturw. Kl., Bd. 117, 1908. 
Dieselben: II. Die Entwicklung des thyreo-thymischen Systems beim Maulwurf. Ebenda, Bd. 118, 1909.

Schmauss und Albrecht, E.: Über Karyorrhexis. Virchows Arch. Bd. 138, Suppl., 1895.

Schridde: Die Körnelungen der Lymphocyten des Blutes. Münchener med. Wochenschr., Nr. 26, 1905.

Derselbe: Beiträge zur Lehre von den Zellkörnelungen. Anat. Hefte, Bd. 28,1905 .

Derselbe: Myeloblasten, Lymphoblasten und lamphoblastische Plasmazellen. Zieglers Beitr., Bd. 41, 1907.

Derselbe: Kapitel Thymus in A sch off $\mathrm{s}$ Lehrbuch der pathologischen Anatomie, Bd. II, 1911.

Schultze, O.: Grundriss der Entwicklungsgeschichte des Menschen und der Säugetiere. Leipzig 1897.

จ. Schumacher: Über die Entwicklung und den Bar der Bursa Fabricii. Sitzungsber. đ. k. k. Akad. d. Wiss. in Wien, Bd. 112, III. Abt., 1904.

Stieda: Zitiert nach Hammar 1909.

St öhr: Lehrbuch der Histologie, 190 o.

Derselbe: Über die Natur der Thymuselemente. Anat. Hefte, Bd. 31, 1906.

Derselbe: Über die Abstammung der kleinen Thymuszellen. Anat. Hefte; Bd. 41, 1910.

Spuler: Zur Histologie der Tonsillen. Anat. Anz., Bd. 39, 1911.

Wallgren: Zur Kenntnis der lymphoiden Zellen des Kaninchenblutes. Folia haemat., Bd. 8, 1909.

Wassjutotschkin: Cntersuchungen über die Histogenese der Thymus. I. Über den Ursprung der myoiden Elemente der Thymus des Hühnerembryos. Anat. Anz., Bd. 43, 1913.

Watney: On the minute anatomy of the Thymus. Philos. Transact., Vol. 173, 1882.

Weidenreich: Über Speichelkörperchen. Folia haemat., Bd. ż, 1908.

Derselbe: Beiträge zur Kenatnis der granulierten Leucocyten. Arch. $f$. mikr. Anat., Bd. 72, 1908.

Derselbe: Zar Morphologie und morphologischen Stellung der ungranulierten Leucocyten - Lymphocyten - des Blutes und der Lymphe. Arch. f. mikr. Anat., Bd. 73, 1909.

Derselbe: Die Leucocyten und verwandte Zellformen. Ergebn. d. Anat. u. Entwicklungsgesch., Bd. 19, 1909.

Derselbe: Die Thymus erwachsener Menschen als Bildungsstätte ungranulierter und granulierter Leucocyten. Münchener med. W ochenschr., Nr. 48, 1912.

Weill: Über die Bildung von Leucocyten in der menschlichen und tierischen Thymus des erwachsenen Organismus. Arch. f. mikr. Anat., Bd. 83, 1913.

Wiesel: Pathologie des Thymus. Ergebn. d. allg. Path. (LubarschOs tertag), Bd. 15, II, 1911. 


\section{Erklärung der Abbildungen auf Tafel IV-VIr.}

Sämtliche Figuren wurden mit dem $\mathrm{A}$ b béschen Zeichenprisma auf Objekttischlöhe entworfen; Fig. 12, 13, 16, 17 und 19 auf zwei Drittel der Originalzeichnung verkleinert.

Fig. 1. Kopfmesenchym aus einem 10 Tage alten Kaninchenembryo. Mesenchymzellen runden sich zur Teilung ab. Azur II-Eosin. Z e is s hom. Immers. ${ }^{1} 1$, , Compens.-Ocul. 4.

Fig. 2a. Kopfmesenchym aus einem 12 Tage alten Kaninchenembryo. Mesenchymzellen werden frei.

Fig. 2b. Lymphocyten aus dem strömenden Blute desselben Embryos. Einer davon in Teilung. Zum Vergleich wurde ein Erythroblast mitgezeichnet.

Azur II-Eosin. Z e is s hom. Immers. ${ }^{1 / 12}$, Compens.-Ocul. 4.

Fig. 3a. Schnitt durch die Parathyreoidea eines 13 Tage alten Kaninchenembryos.

$$
\begin{aligned}
a \mathrm{c} & =\text { Arteria carotis. } \\
\mathrm{v} j & =\text { Vena jugularis. } \\
\mathrm{n} \mathrm{v} & =\text { Nervus vagus. }
\end{aligned}
$$

Fig. 3b. Schnitt durch die Thymus desselben Embryos.

$$
\text { ao Aortenbogen. }
$$

Azur II-Eosin. Apochromat $16 \mathrm{~mm}$, Compens.-Ocul. 6.

Fig. 4. Epitheliale Thymus eimes 16 tägigen Kaninchenembryos: Faserstrukturen in den basalen Epithelzellen. Mallory hom. Immers. ${ }^{1 / 12}$, Compens.-Ocul. 6.

Fig $\check{0}$. Thymus aus einem 13 Tage alten Kaninchenembryo: Sogcnannte „geschrumpfte" Epithelzellen nach $\mathrm{M}$ aximow. Vakuolen in Epithelzellen. Hämatoxylin-Eosin. Hom. Immers. 1/12, Compens.-Ocul. 6.

Fig. 6. Schnitt durch die Thymus eines 18 tägigen Kaninchenembryos zwischen cervicalem und thoracalem Abschnitt. Starke Faltung des Epithels, wodurch das Vorkommen von Mesenchym in einem scheinbaren Lumen erklart wird. Azur II-Eosin. Apochromat $4 \mathrm{~mm}$, Compens.-Ocul. 6.

Fig. 7. Thymus eines 17 tägigen Kaninchenembryos. Reihenförmige Anlagerung der Lymphocyten am Epithel. Panchrom. Apochromat $4 \mathrm{~mm}$, Compens.-Ocul. 6.

Fig. 8. Degenerationsformen von Epithelzellen:

a und b. Aus der Thymus eines 27 tägigen Kaninchenembryos. $\mathrm{K}$ ardos.

c. Aus der Thymus eines hungernden 5 Wochen alten Kaninchens. Azur II-Eosin.

d. Aus der Thymus eines mässig mit Röntgenstrablen behandelten Kaninchens.

Von Lymphocyten :

e. Aus der normalen Thymus eines 27 tägigen Kaninchenembryos, sehr spärlich. K ardos.

$f$ und g. Aus der'Thymus des hungernden Kaninchens. Azur II-Eosin. Homog. Immers. $1 / 12$, Compens.-Ocul. 6. 
Fig. 9. Anschnitt durch eine Epithelknospe von einem 20 tägigen Kaninchenembryo. Panchrom. Apochromat $8 \mathrm{~mm}$, Compens.-Ocul. 6.

Fig. 10. Lipoidtröpfchen in Reticulumzellen der Marksubstanz eines neugeborenen Kaninchens nach der Methode von Ciaccij. Homog. Immers. 1/12, Complanat.-Ocul. 3.

Fig. 11. Faserreticulum aus der Marksubstanz der Thymus eines 7 Monate alten Kaninchens. Färbung nach $\mathrm{P}$ asini.

Fig. 11a. Gezeichnet bei weissem Licht der $\mathrm{Z}$ e is s schen Mikroskopierlampe.

Fig 11b. Dieselbe Stelle gezeichnet bei monochromatischem grünen Licht der von $\mathrm{Köhler}$ angegebenen Quecksilberlampe.

Apochromat $2 \mathrm{~mm}$, norm. Ap. 1,35, Compens.-Ocul. 6.

Fig. 12. Zwei Hassalsche Körperchen aus der Thymus eines neugeborenen Kaninchens. Pasini. Apochromat $2 \mathrm{~mm}$, norm. Ap. 1,3ら, Compens.Ocul. 8.

Fig. 13. Aus der Thymus eines 18 Tage alten Kaninchenembryos. Zwischen die Epithelknospen der Thymusanlage eindringendes Mesenchym (vgl. Fig. 6). Vakuoläre Auflockerung des Epithels; die Vakuolen sind kleiner und gleichmässiger als im Mesenchym.

$$
\begin{aligned}
\text { mes } & =\text { Mesenchym. } \\
\mathrm{w}_{1} & =\text { freie Wanderzelle. } \\
\mathrm{w}_{2} & =\text { eindringende Wanderzelle. }
\end{aligned}
$$

Azur Ir-Eosin. Apochromat $2 \mathrm{~mm}$, norm. Ap. 1,35), Compens.-Ocul. 8.

Fig. 14. Aus der Thymus eines 18 Tage alten Kaninchenembryos: das aufgelockerte Epithel ist schon reichlich ron lympboiden Zellen durchsetzt, die an der starken Basophilie ihres Protoplasmas kenntlich sind. Panchrom. Apochromat $2 \mathrm{~mm}$, norm. Ap. 1,35, Compens.-Ocul. 4.

Fig. 15. Einzelne Zellformen aus der Thymus.

$\mathrm{a}=$ Epithelzellen noch geschlossen, vom Rande.

$\mathrm{b}$ und $\mathrm{c}=$ freie lymphoide Zellen.

$\mathrm{d}, \mathrm{e}, \mathrm{f}=$ besonders grosse Formen derselben.

$\mathrm{g}, \mathrm{h}=$ Reticulumzellen.

Dom in ici. Hom. Immers. 1/12, Compens.-Ocul. 8.

Fig. 16. Aus der Thymus eines 19 tägigen Kaninchenembryos. Gegenseitige Durchdringung von epithelialem und mesenchymatösem Reticulum. $\mathrm{ep}=$ Epithelzellen.

mes $=$ Mesenchymzellen.

$1=$ lymphoide Zellen von verschiedener Grösse.

Panchrom. Apochromat $2 \mathrm{~mm}$, norm. Ap. 1,35, Compens.-Ocul. 8.

Fig. 17. Aus der Thymus eines 16 tägigen Kaninchenembryos. Auflösung des Epithels durch in die Falten eindringendes Mesenchym. Grenze zwischen beiden Geweben nicht mehr sicher bestimmbar. P a sin i. Apochromat $2 \mathrm{~mm}$, norm. Ap. 1,35, Compens.-Ocul. 8 .

Fig. 18. Aus der Thymus eines 19 tägigen Kaninchenembryos. Blaue Grenzmembran des Epithels, löst sich in der Tiefe der Septen auf. Pasini. Apochromat $2 \mathrm{~mm}$, norm. Ap. 1,35, Compens.-Ocul. 6. 
192 A. Hartmann: Die Entwicklung der Thymus beim Kaninchen.

Fig. 19. Aus der Thymus eines 16 Tage alten Kaninchenembryos. Die Einwanderung einzelner Lymphocyten aus dem umgebenden Mesenchym in das aufgelockerte Epithel ist im Gange. Die festgeschlossenen, plattenepithelähnlichen (x) Schichten der Thymusknospen widerstehen sehr lange. Panchrom. Apochromat $2 \mathrm{~mm}$, norm. Ap. 1,35, Compens.-Ocul. 6.

Fig. 20. Aus der Thymus eines 20 Tage alten Kaninchenembryos. Verteilung der Lymphocyten, die sich zu kleinen umzuwandeln beginnen, in Gruppen im Epithel. Verschmälerung der bindegewebigen Septen. Beginn des Eindringens von Gefässen. Panchrom. Apochromat $8 \mathrm{~mm}$, Compens.-Ocul. 6 .

Fig. 21. Läppchen aus der Thymus eines 22 Tage alten Kaninchenembryos. Ziemlich gleichmässige Verteilung der Lymphocyten im Epithel. Beginn der Markbildung. Gefässe in der Thymus. Dominici. Apochromat $8 \mathrm{~mm}$, Compens.-Ocul. 6 .

Fig. 22. Schnitt durch die Thymus eines 14 Tage alten Kaninchenembryos. Hellere Färbung im Innern der Knospen als Zeichen beginnender Auf lockerung. Wor on in. Apochromat $16 \mathrm{~mm}$, Compens.-Ocul. 6.

Fig. 23. Schnitt durch eine epitheliale Knospe aus der Thymus eines 16 tägigen Kaninchenembryos. Vakuoläre Auf lockerung des Epithels, noch ehe die Lymphocyteneinwanderung beginnt. Pasini. Apochromat $2 \mathrm{~mm}$, norm. Ap. 1,35, Compens.-Ocul. 4.

Fig. 24. Freie polymorphe lymphoide Zellen aus dem die Thymus umgebenden Mesenchym (18 tägiger Embryo). Azur II-Ensin. Apochromat $2 \mathrm{~mm}$; norm. Ap. 1,35, Compens.-Ocul. 8.

Fìg. 25. Aus einer müssig mit Röntgenstrahlen behandelten Thymus eines 8 Wochen alten Kaninchens. Vorkommen von reichlich grossen lymphoiden Zellen, von denen sich viele in Teilung befinden. Gross o. Apochromat $2 \mathrm{~mm}$, norm. Ap. 1,35, Compens.-Ocul. 4.

Fig. 26. Aus einem Thymusläppchen eines 27 Jage alten Kaninchenembryos. Mark und Rinde gegeneinander differenziert. Nachschub von lymphoiden Zellen von der Tiefe der Septen her. Azur II-Eosin (Formolfixierung). Apochromat $16 \mathrm{~mm}$, Compens. Ocul. 6.

Fig. 27. Schnitt durch die Thymus eines 18 tägigen Kaninchenembryos. $\mathrm{V} \mathbf{j}=$ Vena jugularis. Panchrom. Apochromat $8 \mathrm{~mm}$, Compens.Ocul. 6.

Fig. 28. Aus der Marksubstanz der Thymus eines 27 tägigen Kaninchenembryos. Die ,hypertrophischen" Markzellen treten noch gegen den Reichtum an Lymphocyten zurück. Dominici. Apochromat $2 \mathrm{~mm}$, norm. Ap. 1,3̄o, Compens.-Ocul. 2. 


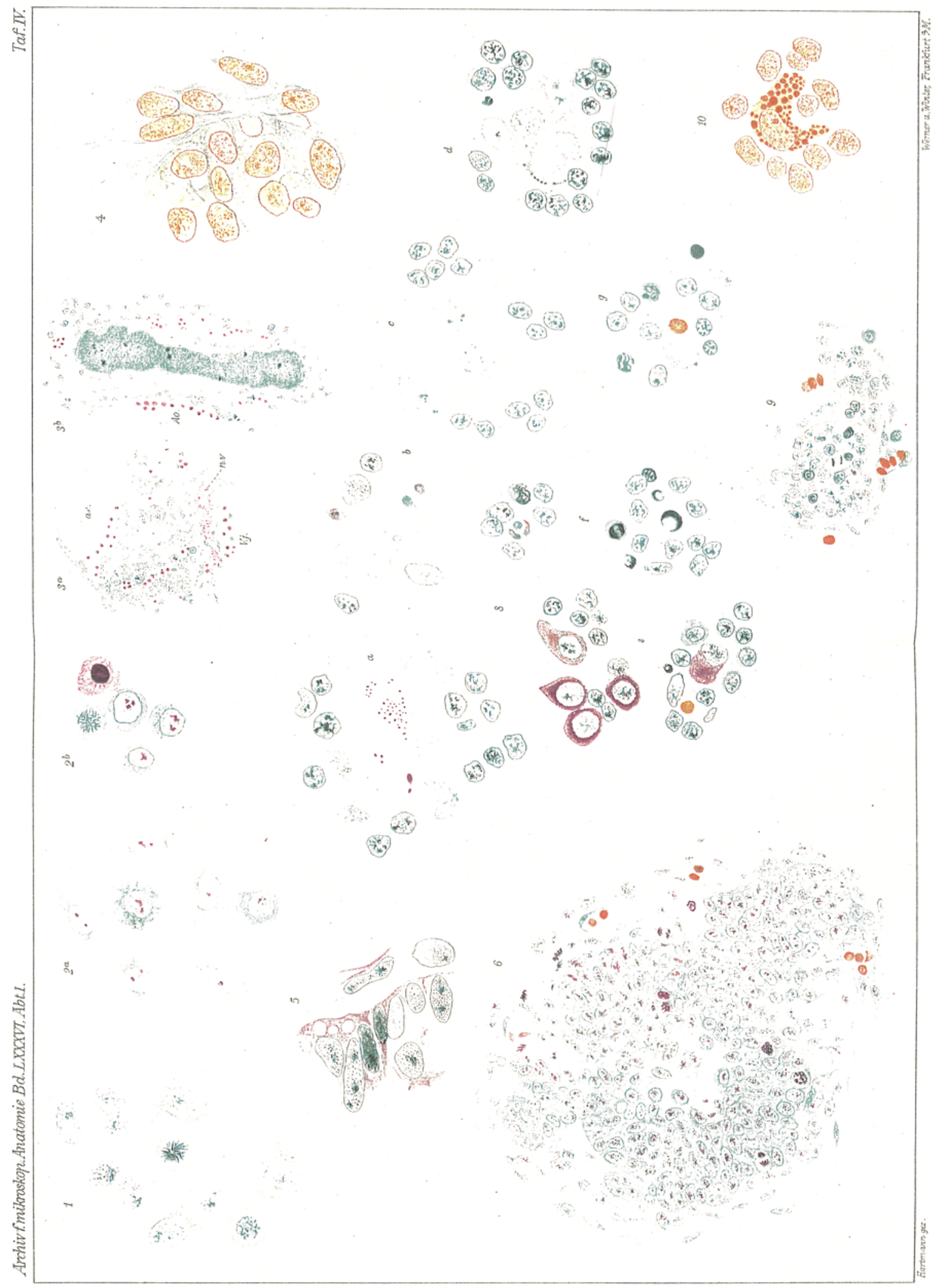




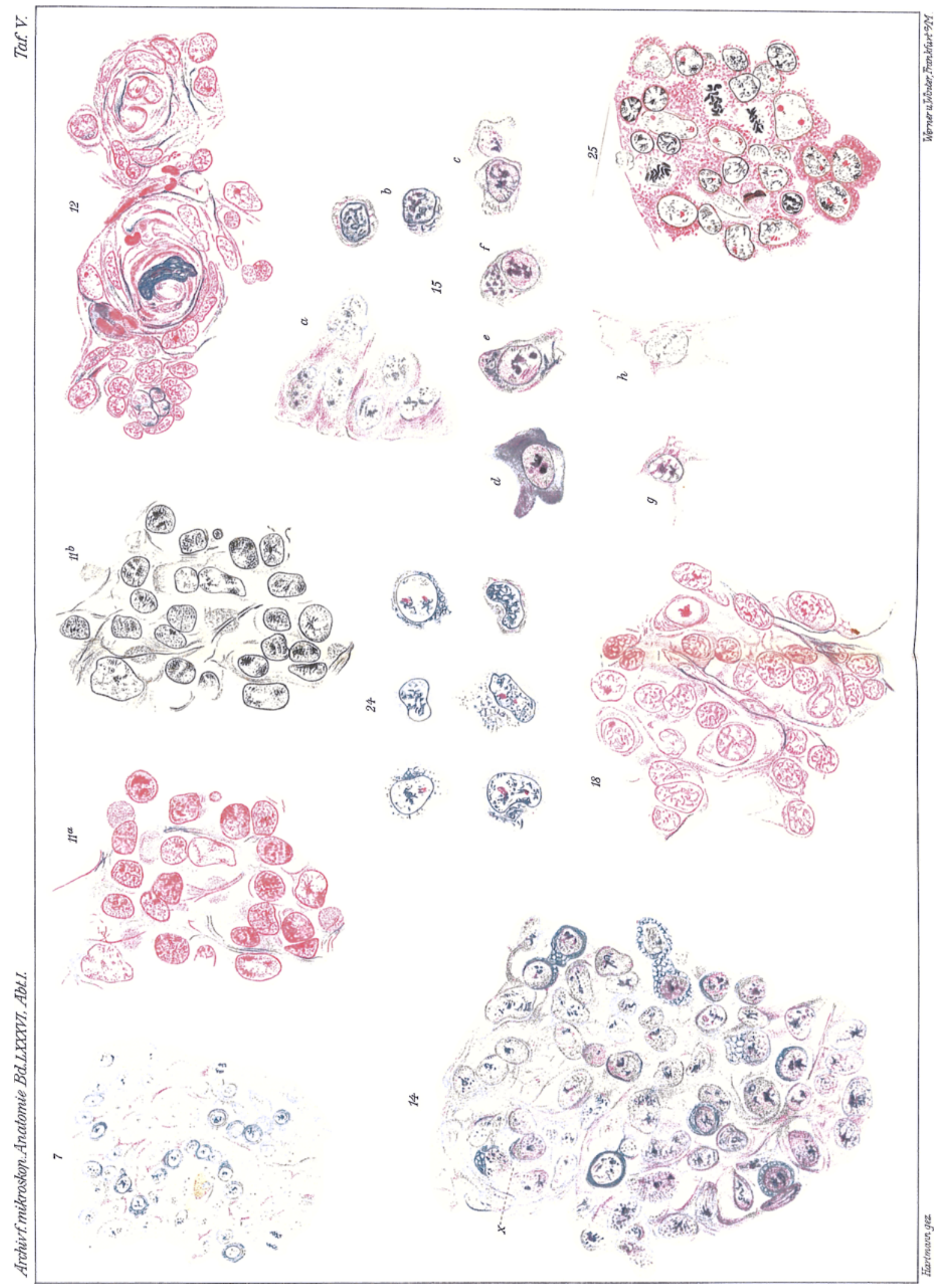




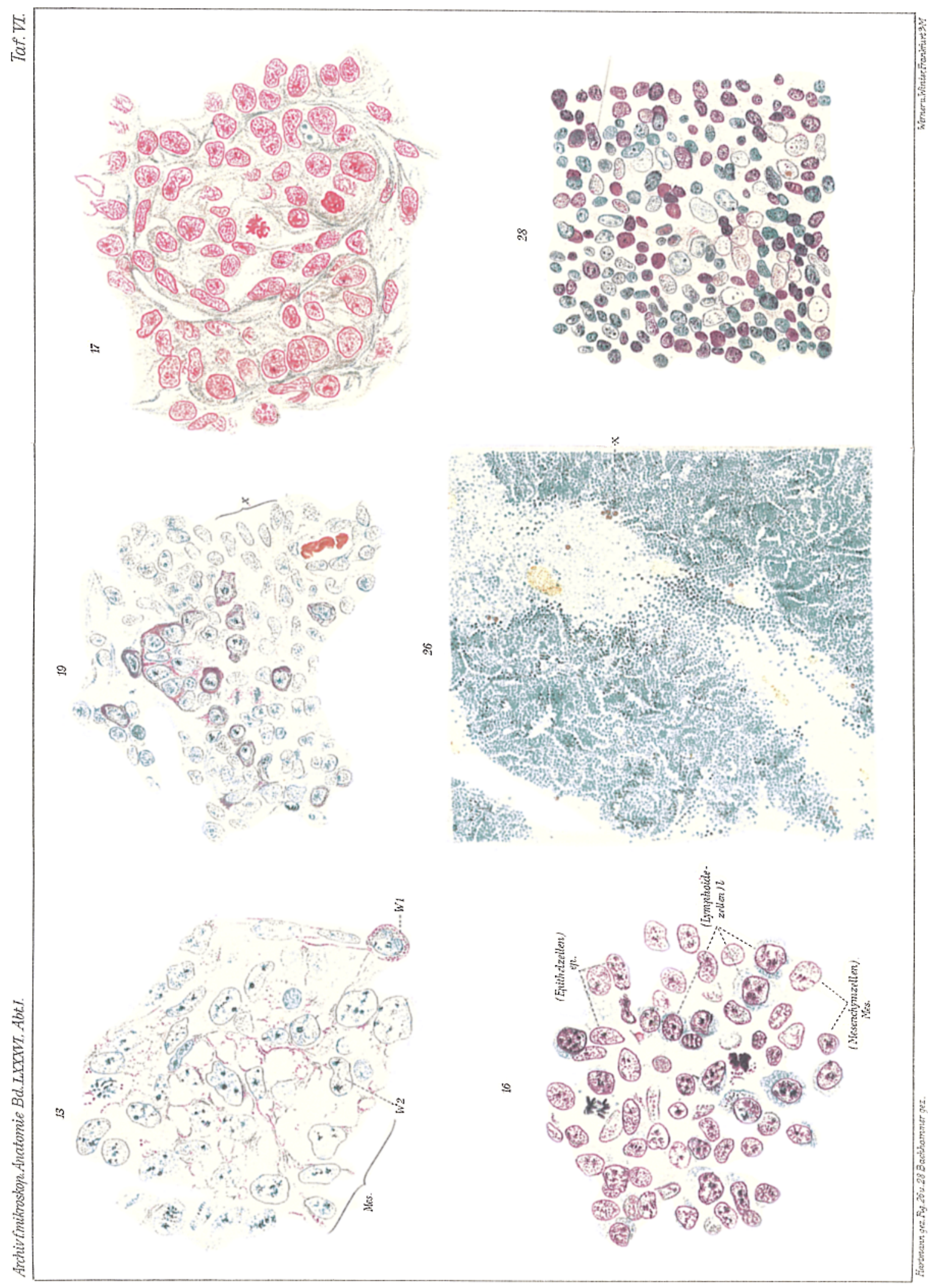




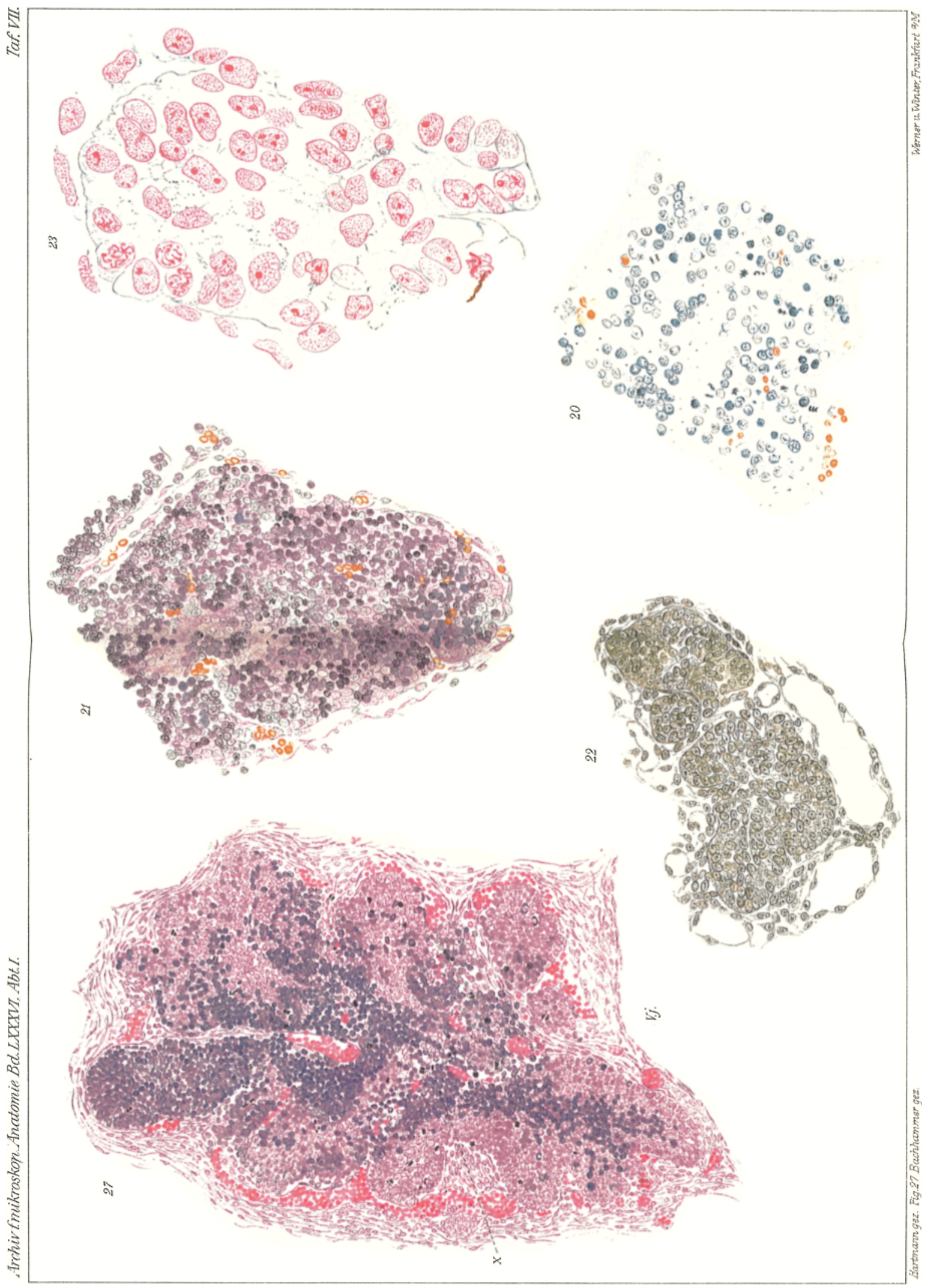

